University of Rhode Island

DigitalCommons@URI

Open Access Master's Theses

2002

\title{
Land Development Planning Handbook for Municipal Officials, Rhode Island, U.S.A.
}

Demian A. Sorrentino

University of Rhode Island

Follow this and additional works at: https://digitalcommons.uri.edu/theses

\section{Recommended Citation}

Sorrentino, Demian A., "Land Development Planning Handbook for Municipal Officials, Rhode Island, U.S.A." (2002). Open Access Master's Theses. Paper 754.

https://digitalcommons.uri.edu/theses/754

This Thesis is brought to you for free and open access by DigitalCommons@URI. It has been accepted for inclusion in Open Access Master's Theses by an authorized administrator of DigitalCommons@URI. For more information, please contact digitalcommons-group@uri.edu. 
Land Development Planning Handbook for Municipal Officials

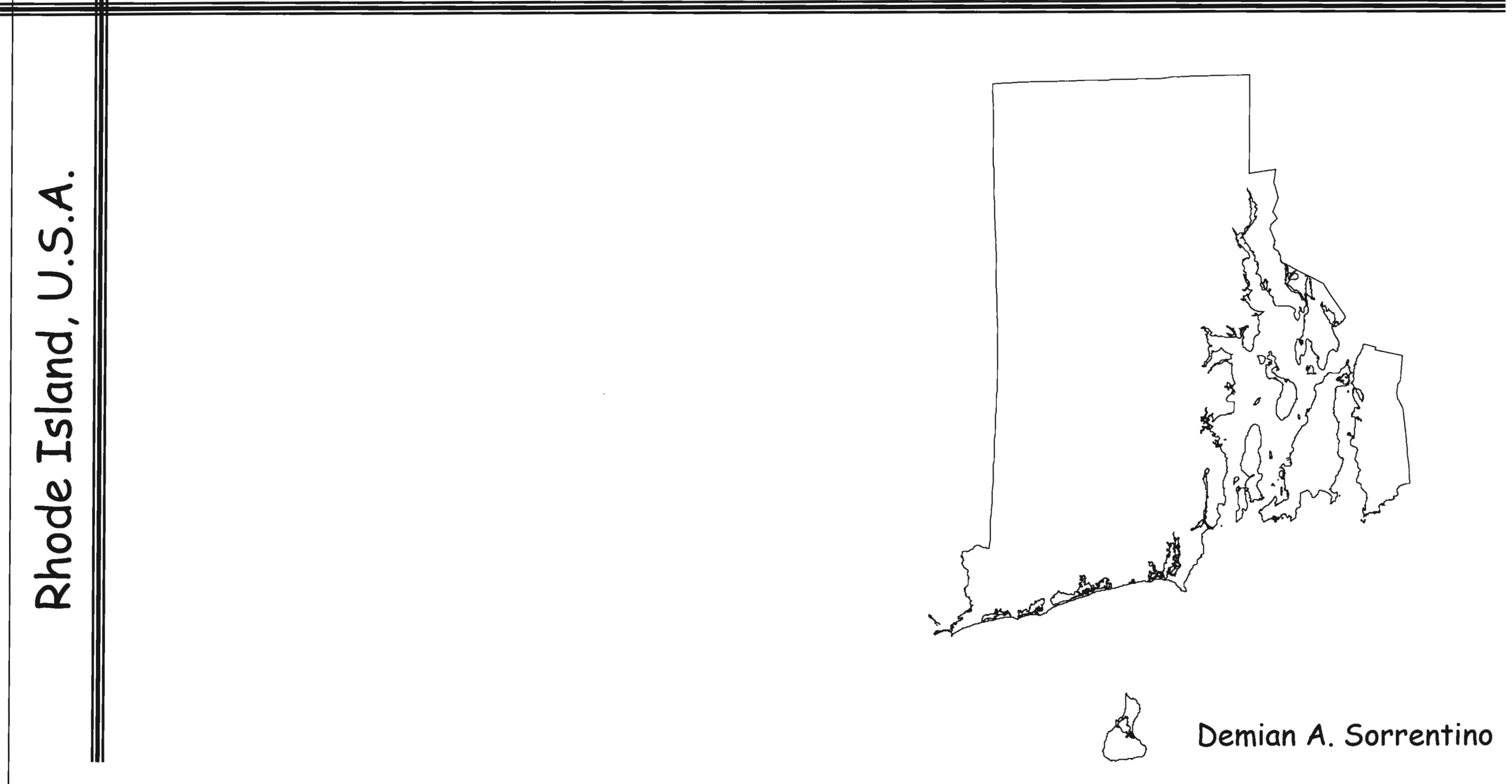




\section{Title and Approvals}

Land Development Planning Handbook for

Municipal Officials

Rhode Island, U.S.A.

BY

DEMIAN A. SORRENTINO

A RESEARCH PROJECT SUBMITTED IN PARTIAL FULFILLMENT OF THE REQUIREMENTS FOR THE DEGREE OF

MASTER OF COMMUNITY PLANNING

UNIVERSITY OF RHODE ISLAND
Land Development Planning Handbook for Municipal Officials Rhode Island, U.S.A.

Research Project

of

Demian A. Sorrentino

Approved:

Major Profe

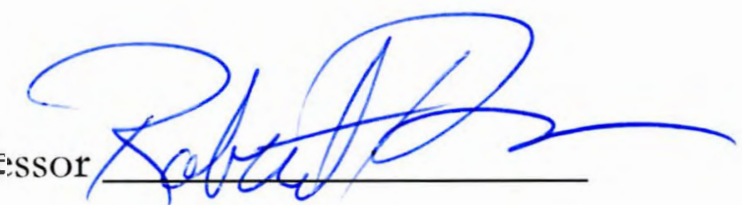

Acknowledged:

Director Faphad Stah 


\section{Acknowledgments}

Acknowledgments:

I would like to thank my Professional Project Committee:

Rob Thompson, PhD., JD. URI Community Planning \& Landscape Architecture: Major Professor

Lorraine Joubert, Coordinator URI NEMO. URI Cooperative Extension in Natural Resource Science: Reader

Farhad Atash, PhD. URI Community Planning \& Landscape Architecture: Reader

As well as:

The North Kingstown Planning Department for their cooperation;

The East Greenwich Planning Department for graphics;

DiPrete Engineering for the development plans;

and staff of the Cranston Planning Department for their input.

Last but not least, I would like to thank my family and friends for their continuous support

of my educational endeavors, especially Ami Cooper for her unwavering patience, love, and

understanding.

I thank you all.

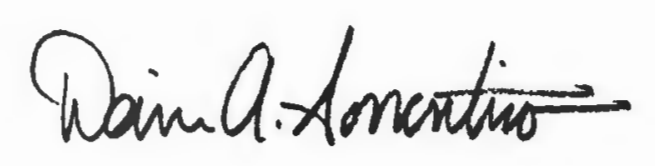

Demian A. Sorrentino 


\section{Table of Contents}

Section I.

Introduction and Purpose

$\ldots 1$

Section II. The Land Development Plan Review

Process in Rhode Island.

.. .2

Administrative Subdivision

Minor Land Development Projects and Subdivisions

Major Land Development Projects and Subdivisions

Regulatory Consistency

Implications for Municipal Officials

Section III. Reading and Understanding Maps...

Map Basics

Orientation

Scale (and Mapping Units)

Measuring Distance

Slope

Topography

Error (Appropriateness for Data Analysis)

Section IV. Types of Maps Typically Encountered.

Maps of the Physical Environment

USGS Topographic Maps

Site Specific Topographic Maps

Soils Maps

Floodzone Maps

Maps of the Legal Environmen

Zoning Maps
Section V.

Maps of Importance for Site Analysis.

Slope Analysis

Soils Analysis

Elevation \& Drainage Analysis

Existing Vegetative Cover Analysis

Climatalogical Analysis

Visual Impacts Analysis

Assessing Potential for Development

.. .19

Section VI. Reading Land Development Plans......................................27

$\begin{array}{ll}\text { Existing Conditions } & 28\end{array}$

Overall / Open Space Plan 31

Landscape Plan $\quad 34$

Landscape Details $\quad 38$

Grading Plan (with Erosion Controls) 40

Plan \& Profile (Road and Drainage System) 44

Engineering Detail 45

Record Plan

Section VII. Site Visits and Field Review...........................................52

Site Visitation Process and Standards in Rhode Island 52

Making General Observations for Field Review 52

Ground-Proofing Maps $\quad 52$

Observing Surveyor's Markers $\quad 52$

Observing the Wetland Edge $\quad 52$

Cataloguing Significant Natural and Cultural Resources 52

Section VIII. Glossary of Terms............................................. 53

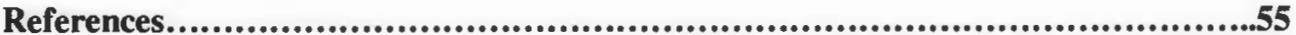




\section{Section I. Introduction \& Purpose}

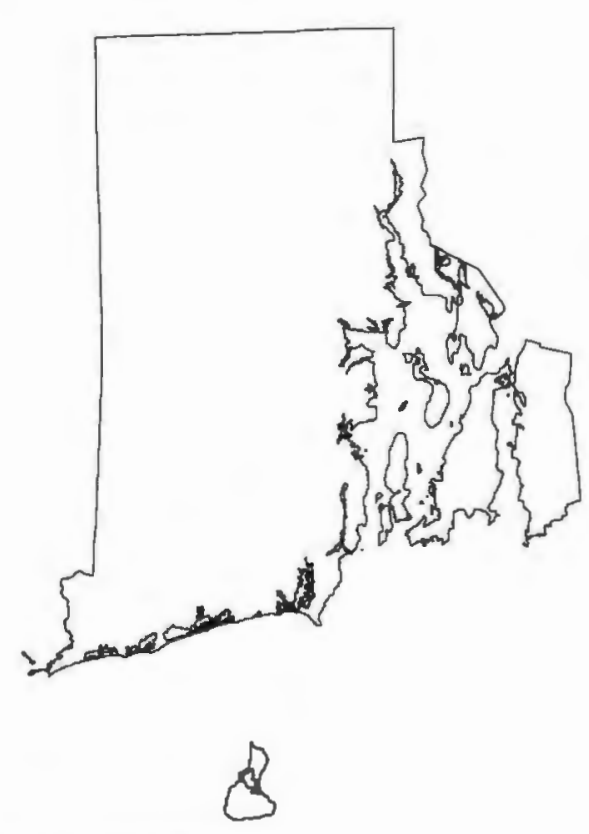

\section{INTRODUCTION}

Poorly planned or implemented land development projects have the potential to create negative impacts that can adversely affect communities. These impacts may be classified on various levels of complexity, but generally may be thought of as "on-site" and "off-site".

Land development may have on-site impacts that effect only the parcel of land for which the project is proposed. For example, a small development project that meets all environmental standards for development will have an impact on that particular site, but generally not beyond that.
If a land development project does not satisfy minimal environmental standards, it may have a myriad of off-site impacts on neighboring parcels, over a given local area, or even on a regional basis.

No matter the scale of these potentially adverse impacts, it is recognized that they should be minimized through a proper process of review and analysis of the land development plans before the project is approved and construction commences.

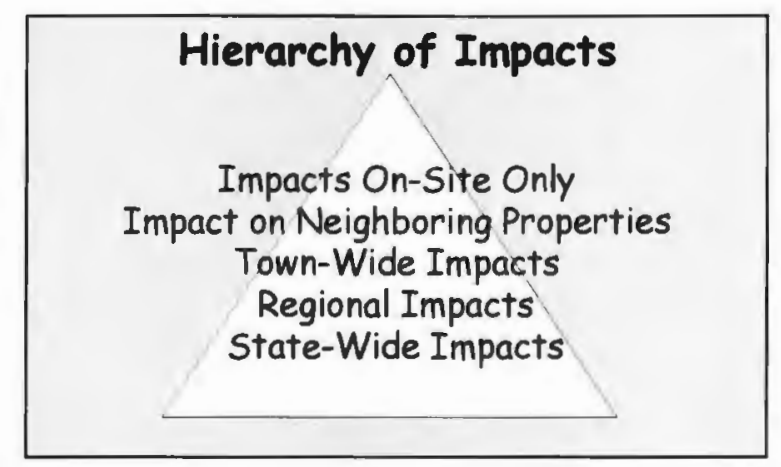

The cumulative effects that land developments create play a major role in determining the future character of Rhode Island communities. Consequently, the municipal officials responsible for the review of land development plans are able to ensure that new developments will be assets, rather than burdens to our communities.
In Rhode Island, local officials that serve on municipal boards and commissions are often the only individuals with the power to make certain that these impacts are minimized, and that land development projects are planned to provide the maximum benefit to the community. Potential problems can be avoided, or at least reduced, if the site plan reviewers know what type of detailed technical information should be included in the land development plans, and know how to interpret and process that information correctly. Moreover, the skilled plan reviewer may also see possible changes to the plan that can benefit both the developer and the community.

\section{PURPOSE}

Within the municipal government structure of Rhode Island, the major reviewers of land development plans are Planning Board (or commission) members, volunteers who come from a wide range of professional and educational backgrounds. Although this wide range of backgrounds often produces a varied group of individuals that makes the review process more dynamic, some individuals may lack certain skills that are needed to review land development plans, and perform necessary analyses in the review process.
Planning Board members need to know general information about the land development review process in Rhode Island, what the local

official's role in the process is, as well as how to understand the language and different components of resource maps and land development plans. These are all good examples of the skills which are required of municipal officials to properly review land development plans. This handbook deals with each of these skill areas, introducing the reader to the land development plan review process and assisting him or her with successful methods of critique.

This handbook is a reference document formulated to aid in the development plan review process. It specifically focuses on the interaction between the natural and built

environment, and has been designed expressly for use by municipal officials in the State of Rhode Island.

\section{Community Character}

The cumulative effects of land development projects determine and define the future character of Rhode Island Communities. 


\section{Section II: The Land Development Plan Review Process in Rhode Island}

Public regulation of the use and development of land comes in a variety of forms, which generally focus on five aspects of land use:

1. The type of use proposed

2. The density of use, manifested in concerns over height, width, or bulk of the proposed development

3. The aesthetic impact of the use

4. The effect of the use of the land on the cultural and social values of the community

5. The performance of a use with respect to the environment, transportation and other infrastructure.

The right to regulate land use is retained by State governments in the U.S. Constitution, under the common term known as the police power. The police power is defined as "the general governmental power to protect the health, safety, morals, and general welfare of the citizenry". (Salsich et al, 1998)

Though the police power belongs to the State, the right to regulate land use has been delegated to the 39 cities and towns of Rhode Island through what is called Enabling Legislation. This legislation empowers municipalities to regulate land use locally.

Thus, while local ordinances (i.e., the Comprehensive Community Plan, Zoning

Ordinance, Subdivision and Land Development Regulations, etc.) provide the requirements and processes involved with local land use decisions in each town, such ordinances must follow State statutes and guidelines that are prepared by Statewide Planning.

The state statutory requirements on how municipalities are to conduct land development plan review are set forth in the Rhode Island General Laws, or RIGL. Title 45 of the RIGL, entitled "Cities \& Towns" contains all of the State requirements regarding the power that municipalities have over land use, and the land use decisionmaking processes.

\begin{tabular}{|c|}
\hline RIGL Title 45 \\
Consult Title 45 of the State of \\
Rhode Island General Laws \\
for more detailed information \\
regarding the local regulation \\
of land use.
\end{tabular}

Sections that set forth the requirements for land development and subdivision plan review can be found in chapter 45-23, entitled "subdivision of land" and pertain to three general categories of land development. These three categories are defined here:

1. Administrative Subdivision: The resubdivision of existing lots, which yields no additional lots for development, and involves no creation or extension of streets. (ex: merging two existing lots into one lot; or moving a lot line to increase or decrease the size of a lot, while maintaining the same number of total lots)

2(a). Minor Land Development Project: A residential development project as described in local regulations, provided that the development does not require waivers or modifications to the regulations. (ex: a residential development that does not require subdivision of land)

2(b). Minor Subdivision: The subdivision of land consisting of five (5) or fewer units or lots, provided that the development does not require waivers or modifications to the regulation. (ex: a residential development that does require the subdivision of land, but is limited to five (5) or fewer lots)

3(a). Major Land Development Project: Any development plan not classified as a minor land development project, including all nonresidential project plans. (ex: any commercial, industrial or mixed use development project that does not require subdivision of land)

3(b). Major Subdivision: Any subdivision not classified as an administrative or minor subdivision (ex: a residential development project that requires the creation of more than five (5) units or lots)

As is apparent from these definitions, words lifted directly from the General Laws can be confusing to the layman. It is important to check your local regulations for further descriptions of these categories of land development, and be sure that you fully understand the qualifying factors of each before you begin to review them.

The land development and subdivision plan review process may include a different sequence of steps, dependent on whether the plan proposes an "administrative subdivision", or "minor" or "major" land development project or subdivision. However, all three type of review follow the same general format. The general process for review is as follows:

Pre-application meetings are the general starting point in the development plan process. Here, applicants may request the assistance of the planning board or technical review committee in reviewing concept plans for a proposed development, and gain insight or advice on the proper way to proceed. Preapplication meetings are held with the intention of sharing information between participants, and provide an opportunity for local officials to have input in the formative stages of the project.

Pre-application Meetings
Pre-application meetings provide
a forum for all those involved
in a land development project to
come together and discuss all
intentions and requirements before
the process formally begins.

Application for Development is the next stage in the process, and developers must receive a certificate of completeness for all proposed 


\section{Section II: The Land Development Plan Review Process in Rhode Island}

land development and subdivision projects, whether administrative, minor or major.

Requirements for development plans to be considered complete vary between

municipalities, but local regulations, including checklists, are available to aid developers that explain exactly what is required to be included in the application packet. Once the application is deemed complete, a certificate of completeness is filed and certified by the administrative officer.

\section{ADMINISTRATIVE SUBDIVISIONS}

Administrative subdivision plan review only consists of one basic stage; application review and the rendering of a decision. However, the length of time required to review and render a decision on an application may vary, dependant on the opinions of the administrative officer, review committee, or planning board.

Once the application is filed, the administrative officer must certify the application packet complete or incomplete within fifteen (15) days of receipt from the applicant.

Within fifteen (15) days of the application being certified complete, the administrative officer or technical review committee will review the plans and approve, deny, or refer it to the planning board with recommendations if it requires additional consideration. The officer or committee will report its actions to the planning board at its next regular meeting, to be entered into the legal record.

If no action is taken by the administrative officer or committee within these fifteen (15) days, the application is placed on the agenda for the next regular planning board meeting.

If the application is referred to the planning board, the board has sixty-five (65) days to review the application while considering the recommendations, and either approve, approve with conditions, or deny the application. Denial of an administrative subdivision application is not appealable, and

requires the plan to be submitted as a minor subdivision application. Failure to render a decision within the sixty-five (65) day period guarantees approval for the applicant.

\section{MINOR LAND DEVELOPMENT PROJECTS AND SUBDIVISIONS}

Minor land development and subdivision plan review consists of two major stages: preliminary plan and final plan. It also requires a public hearing if streets are to be created or extended.

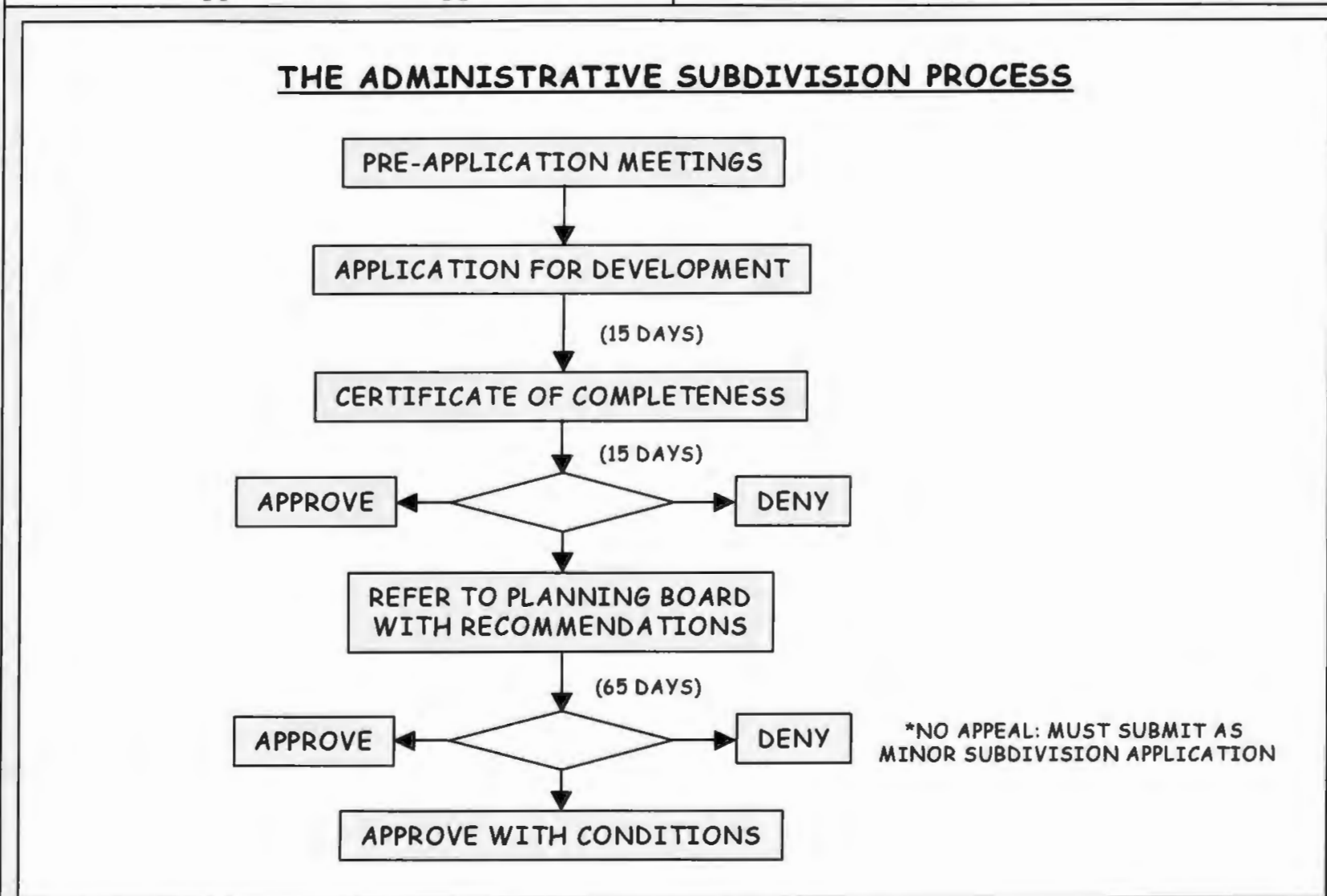

The administrative officer must certify an application complete or incomplete within twenty-five (25) days of receipt, or fifteen (15) days if no street extension or creation is required. Once the application is certified complete, the administrative officer or technica review committee will review the plans, and comment or make recommendations to the planning board prior to their review.

If no street creation or extension is required, the planning board must approve, approve with conditions, or deny the preliminary plan within sixty-five (65) days of certification of completeness, unless a longer period is agreed to by both the board and the applicant.

If street creation or extension is required, the board must hold a public meeting prior to rendering a decision, and has ninety-five (95)days to make said decision.

The planning board may delegate final plan review and approval to either the administrative officer or the technical review committee. After the administrative officer or technical review committee makes a decision, it is reported at the next scheduled planning board meeting, so that it may be included in the legal record.

\section{MAJOR LAND DEVELOPMENT} PROJECTS AND SUBDIVISIONS

Major land development and subdivision plan review consists of three major stages; master plan, preliminary plan, and final plan, and 


\section{Section II: The Land Development Plan Review Process in Rhode Island}

require both a public informational meeting, and a public hearing.

The administrative officer must certify a master plan application complete or incomplete within sixty (60) days of receipt from the applicant. Once the application is certified complete, the project master plan is forwarded to the technical review committee, if established, so they can review it and prepare comments and recommendations for the planning board.

There must be a public informational meeting before the planning board renders a decision on the master plan, unless master and preliminary plan approvals are being done simultaneously, in which case this meeting is optional, based on planning board determination.

Notice of this public meeting is required by law, and must be posted in "a newspaper of general circulation in the municipality" at least seven (7) days prior to the date of the meeting. Also, postcard notice must be given to the applicant and all those property owners within the notice area specified in local regulations. During this meeting, the applicant will present the project, and the planning board will allow questions and comment from the general public. All comments then become part of the record.

Within one hundred and twenty (120) days of certificate of completeness, the planning board must render a decision to approve, approve with changes and/or conditions, or deny the master plan. This time period may be extended with the consent of the applicant.
After making the appropriate changes or meeting specified conditions, the applicant will return with a preliminary plan, which must be certified complete or incomplete within sixty (60) days. From this point, the technical review committee, if established, will make comments and recommendations to the planning board.

Before the planning board makes a decision on the preliminary plan, a public hearing must

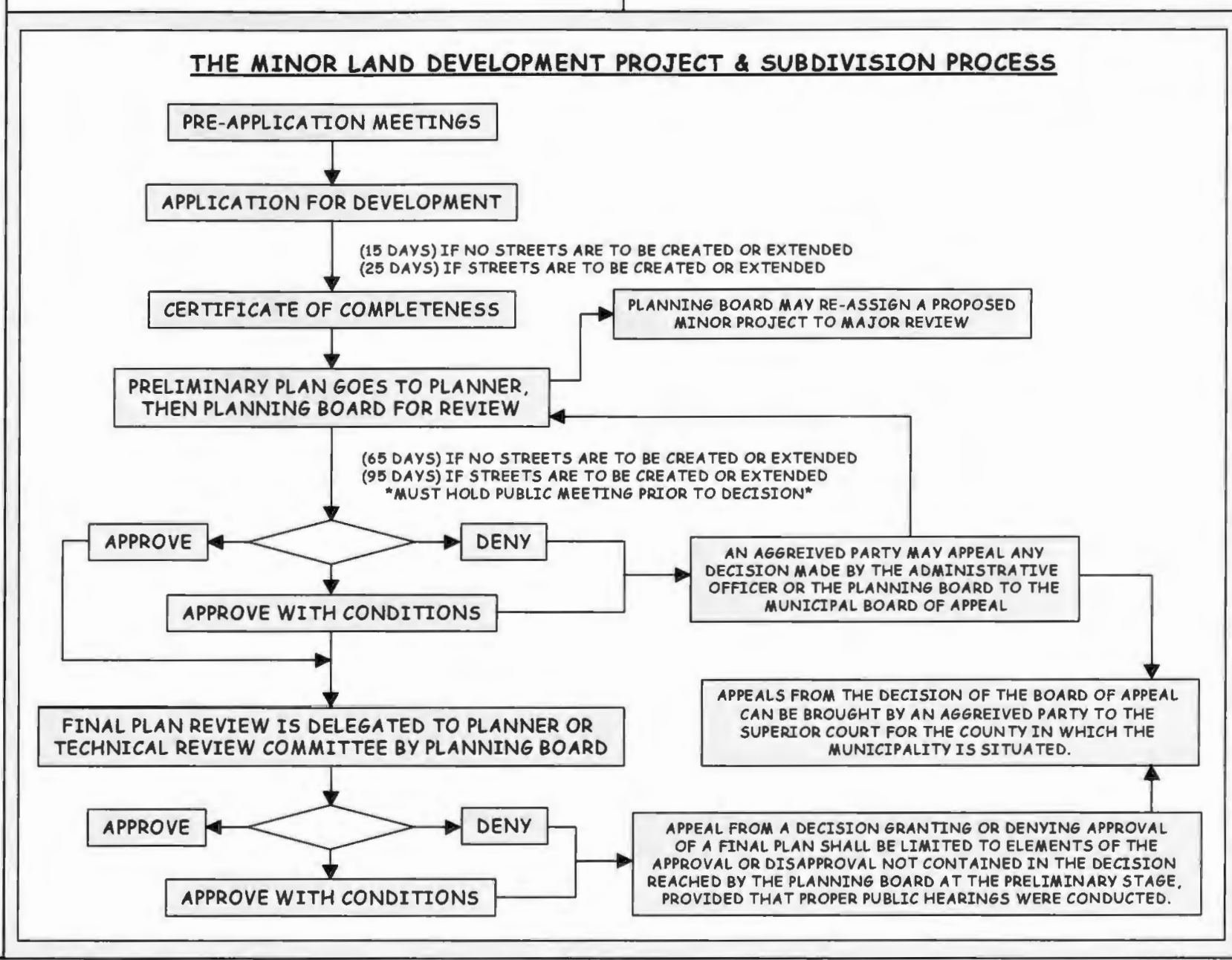

The notice must include the time and place of be held. Public notice of a hearing must be given fourteen (14) days in advance, in "a newspaper of general circulation in the municipality". Notice must be sent to the applicant and those property owners within the notice area by certified mail, return receipt requested, no less than ten (10) days prior to the hearing.

t
subject property. Additional notice is given within watersheds, and to adjacent municipalities if the application is likely to have impacts on a regional level. The applicant is required to cover the costs associated with providing notice.

From the time of certification of completeness of the preliminary plan, the planning board has one hundred and twenty (120) days to render a decision to approve, approve with changes and/or conditions, or deny the preliminary plan. The time for public hearing is included in this 120 days.

For the final plan, the applicant must submit all items required for final plan, and all material required by the planning board when the application was given preliminary approval. The application must include arrangements for completion of required public improvements, including construction schedules and/or financial guarantees, proof that property taxes are current, and phased projects require special submittals.

Applications for final plan approval must be certified complete or incomplete within twentyfive (25) days of receipt from the applicant.

This may be extended to forty-five (45) days by written notice from the administrative officer to the applicant where the final plan contains changes or elements not included in the preliminary plan approval. 


\section{Section II: The Land Development Plan Review Process in Rhode Island}

If the administrative officer decides that an application for final approval does not meet the requirements set by local regulations or by the planning board at preliminary plan approval, the application is forwarded to the planning

board for review. The planning board then has forty-five (45) days from the certification of completeness to approve or deny the application.

It should be noted that the processes described herein are not strictly linear as the flowcharts which describe them would lead you to believe. Each municipality has developed its own manner by which denials and approvals with conditions are handled. Municipalities may have a legal process for appeal when plans are denied, or when the applicant believes that the conditions placed on approval are too cumbersome to be realistic. Again, you should check your local regulations to be sure that you understand how your municipality deals with the non-linear aspects of these processes.

\section{REGULATORY CONSISTENCY}

As was mentioned earlier in this section, the State of Rhode Island has established, within it's general laws, a process through which local municipalities are to regulate land use. The components of this regulatory framework are several chapters found within Title 45 of the RIGL.

When dealing with the development of land, it is absolutely crucial that the land development project be consistent with the municipality's

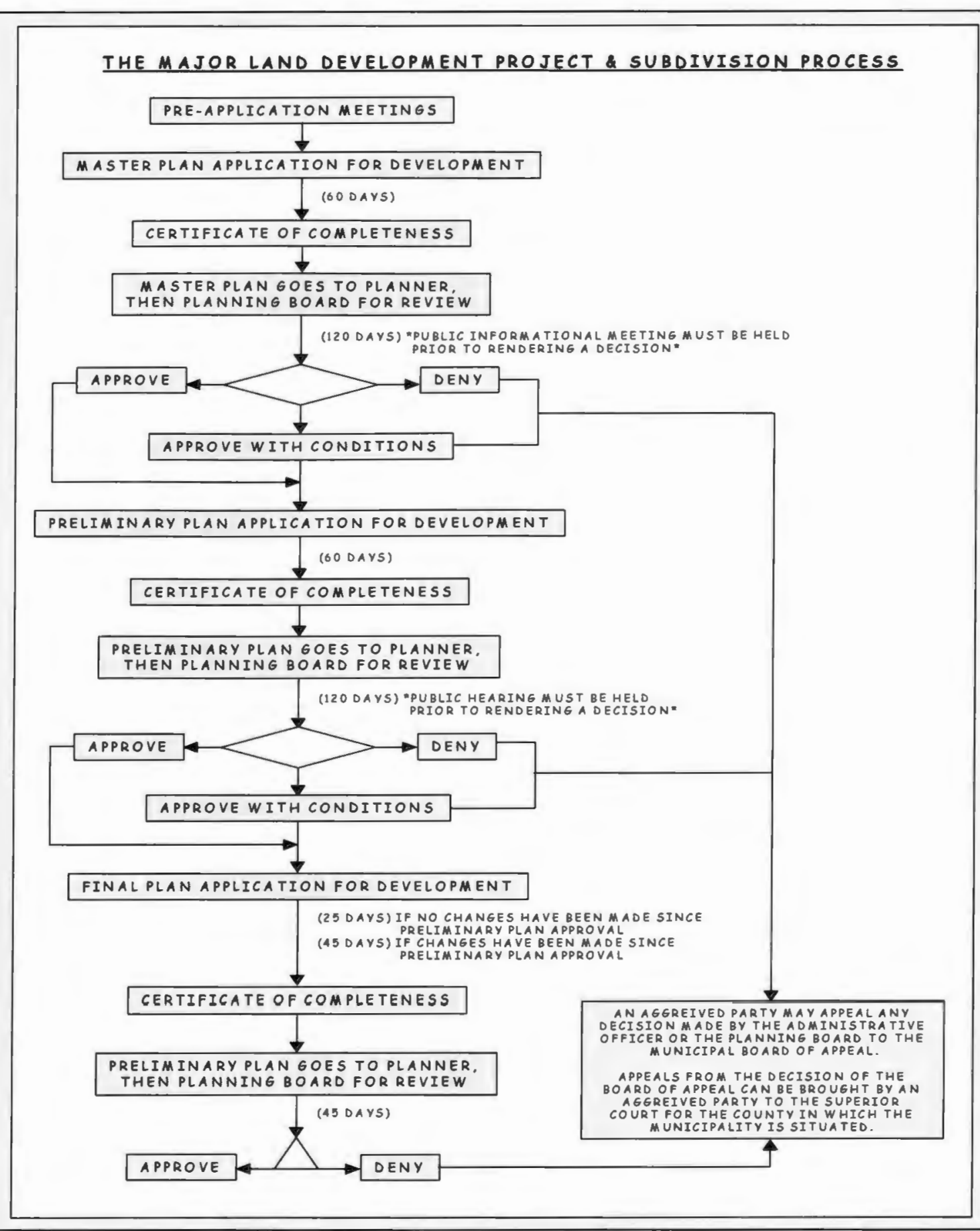

three major land use regulations. These regulations are the Comprehensive Community Plan, the Zoning Ordinance and Map, and the Subdivision and Land Development Regulations. The power to create and enforce these documents are delegated from the State of Rhode Island to the 39 cities and Towns through the following Enabling Acts:

RIGL 45-22.2: the "Rhode Island Comprehensive Planning and Land Use Regulation Act"

RIGL 45-24: the "Rhode Island Zoning Enabling Act of 1991".

RIGL 45-23: the "Rhode Island Land

Development and Subdivision Review Enabling Act of 1992".

Proposed developments must be consistent with the Comprehensive Plan, Zoning Ordinance and Subdivision Regulations of the town in which

the proposed development is to take place. Inconsistencies require special proceedings to amend the Comprehensive Plan or request relief from the Zoning Ordinance or Subdivision Regulations. This should not be a generally accepted practice, and should only be allowed under very unusual circumstances.

Land Development proposals that stay within the bounds of local regulations should be the norm. These documents were formulated to protect cities and towns from growth that could be damaging to a community's character and therefore, should be respected and enforced properly. 


\section{Section II: The Land Development Plan Review Process in Rhode Island}

\section{IMPLICATIONS FOR MUNICIPAL OFFICIALS}

The land development plan review process has been designed to provide ample opportunity for intervention by a municipality's public officials as well as the general public. Local officials have the opportunity to participate during the pre-application phase, during master plan, preliminary plan, and final plan stages of review. Public meetings and hearings are a very important part of this process, as well.

The general public has the opportunity to voice their opinions, present evidence, offer verbal comments or submit written comments on a particular development project at public meetings and hearings. These comments will all be entered into the record for review when it comes time for the local officials to render the decision on the project.

Each level of land development application review requires different maps and plans, dependent on local checklists and planning board requirements. Each municipality has developed detailed checklists, as to what information must be supplied to the reviewing body at a particular stage of review.

It is important for the development plan reviewer not to be limited by the components of a municipal checklist. If one thinks that additional information would make for a better review of the proposed project, then one can require additional maps or other helpful information from the developer at that time.
Checklists should be used as a guideline, or a "starting point" when analyzing what information is pertinent to a good review of a proposed project. Still, the checklist is used to determine completeness and to measure the time limits placed on the development plan submission and review process.

If the board finds that it is repeatedly asking developers for something that is not required by the checklist, then the checklist requirements should be amended to require this information in the future

As the review process advances through the various stages of review, the intensity of information on the applicable maps and plans that are presented will increase dramatically. The most basic site information will come from resource maps, maps already created for different purposes, but which include the proposed development site in them (explained in section IV).

As the process moves forward, detailed analysis of the site will occur, creating a new set of maps and plans which explain the suitability of the site and its component parts for the development that is proposed (explained in Section V).

This continued analysis will culminate in a set of detailed land development plans, on which the proposed project is based (explained in Section VI)

Understanding and analyzing all of these documents properly will ensure that the

\section{Process \& Information}

\section{Pre-Application}

Master Plan

Preliminary Plan

Final Plan $\checkmark$ Project Concept (commercial, residential, etc.) $\checkmark$ Consistency of Project w/ Local Regulations Established (comp. plan, zoning, etc.)

$\checkmark$ Resource maps (USGS, FIRM, etc.)

$\checkmark$ Baseline Data

$\checkmark$ Basic Mapping of Site

$\checkmark$ Detailed Environmental Data

$\checkmark$ Detailed Mapping

$\checkmark$ Site Analysis

$\checkmark$ Basic Development Plans

$\checkmark$ Continued Analysis \& Engineering

$\checkmark$ Detailed Development Plans

$\checkmark$ Continued Analysis

$\checkmark$ Refined Development Plans review process functions as it is intended to, and that all applicable regulations and municipal ordinances will be upheld to the benefit of all involved.

From the very inception of the planning stages of a land development project, municipal officials should be thinking about the potential impacts of the project on the site itself, and on the community or surrounding municipalities.

There are many ways in which land development projects can impact our communities, both negatively and positively. Reducing the negative impacts and maximizing the positive benefits of the physical development of land should be a product of the cooperative process between the land developer and municipal officials, but this process can only be cooperative if both sides have a solid understanding of the requirements of the process, and the information that is needed to make informed decisions.

In the following section, we will begin to explore some fundamentals of mapping. This will be the first step in beginning to analyze what it is that maps and plans are conveying to you, and what the significance of this information is to the proposed land development project that you are reviewing. 


\section{Section III: Reading and Understanding Maps}

Maps are very important tools in the proper planning and review of land development projects. They show the relative locations of various physical and legal environments that exist on the landscape. Although all of these maps are literally two-dimensional, some are designed to specifically convey data of a threedimensional nature

Maps can be produced that show most natural and man-made features that should be considered when reviewing a development proposal. Aerial photographs can also be valuable tools for use in reviewing site development plans.

Maps that have been created previously can be available in hard copy, i.e. paper form, or in digital form to be viewed and manipulated with the use of a personal computer and the proper software.

If maps are not available that show specific features about a site that are deemed to be important, a map can be created using today's technologies. The Rhode Island Geographic Information System (RIGIS) provides environmental and social data in digital form, that can be manipulated through GIS programs on a personal computer. This data may be found at:

http://www.edc.uri.edu/rigis/

Several other engineering and drafting software programs can create maps as well, providing a myriad of applications for digital data and mapping.

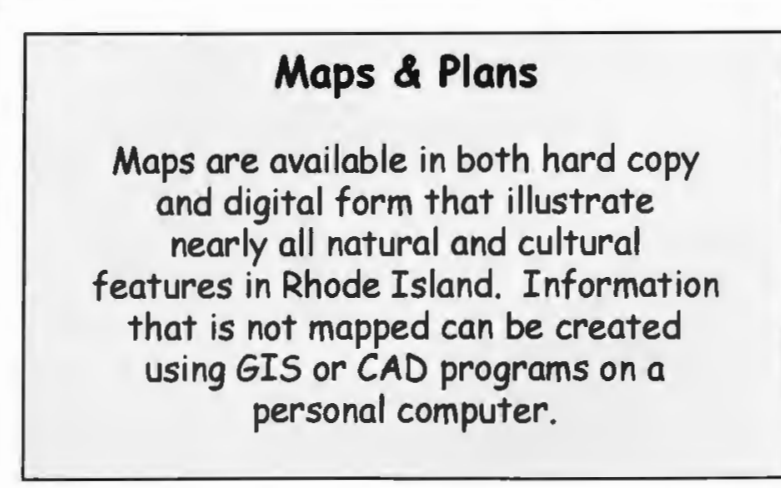

The boards and commissions responsible for site plan review and advisory opinions should have on hand, a full set of the relevant maps for use during the review of a land development project. If maps are missing that provide information that is crucial to the proper review and analysis of the proposed land development project, the developer should always be requested to provide them.

One good resource that you can utilize for digital environmental mapping of your municipality is the Rhode Island Critical Resources Atlas. This resource provides mapped data for every municipality, as well as the watersheds found in the state, including maps of municipal facilities, forests and wetlands, land use, groundwater resources, soil hydrology, watershed sub-basins, and biodiversity resources. This data can be accessed at:

\section{http://www.edc.uri.edu/riatlas/}

\section{MAP BASICS}

For planning board members, learning to read and understand numerous types of maps, many of which they may have little or no familiarity with, is an absolutely necessary skill that must be developed in order to properly review land development plans.

In the next pages, the reader will encounter some of the basic functions of reading maps, and begin to understand the different components that maps contain.

Of the basic functions of map reading, this section will explain:

-The orientation of a map;

-Understanding the different types of scale and what they mean;

-How to measure distance on a map including using an engineer's scale;

-A discussion of slope including how it is calculated and some general characteristics of slope;

-An explanation of topography, what it means, and how to read it;

-A brief discussion of error.

With the basic understanding of the topics explained and defined here, one should be able to approach maps with confidence, understand what the map is illustrating, and know how to obtain the proper information from the map for analysis. Of course, this process will take time and practice to master, but the topics explained in the following pages should have you on your way to understanding maps of all types.

Orientation. Understanding the orientation of a map does not require much explanation.

Everyone who has used a road map or other simple geographically referenced map has experienced the orientation of the map.

Every map, no matter what the source or purpose it is used for, should contain a north arrow to orient the reader to the context of the map. Particularly in land use maps, it orients the reader to the particular site and its surroundings by making the reader aware of which direction is north.

The reader should be aware that not all maps have a north arrow that points up when the map is held upright. Sometimes the context of the information lends itself to be mapped with an alternate direction pointing up when the map is held upright.

Look to the examples of maps throughout the remainder of this handbook to observe this phenomenon. Some are oriented with north up, and others are not.

Scale. Map scale is the relationship between distance on a map and the corresponding distance on the ground. It is expressed in three different forms: graphic scale, ratio scale, and equivalent scale. 


\section{Section III: Reading and Understanding Maps}

The ratio scale is expressed as a ratio of the same units, such as 1:24,000, where one inch on the map equals 24,000 inches on the ground.

The same ratio holds for different units so 1 foot on the map would equal 24,000 feet on the ground.

\section{RATIO SCALE}

\section{$1: 24,000$}

1 UNIT ON MAP EQUALS 24,000 UNITS ON THE GROUND

Equivalent scale converts distance on the ground to more workable units. For example, the equivalent scale of $1 "=200$ ' means 1 " on the map or plan equals 200 feet on the ground.

\section{EQUIVALENT SCALE}

$$
1^{\prime \prime}=2000^{\prime}
$$

1 INCH ON MAP EQUALS 2,OOO FEET ON THE GROUND

The common ratio scale $1: 24,000$ converts to the equivalent scale 1 inch $=2,000$ feet by dividing the ground distance by 12 (12 inches in one foot, so $24,000 / 12=2,000$ ). Equivalent scale is typically used in land development plans.
The graphic scale is a ruler-like bar used to correlate distance on the map to distance on the ground, usually in feet, miles, or

kilometers. Graphic scales are the only type of scaled maps that are easily adaptable to

reduction or enlarging when photocopying, as it remains accurate when reducing or

enlarging maps and drawings.

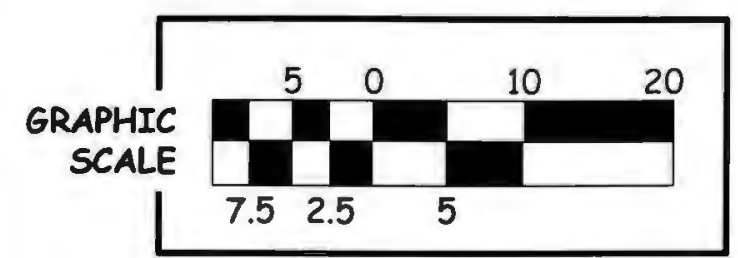

Switching from one type of scale to the other can be confusing. The table below presents corresponding ratio and equivalent scales. Site plans are commonly produced at scales ranging from $1 "=100$ ' to $1^{\prime \prime}=40$ ' depending on site size and submittal requirements.

\begin{tabular}{|c|c|}
\hline Ratio Scale & Equivalent Scale \\
\hline $1: 24,000$ & 1 inch $=2,000$ feet \\
\hline $1: 15,840$ & 1 inch $=1,320$ feet \\
\hline $1: 12,000$ & 1 inch $=1,000$ feet \\
\hline $1: 5,000$ & 1 inch $=416.7$ feet \\
\hline $1: 720$ & 1 inch $=60$ feet \\
\hline $1: 480$ & 1 inch $=40$ feet \\
\hline
\end{tabular}

Other terminology involved with scale includes the difference between what are considered "small" and "large" scale maps.

Conceptually, the designation of small and large scale maps seems counter-intuitive when first encountered, but with further explanation one can learn to decipher the two from each other.

Small scale maps show a large area of land, but do not show great detail for site specific purposes. Large numbers in the ratio,

equivalent, or graphic scale are a determining factor of small scale maps. For example,

USGS topographic maps at 1:24,000 scale are able to convey small scale data over a large

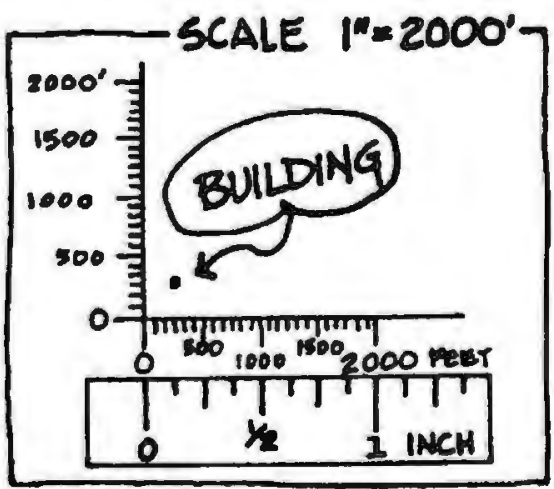

Small Scale $=$ small features on map This figure shows a building as it would appear on a small scale map at a scale of $1^{\prime \prime}=2,000^{\prime}$ (same as ratio scale of a scale of 1 " $=2,000$. less detail, as if you "zoomed out" with a less detail, as if you "zoomed out" with a camera. Features on small scale maps are small, even though a large area may be shown. land area, and are therefore considered to be small scale maps.

Large scale maps convey greater detail, but the area that is shown on the map is generally smaller. The smaller numbers in the ratio, equivalent, or graphic scale are a determining factor of large scale maps. For example, all site-specific maps and plans are considered to be large scale maps.

Perhaps the concept will be easier to grasp with the help of the figures and explanations provided below.

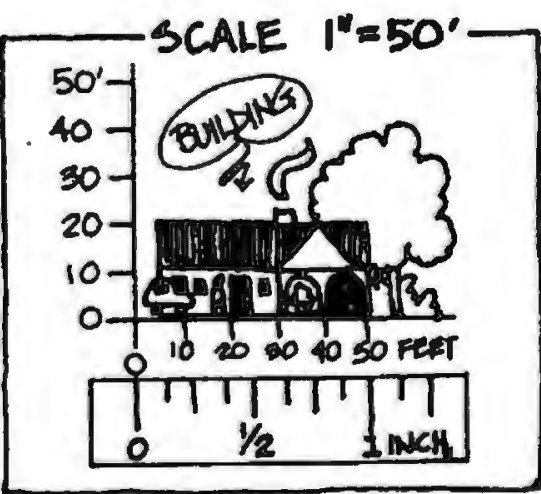

Large Scale = large features on map This figure shows the same building. in much greater detail on a large scale map of $1^{\prime \prime}=50$. Features appear much larger on a large scale map, but the areas shown may be small. 


\section{Section III: Reading and Understanding Maps}

Measuring Distance. Those who work with land development plans typically use an Engineer's Scale as an aid in measuring distances on a plan. This scale looks like a ruler but has inches divided into commonly used multiples of ten (i.e. $1 "=50^{\prime}, 1^{\prime \prime}=100^{\prime}$ ) corresponding to different map scales. Distance measurements can be read directly from the scale, skipping the conversion from inches to ground distance.

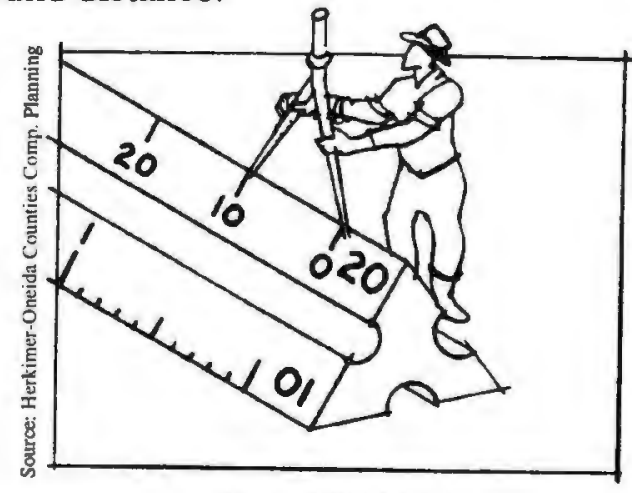

ENGINEER'S SCALE

An Architect's Scale looks similar, but has divisions based on fractions of an inch $(1 / 4$, $1 / 8$, etc.) for use in measuring buildings.

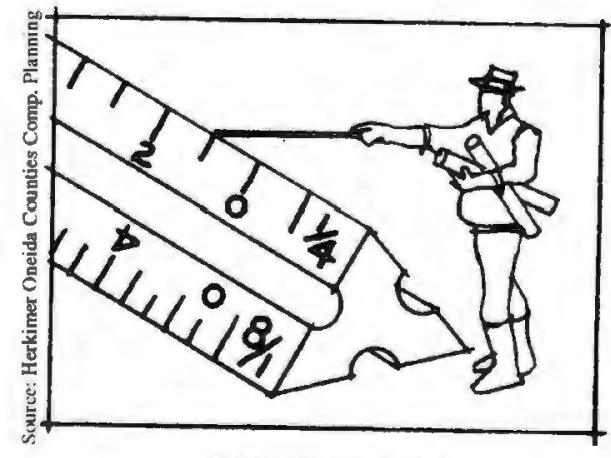

ARCHITECTS SCALE

\section{Using an engineering scale}

The standard 3-sided scale has 6 sides, with a different scale on each side, typically as follows:

\begin{tabular}{|c|c|}
\hline Scale & \multicolumn{1}{|c|}{ Meaning } \\
\hline $10^{\star}$ & 1 inch $=10$ feet $^{\star}$ \\
\hline 20 & 1 inch $=20$ feet \\
\hline 30 & 1 inch $=30$ feet \\
\hline 40 & 1 inch $=40$ feet \\
\hline 50 & 1 inch $=50$ feet \\
\hline 60 & 1 inch $=60$ feet \\
\hline
\end{tabular}

"This scale can be used as a 12" ruler

Many plans and maps are in scales other than those printed on your engineering scale. For measuring distances on plans at other scales, just adjust your measurements as follows:

\begin{tabular}{|c|c|c|}
\hline Sode & Mearing & Adjustment \\
\hline 80 & 1 inch $=80$ feet & $\begin{array}{c}\text { Use the } 40 \text { sode } \\
\text { and multiply by two }\end{array}$ \\
\hline 100 & 1 inch $=100$ feet & $\begin{array}{c}\text { Use the } 10 \text { sode and } \\
\text { add a zero }\end{array}$ \\
\hline 2000 & 1 inch $=200$ feet & $\begin{array}{c}\text { Use the } 20 \text { socle } \\
\text { and add a zero }\end{array}$ \\
\hline 2000 & 1 inch $=2000$ feet & $\begin{array}{c}\text { Use the } 20 \text { sode } \\
\text { and add two zeros }\end{array}$ \\
\hline
\end{tabular}

\section{Tech Tip}

For measuring distance on a USGS topographic map with 1:24,000 ratio scale (or 1 inch $=2,000$ ), use the 20 scale on your engineer's scale and add two zeros to the measurement.

Slope. In general, slope is an expression of a change in elevation between two points over a given distance. Slope is expressed in two ways: percent slope and degrees. Percentages are the standard units used in planning and slope classification, whereas degrees are commonly used in engineering calculations of slope stability. When in doubt about units, be sure to ask.

To calculate slope, one must know the change in elevation between the two points, as well as the distance between the two. Thereafter, the slope is calculated as the change in elevation divided by the distance between the points, or slope $=$ rise $/$ run. To change this to percent slope, just multiply this by 100 , or percent slope $=$ change in elevation/distance $\mathrm{x} 100$

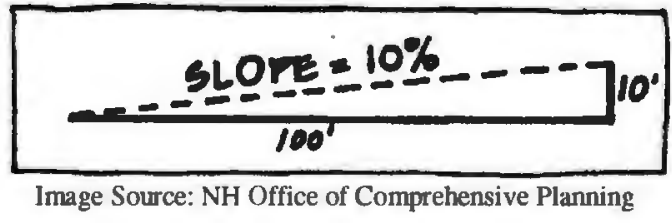

The slope of land is a very important consideration when reviewing land development plans. Land may act in very different ways dependant on the slope of the terrain, the texture of the soils, and the vegetative cover that is present on the site.

There are many generally accepted rules about the development potential of land based on slope. These are explained here:

Existing slopes of $0<5 \%$ require slight changes in topography during site construction, and will result in minimal land disturbance on site. Although a minimal slope is ideal for most types of development, if the slope of the land is zero or $1 \%$ water will tend to collect rather than drain from the area, creating many potential problems. So therefore, land should be sloped slightly for good site drainage and suitable stability. A good example of this rule is observed in road construction. As the figure below indicates, roads are constructed to slope 1 to $2 \%$ away from the center line so that water will drain to the sides instead of collecting in the travel lanes.

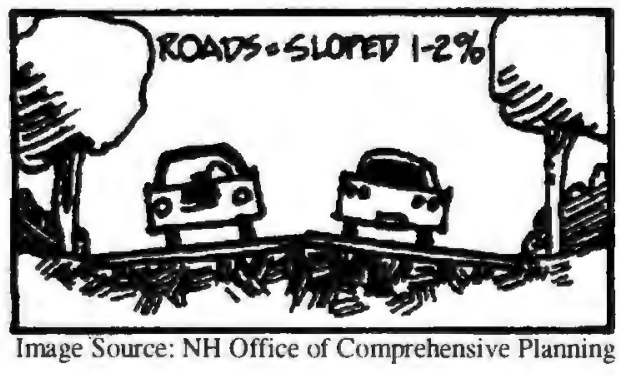

Existing slopes of 5 - 8\% require moderate topography changes for development, resulting 


\section{Section III: Reading and Understanding Maps}

in a moderate amount of land disturbance on site. Grass is often planted on these slopes to maintain stability and reduce runoff, however they can be difficult to mow.

Existing slopes of $8-15 \%$ involve significant changes in topography for development and require a large amount of land disturbance on site. Erosion is a serious problem if vegetation is absent or if erosion control measures are not properly installed and frequently maintained during the construction process.

Slopes greater than $15 \%$ involve severe changes in topography for development, and therefore very high levels of land disturbance. High costs and several risk factors are associated with developing land that contains slopes of this magnitude. Some common risk factors are the possibility of extreme erosion, these slopes are unstable and sensitive under the slightest disturbance, they have high construction costs associated with them, and there is a demand for long-term maintenance if they are developed.

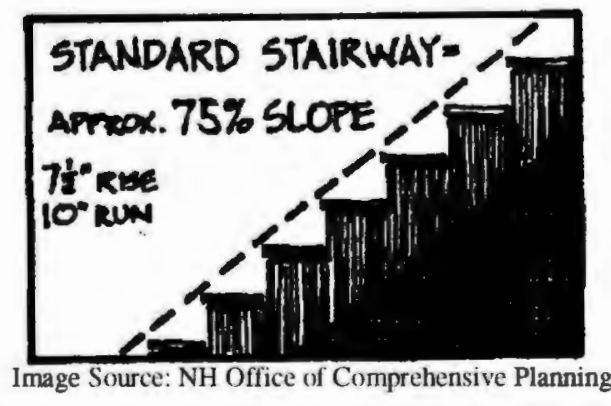

There are several ways to measure slope, both from maps and in the field. These methods will be discussed in later sections.
Topography. Reading and understanding topography and topographic maps is simple, once the reviewer is familiar with a few common terms and practices. The first of these to understand is what, exactly, you are looking at when you use a topographic map. To understand this you need a basic understanding of what is called "view".

There are several different "views" which can be used to represent three-dimensional objects or landforms by using only two-dimensions. Topographic maps are such representations of three-dimensional land forms on twodimensional paper, in what is called the "plan view" which is like looking at the ground from above. The other two views commonly used are "profile" and "cross-section". The figure below shows the relationship between the three views and the actual landform, which are further explained on the following page.

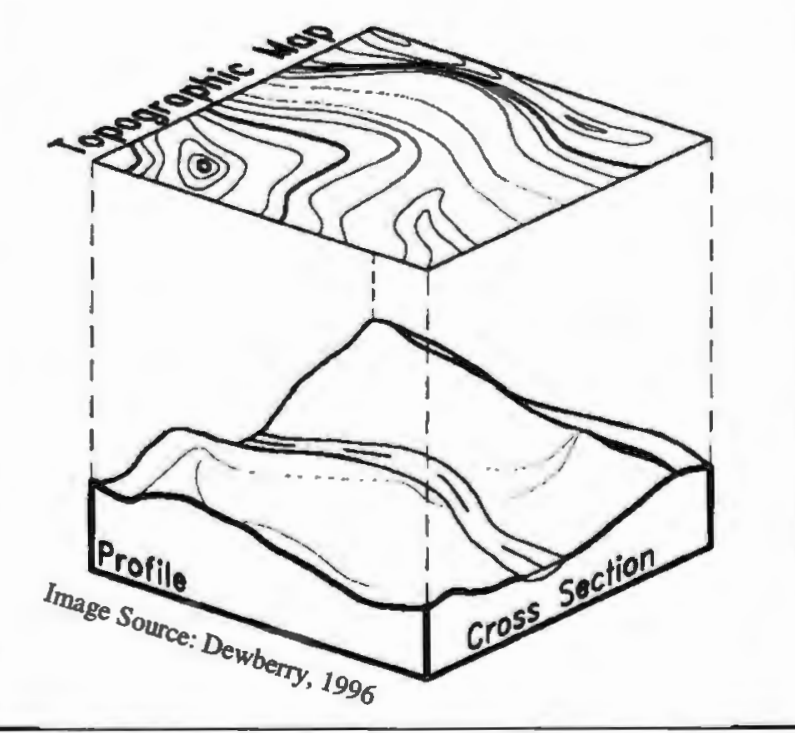

Topographic maps in the plan view show the third dimension of height (actually distance above sea level), as a series of lines called contour lines. Each contour line represents a series of points on the land that are exactly that many feet above sea level. For example, if a contour line shows a value of 200 , then all points found on that line are 200 feet above sea level.

The next thing to understand about contour lines is the change in elevation between lines on a map. This is termed the contour interval. The contour interval is given in the legend of a topographic map, and may vary from map to map.

Maps of different scales may show different contour intervals. Since Rhode Island has a relatively mild topography, the contour interval on USGS topographic maps of Rhode Island will be 10 . This means that there is a 10 foot change in elevation between each of the contour lines. Below is a close-up sample of a Rhode Island USGS Topographic map with a contour interval of 10 feet:

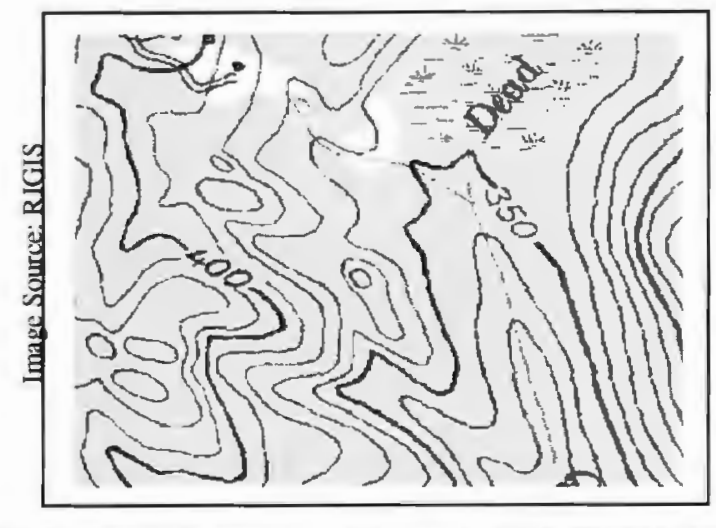

It is not uncommon to show site-specific topography with a contour interval of 1 or 2 . See the sample of a site-specific topographic map on page 12 of this handbook.

Once the contour interval is known, the reviewer can begin to make observations about the structure and slope of the land by analyzing the distance between the contour lines on the map, in conjunction with the other two measurements discussed above.

An area with a large space between the contour lines at a 10 foot contour interval would mean that the land rises ten feet over a relatively long distance, and therefore has a low \% slope. An area with a small space between the contour lines at a 10 foot contour interval would mean that the land rises ten feet over a relatively short distance, and therefore has a high \% slope.

When contour lines are directly on top of one another, this represents and extremely steep slope like a cliff.

To measure the slope by using contour lines, you will use the formula given previously in the slope section: slope $=$ rise/run .

First you would observe the change in elevation between the contour lines at the two ends of the slope you are measuring. Next, using the engineer's scale that corresponds with the scale of the map, measure the distance between the two extreme contour lines. Plug the first measurement in as the rise of the slope, the second measurement as the run, and divide to calculate slope. 


\section{Section III: Reading and Understanding Maps}

Many other natural features can be observed by using the topography of a land area. You can determine the direction of stormwater flow, the location of intermittent streams, or delineate watersheds and sub-basins.

To better understand what topographic maps are explaining to you, it is important to revisit the idea of "view" that was mentioned briefly earlier in this discussion.

The profile view is a representation of the landform which is being described from the side, as if the landform were cut along a straight line from top to bottom, then flipped vertically. In the figure to the right, this is represented by the line labeled "base line" that bisects the upper plan view into top and bottom.

Elevation above sea level is plotted on the $y$ axis, with the corresponding distance of the base line is plotted on the $\mathrm{x}$-axis. Points on the base line that intersect contour lines are plotted to the corresponding elevation on the y-axis of the profile view. Continuing this across the length of the base line, and connecting the dots created in the profile view give a representation of what the landform looks like at the location of the base line.

If this is a bit confusing, the figure at the top of the next column should make this explanation more clear.

The "cross-section" view is similar to that of the profile, but shows another dimension of the land form, as if it were cut along a straight

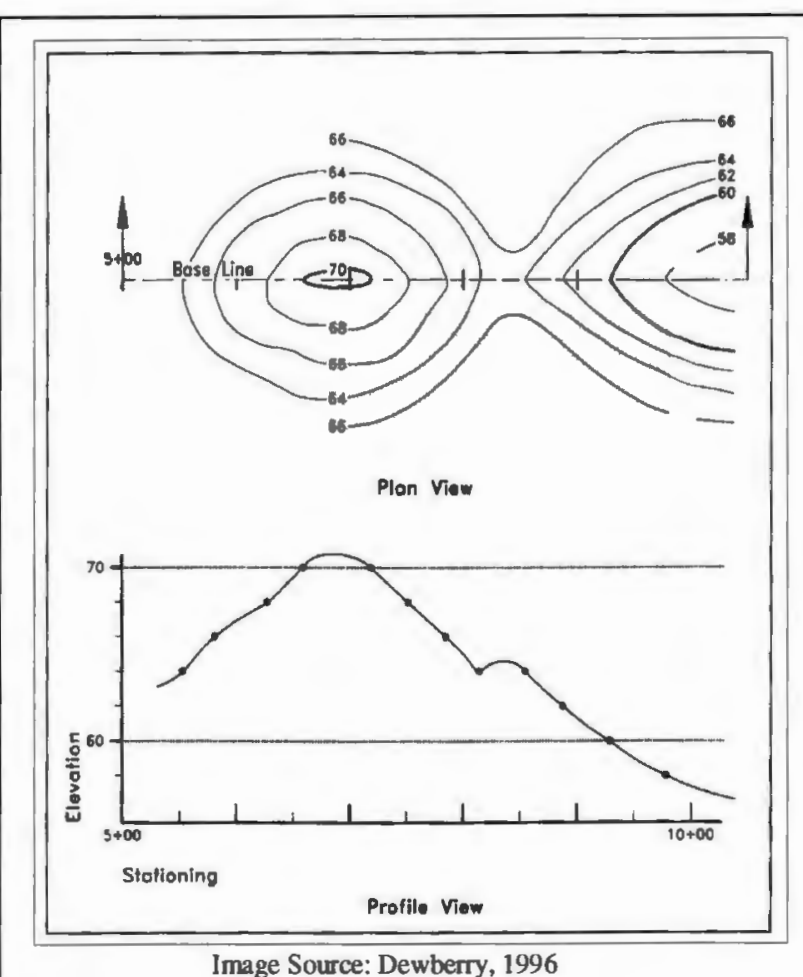

line from top to bottom, then flipped horizontally. This line is labeled as "cross section" on the right side of the plan view of the figure in the next column.

Again, elevation above sea level is plotted on the $y$-axis, and points on the cross section line that intersect contour lines are plotted to the corresponding elevation on the cross-section view. Continuing this across the length of the cross-section line, and connecting the dots created in the cross-section view give a representation of what the landform looks like at the location of the cross-section line.
The figure below should make this explanation more clear:

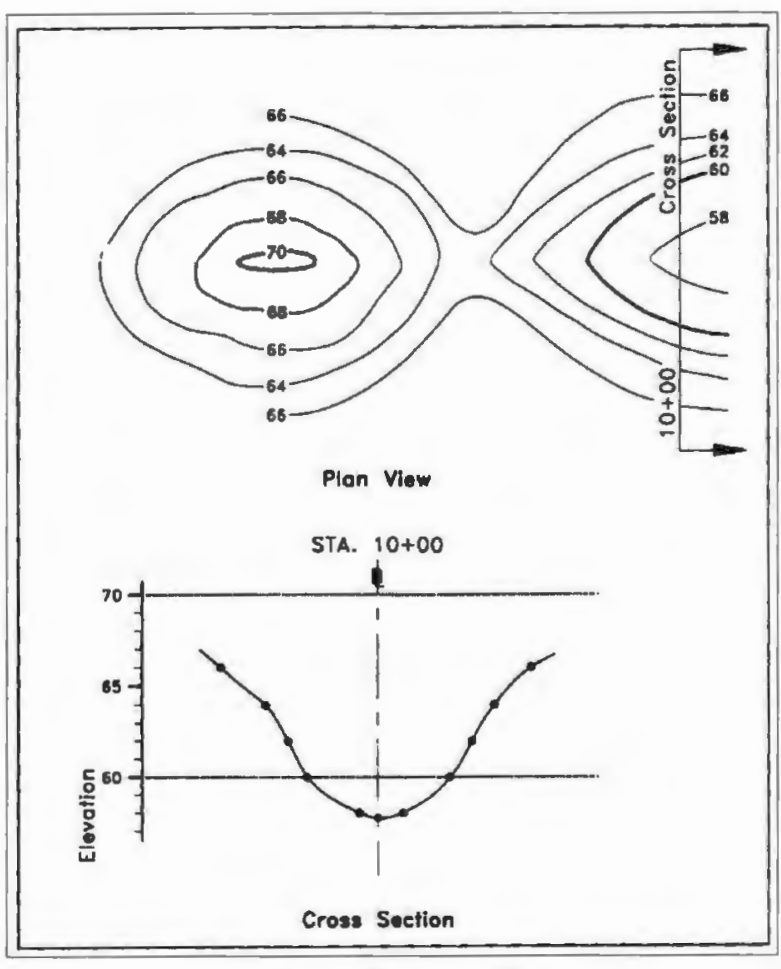

Image Source: Dewberry, 1996

When you see topographic maps in the plan view, you should be able to visualize what the landform looks like by following a thought process similar to that described here.

When analyzing water flow on a particular site, it is important to note that water flows perpendicular to contour lines downslope, and typically gathers into areas where contour lines take a concave form (where the contour lines look like a series of " $v$ 's", with the open side of the " $\mathrm{v}$ " facing downslope.
It is important that a plan reviewer pay close attention to topography, because topography plays such a large role in many aspects of land development, from the planning stages all the way through construction.

Practice in dealing with topography and topographic maps will sharpen your skills in visualizing landforms and site characteristics over time, skills that are invaluable in analyzing land development plans.

Error should be considered whenever one is trying to analyze data on a larger scale than that for which the data set or map was intended. Small scale data sets and maps lose their accuracy when they are applied to site level analysis. For example, digital data from RIGIS is great for analyzing land use issues on a small scale (remember this means less detail), but when it is applied to large scale analysis such as site-level analysis, it should not be used as a basis for any important decision-making because it will no longer be accurate. For this purpose, site specific data collection and mapping should be done.

Error also occurs in data sets even when they are used at their proper scales, ultimately because they are made by humans, and humans make occasional mistakes and miscalculations.

It is impossible to correct error that is inherent in data sets, but you should always try to minimize the occurrence of error whenever possible, and always use appropriate data sets for your analyses. 


\section{Section IV. Types of Maps Typically Encountered (Physical)}

Several different types of maps are used in land use planning. The following is a brief description of several of the most common maps a plan reviewer should be familiar with.

USGS Topographic Maps are topographic maps produced by the U.S. Geological Survey, showing large areas with regional topographic data.

Because of their small scale, these maps are best suited for showing land contours, and determining the direction of slope and surfacewater flow over the land. Many other features are shown on these maps, including roads, wetlands, waterbodies, landmarks, urban areas, extended urban areas, railroad lines, public facilities, and individual buildings as the scale allows (the image on top at the right is not an entire USGS 7.5" quadrangle, but only a portion selected to show detail).

Site-Specific Topographic maps are created for the potential project site to show the finite changes in topography over a smaller land area than can be depicted on the USGS topographic maps.

Contour intervals on site-specific topographic maps are generally 2 (two) feet, which is necessary when dealing with site-specific data. Land development plans are generally drawn with a site-specific topographic map as its background. The image at the far right is a section of a site-specific topographic map enlarged so that the 2-foot contour interval can be observed.

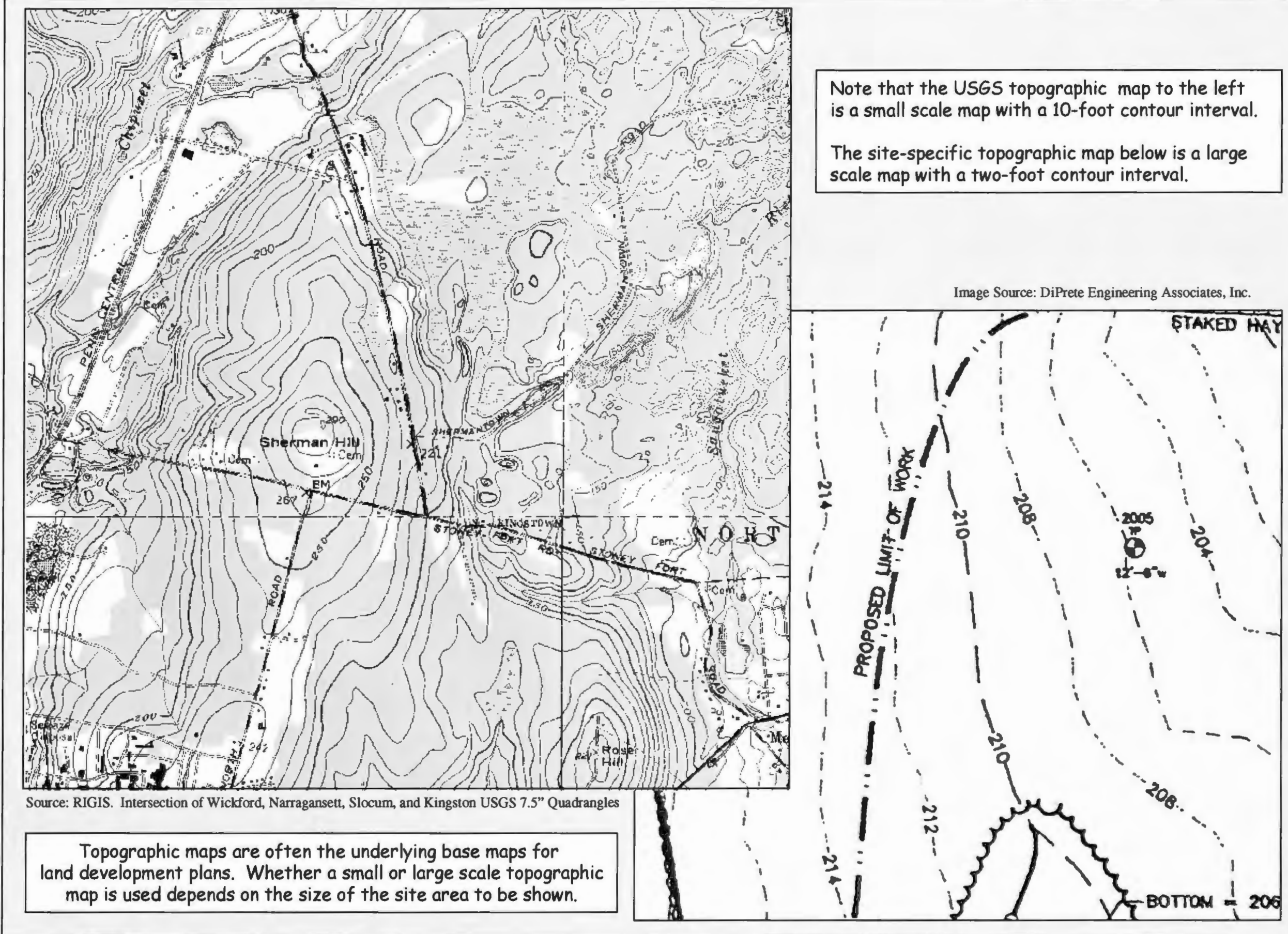




\section{Section IV. Types of Maps Typically Encountered (Physical)}

Soils Maps are particularly useful graphic tools that show soils characteristics including suitability for development, permeability, and depth to the seasonally high water table, among others.

Soils are unquestionably a key determinative factor when assessing whether or not a site can support a particular type of land development project. A common issue regarding analysis of soil suitability is for the placement of on-site, or "individual sewage disposal systems" (ISDS) for projects where no public sewers are available. If the soils are too sandy, the effluent will not be properly treated because it will move through the soil profile too quickly. On the other hand, if the soil is impermeable, the effluent will not filter downward, may inundate the system and cause "ponding" on the soil surface which is a hazard to public health. If a system is placed in soils that experience a seasonally high water table (SHWT), or the fixed water table is too close to the leachfield, there is a serious potential for groundwater contamination.

Although technology can help reduce environmental pollutants, it should never be used in place of good sighting and planning of land development projects.

Soil characteristics are also important when considering a site for a development project where on-site sewage disposal is not a large concern. Soil characteristics on a potential development site such as stability, permeability, depth to the SHWT, slope, depth to bedrock, and others can be important to the construction processes for varied reasons.

Standard soils maps are available from the Rhode Island Soil Survey produced by the USGS in 1977. The maps are contained in a book, and show abbreviated soil type names over aerial photographs for all land areas throughout the state. The book also includes tables of characteristics for each soil type presented.

Although this was once the premier source of soils data for the state, digital maps have become the most useful source as of late.

Soils maps are available in digital form from the Rhode Island Geographic Information System. Basic data sets can be manipulated to serve a multitude of purposes, with the user being able to include or exclude

characteristics that are or are not important to a particular land development project. To the right is an example of a soil hydrology map created from RIGIS soils data.

Soils should also be analyzed and mapped on a site-specific level to make certain that the mapped data is complete and relevant, and that error is reduced. This is a practical example of the problematic issues of analyzing data on a larger scale than that for which it was intended. Municipal officials responsible for reviewing development plans should always require developers to provide soils maps that show the data that is most pertinent to the project at hand to ensure their usability.

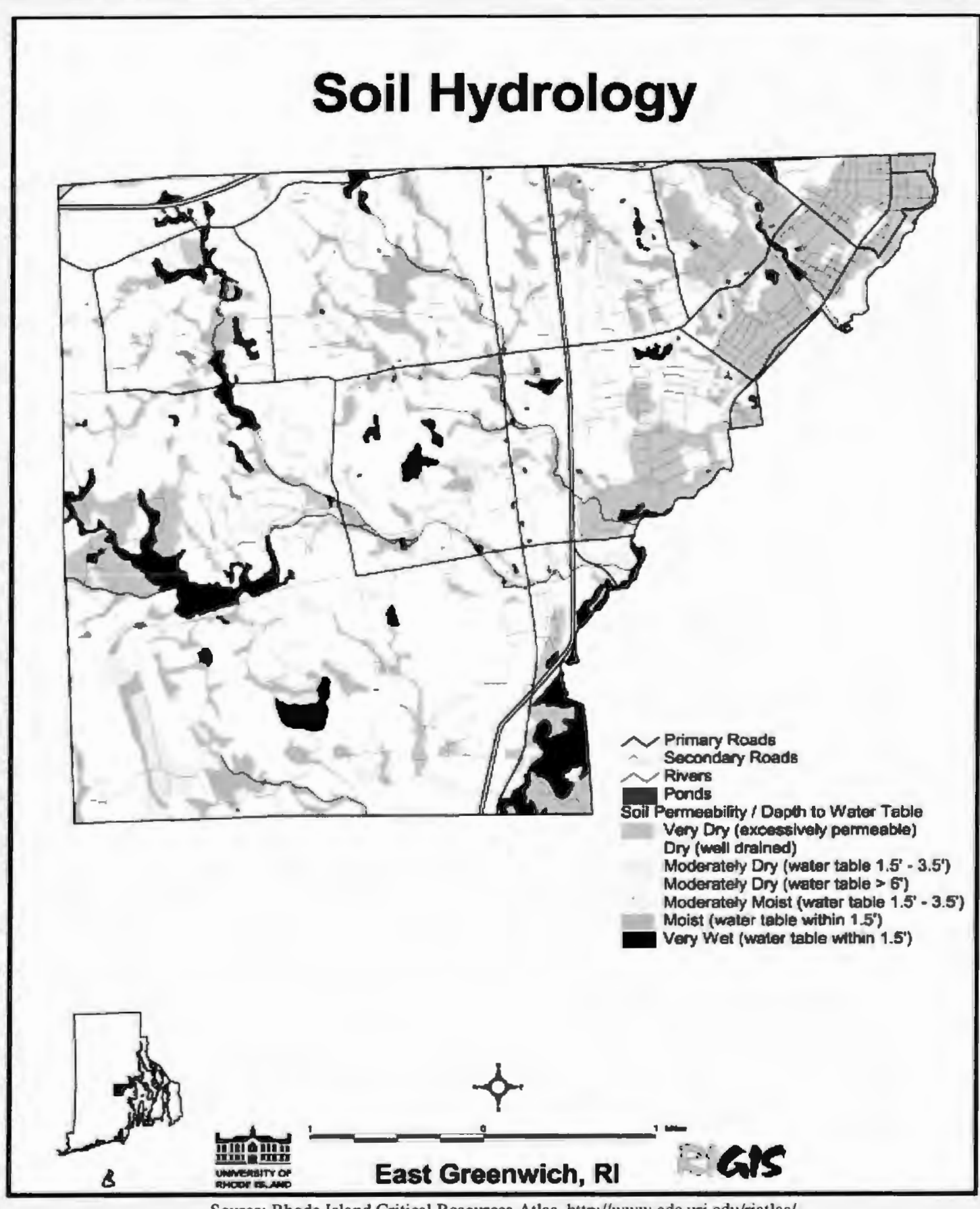

Source: Rhode Island Critical Resources Atlas. http://www.edc.uri.edu/riatlas 


\section{Section IV. Types of Maps Typically Encountered (Physical)}

Flood Zone Maps can be a particularly valuable resource in a coastal state like Rhode Island, because many properties throughout our state are located in floodplains, and are prone to inundation by flood waters during an extreme weather event.

Floodplains are those areas adjacent to surface water features that may become inundated by flood waters after a rain event.

The importance of these areas is that they moderate the flow of flood waters by allowing them to cover a larger area and therefore reduce their overall velocity and ability to carry sediment and debris. Floodplains provide an area of replenishment for underlying groundwater supplies and often comprise areas of very fertile soils which are a good resource for agricultural endeavors, as well as being aesthetically pleasing.

The floodplain is comprised of the floodway, which contains the deeper, more swiftly moving water during a flood event, and the floodfringe to the outside, which may only be inundated during the most severe of weather events.

The map shown at the right, titled FIRM or Flood Insurance Rate Map, shows waterways, floodways (areas that flood frequently), and flood fringes, such as the 100 year flood zone (which floods less often).

Flood zone maps have been prepared by the Federal Emergency Management Agency (FEMA) for purpose of rating a property's likeliness to be inundated by flood water, and gauge the severity of that inundation, thus they are often referred to as "FEMA maps". These are available at your Town or City's Municipal offices, or directly through FEMA. Note the explanations of the different zones that are designated on this map. All A zones are within the 100 year flood plain, and the map shows different characteristics of potential flood hazards dependent on which type of A zone the subject property is in. The base flood line elevation is also given within the A zone, showing the height above sea level (in feet) that floodwaters are likely to reach during a 100 year flood event. Other zones are the $\mathrm{B}$ zone, which is between the 100 and 500 year flood zone, $\mathrm{C}$, which is outside of flood zones, D zones are undetermined, and all $\mathrm{V}$ zones represent coastal flood areas where wave velocity is a factor, which are very important in coastal communities.

Each municipality may have different requirements for building standards in the different flood zones, so be sure to check with your local regulations when reviewing a land development project which could be in a flood zone.

Unfortunately, development within the floodplain does occur, but with special consideration for these sensitive areas, municipal officials have the power and obligation to reduce the negative impacts of development, and decrease the risks to life and property associated with floods.

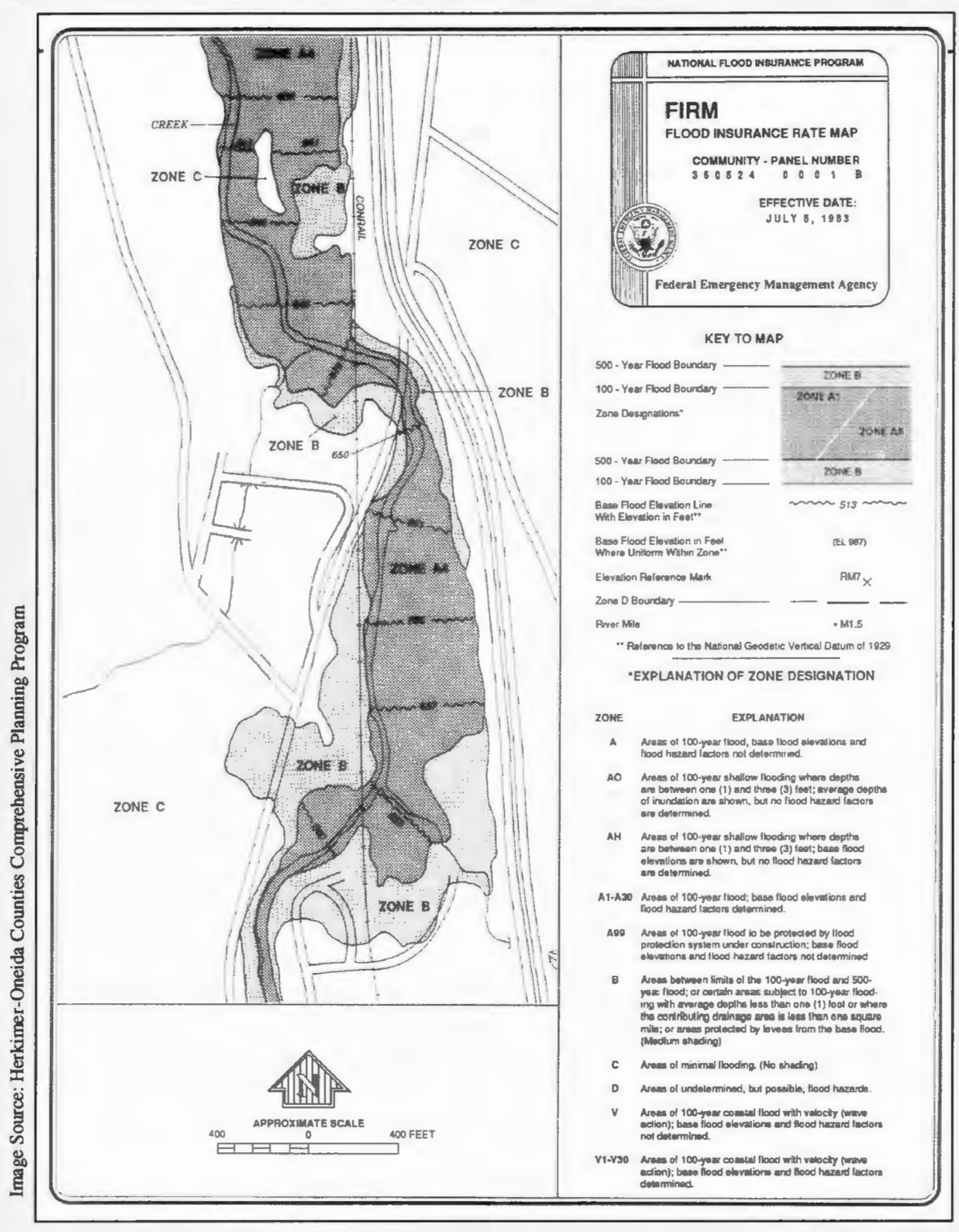




\section{Section IV. Types of Maps Typically Encountered (Legal)}

The Zoning Map is a necessary component of a municipality's Zoning Ordinance, and visually describes the land use control districts prescribed for a given area. The intent is to establish land use compatibility within each zoning district and among adjacent districts.

A variety of uses may be regulated by a community Zoning Ordinance, including residential, industrial, agricultural, business/commercial, conservation and open space. It also determines densities, lot sizes, setback requirements, building heights, dimensional requirements, among other things.

The particular map to the right is a typical example of a zoning map for a Rhode Island municipality. It graphically depicts the spatial location of existing zoning districts as described in the Zoning Ordinance.

The legend shows the zoning district title that corresponds to the shaded area on the town map. Explanations of what the designations mean and what limitations there are for development in each of those districts can be found in the Zoning Ordinance.

The Zoning Ordinance generally regulates the use of land by establishing areas (or zones) for specified uses, and also establishing dimensional requirements for lots employing those designated uses.

The figures on the following page are examples of typical tables (actually portions thereof) that explain what types of uses are permitted in established zones, and what types of

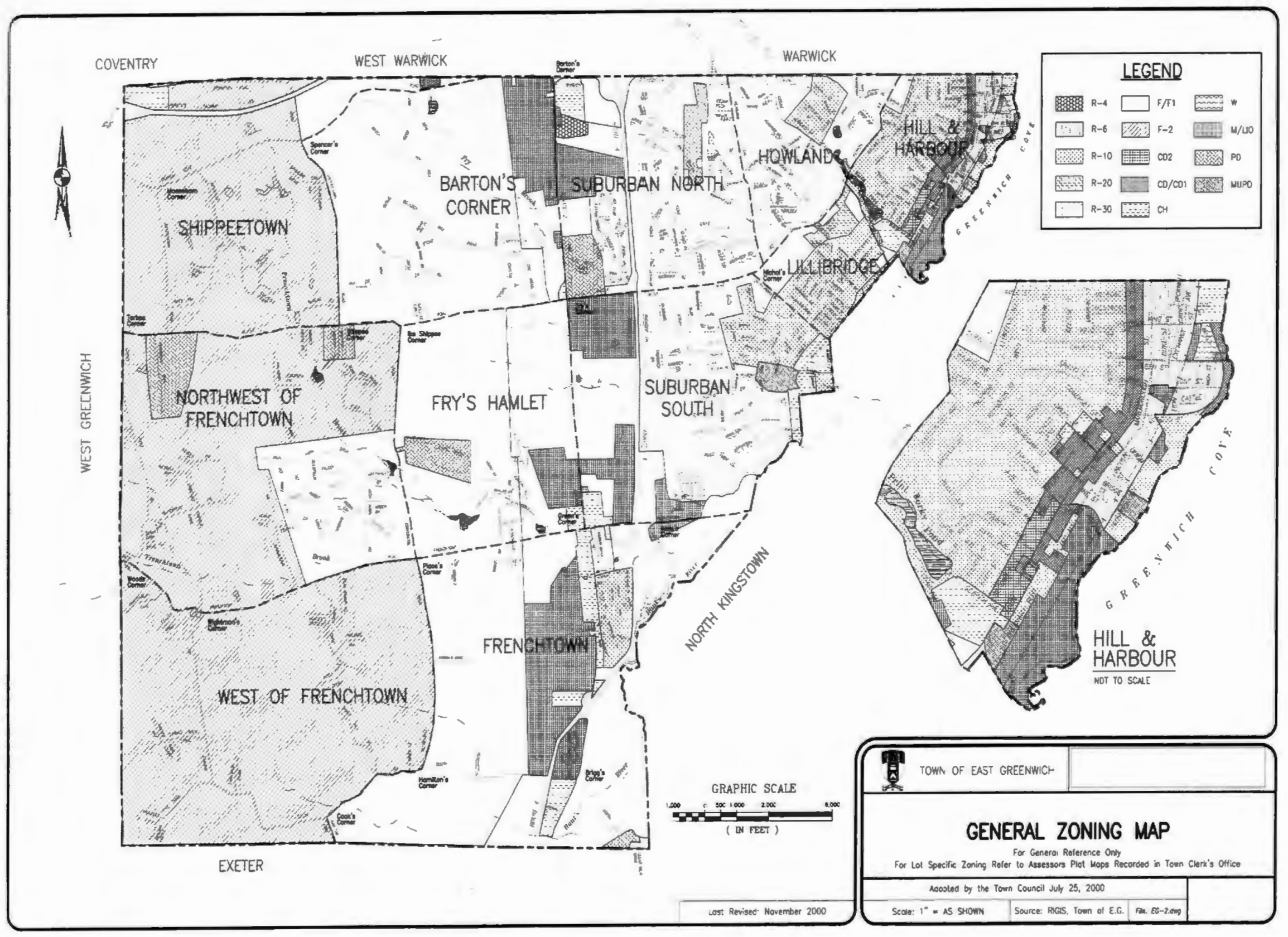

Image Source: East Greenwich Town Planner's Office 


\section{Section IV. Types of Maps Typically Encountered (Legal)}

\section{The Zoning Map (continued)}

dimensional requirements are regulated according to use.

The partial table on top to the right explains what types of uses are permitted within each of the established zones. You will note that each zone has different uses that are either permitted, not permitted, or permitted with special restrictions or provisions that must be approved by a municipal review body. This table is often called a "schedule of permitted uses".

The partial table on the bottom exemplifies the types of dimensional requirements (or minimum standards) that a lot must satisfy to employ a specific use. You will note that each of the zones is broken down into its possible uses, and the dimensional requirements vary according to the use to be employed. This table is often called a "schedule of dimensional requirements".

Reviewers should be aware of special circumstances where zoning may not be enforced on a particular lot or series of lots. This may be because they do not conform to the dimensional requirements of the zone of employed use, or the use itself does not comply with the established zone. These are called existing lots (or uses) of record, or grandfathered lots (uses). These are not regulated under the Zoning Ordinance because they were in place before the present restrictions were created.

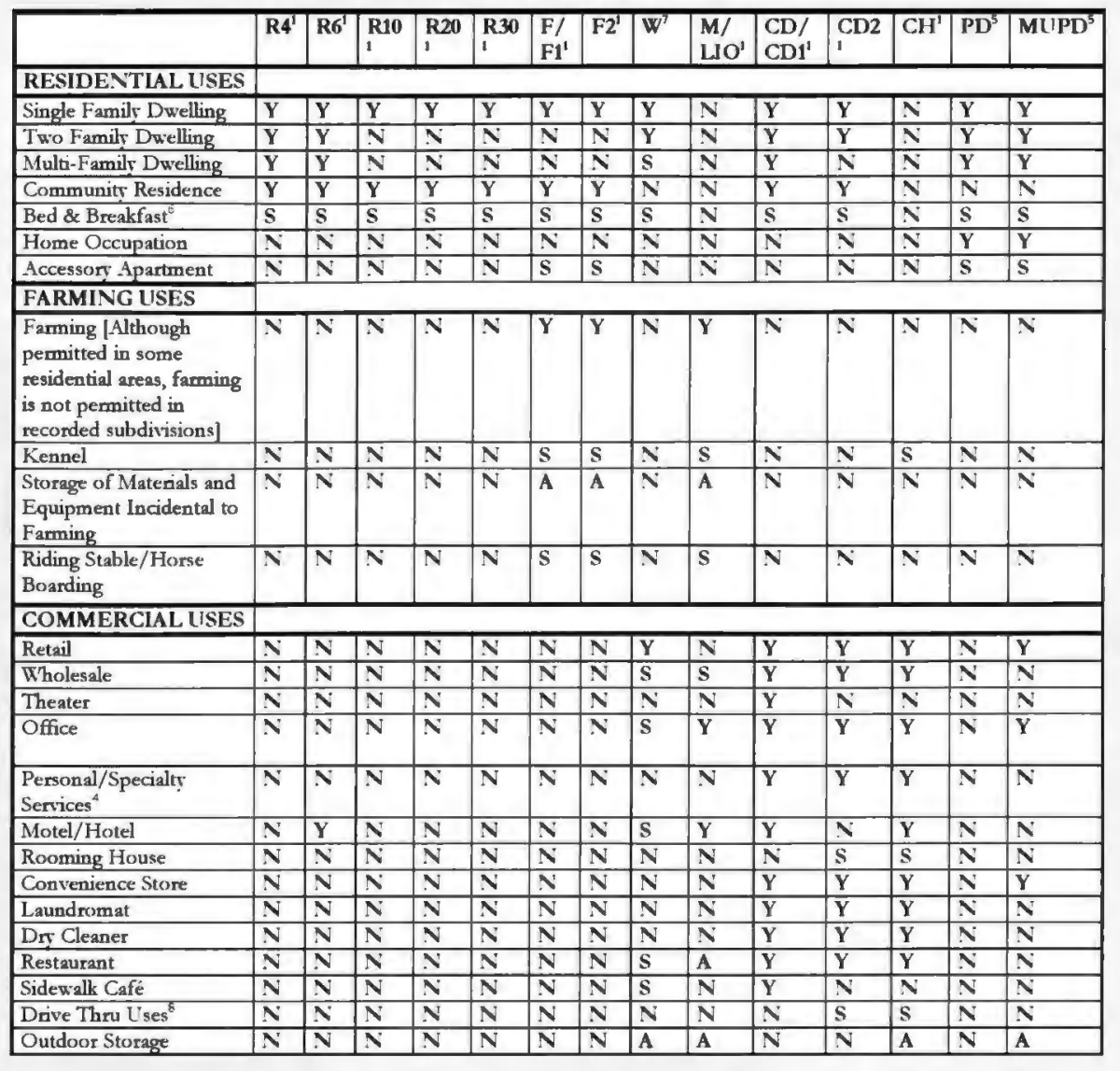

$Y=$ The use is permitted.

$N=$ The use is not permitted

$S=$ The use is permitted by special use permit only

$A=$ The use is permitted as an accessory use only

Source: East Greenwich, RI Zoning Ordinance

\begin{tabular}{|c|c|c|c|c|c|c|c|c|c|}
\hline Zone \& Use & Min. Lot Size & $\begin{array}{l}\text { M in. } \\
\text { Frontage }\end{array}$ & $\begin{array}{l}\text { Max. Lot } \\
\text { Coverage } \\
\text { Structure } \\
\end{array}$ & $\begin{array}{l}\text { Max, Lot } \\
\text { Coverage } \\
\text { Pavement }\end{array}$ & $\begin{array}{l}\text { Front } \\
\text { Yard }\end{array}$ & $\begin{array}{l}\text { Side } \\
\text { Yard }\end{array}$ & $\begin{array}{l}\text { Rear } \\
\text { Yard }\end{array}$ & $\begin{array}{l}\text { Height Main } \\
\text { Structure }\end{array}$ & $\begin{array}{l}\text { Height } \\
\text { Accessory } \\
\text { Structure }\end{array}$ \\
\hline \multicolumn{10}{|l|}{ RESIDEN TIAL R 4 } \\
\hline All Uses & $4,000 \mathrm{sf}$ & 100 & $30 \%$ & $60 \%$ & 10 & 10 & 20 & 35 & 15 \\
\hline \multicolumn{10}{|l|}{ RESIDENTIAL R6 } \\
\hline Single family & $6,000 \mathrm{sf}$ & 60 & $30 \%$ & $60 \%$ & 10 & 10 & 20 & 35 & 15 \\
\hline Two-Family D welling & $10,000 \mathrm{sf}$ & 80 & $30 \%$ & $60 \%$ & 10 & 10 & 20 & 35 & 15 \\
\hline $\begin{array}{l}\text { M ulti-Family } \\
\text { Dwellings (not } \\
\text { including two-family } \\
\text { dwellings) }\end{array}$ & $\begin{array}{l}4,000 \text { sf perdwelling } \\
\text { unit }\end{array}$ & 100 & $30 \%$ & $60 \%$ & 10 & 10 & 20 & 35 & 15 \\
\hline Community Residence & $10,000 \mathrm{sf}$ & 80 & $30 \%$ & $60 \%$ & 10 & 10 & 20 & 35 & 15 \\
\hline \multicolumn{10}{|l|}{ RESIDENT1ALR10 } \\
\hline All U ses & $10,000 \mathrm{sf}$ & 100 & $25 \%$ & $60 \%$ & 30 & 15 & 30 & 35 & 15 \\
\hline
\end{tabular}




\section{Section IV. Types of Maps Typically Encountered (Legal)}

Land Use Maps exist both for the present, and future of each Rhode Island municipality. Current land use maps are available in both hard copy and digital form. Municipal offices should have paper copies of current land use maps, and digital GIS coverages are available from RIGIS, which can be manipulated to show a variety of land use classifications dependent on the intended application.

The Future Land Use Map is a necessary component of the Future Land Use Plan of a municipality's Comprehensive Community Plan. This map shows how land use patterns will be in the future, if the CCP is implemented faithfully.

Much like the Zoning Map, this map breaks the Town into districts (though not necessarily exactly the same as the Zoning Map), with specified development activities planned to take place in each.

For example, the map to the right designates areas for several different densities of residential development, as well as commercial, light industrial, etc.

It is always important to review land development plans within the context of the Future Land Use Plan and map for your municipality, because it is the legally binding guide for the development of the Town.

The Town or City's Zoning Ordinance and map must be brought into consistency with the future land use map within 18 months of the adoption of the CCP, according to State law.

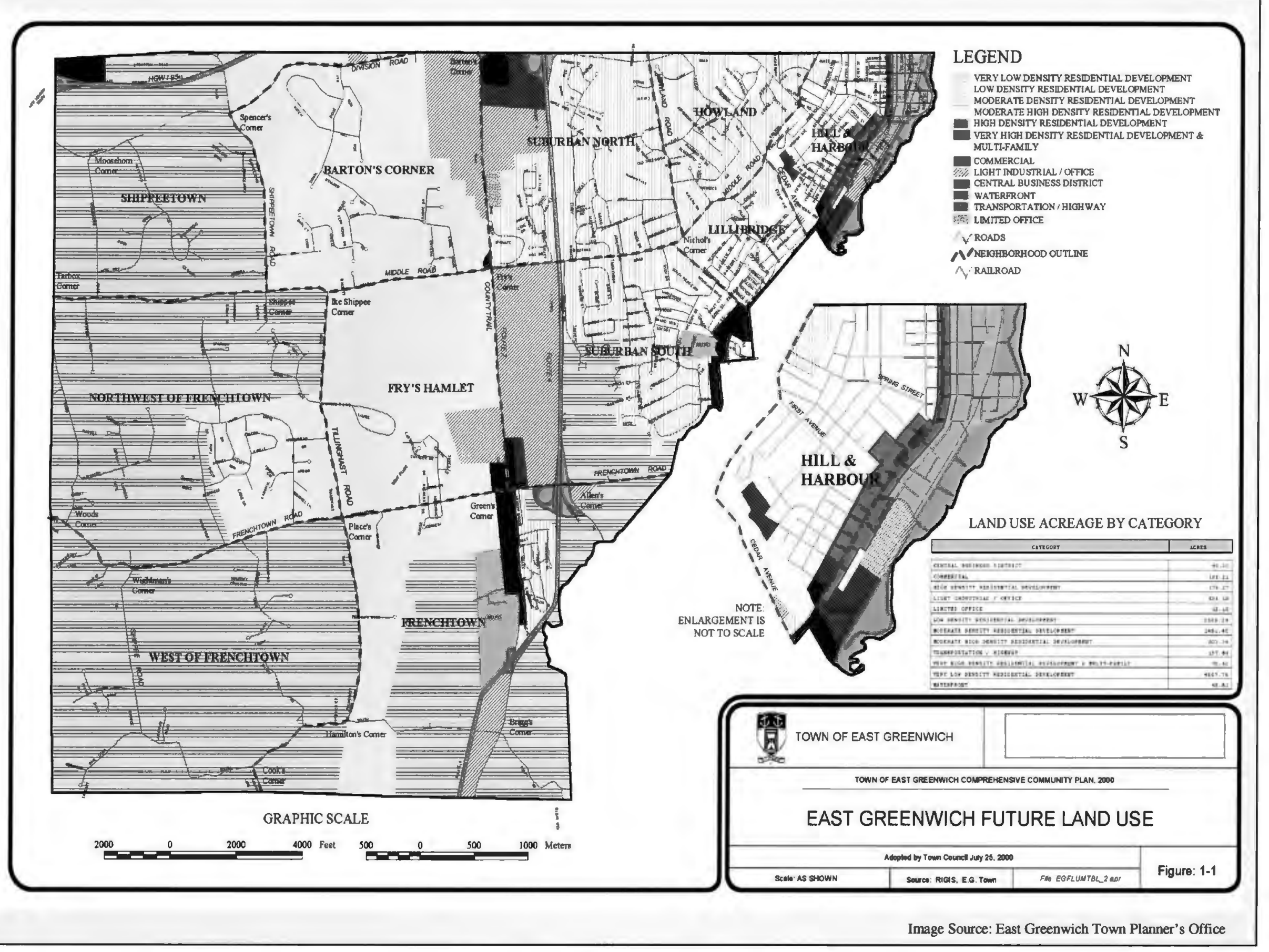




\section{Section IV. Types of Maps Typically Encountered (Legal)}

Tax Maps, also called "assessor's maps" are used to locate property parcels for taxation purposes, and are kept in the Tax Assessor's Office and in the town/city municipal offices. Finding mapped property generally involves first locating an index map, which specifies the location of a property map (also called the plat number). On each plat map, each property is identified with a number identifying the parcel (also known as the lot number). Other information includes:

1. Names and file numbers of existing subdivisions and record of survey maps;

2. Distance along property lines which are not considered legal dimensions, but approximations;

3. Street names and widths, easements, and rights-of-way;

4. Reference numbers to locate existing improvements or construction plans.

The figures to the right are examples of assessor's maps from a Rhode Island municipality. These figures are of the same plat and lot where the land development plans explained in Section VI are located.

Although assessor's maps do vary in content between municipalities, the general format is consistent throughout the state.

These maps are becoming increasingly

available on municipal websites, or through the city/town's GIS system.

To the right is an example of an entire assessor's plat map. This one in particular is plat 9. Note the additional information such as the date it was last updated, the scale and orientation in the bottom right corner of the map.

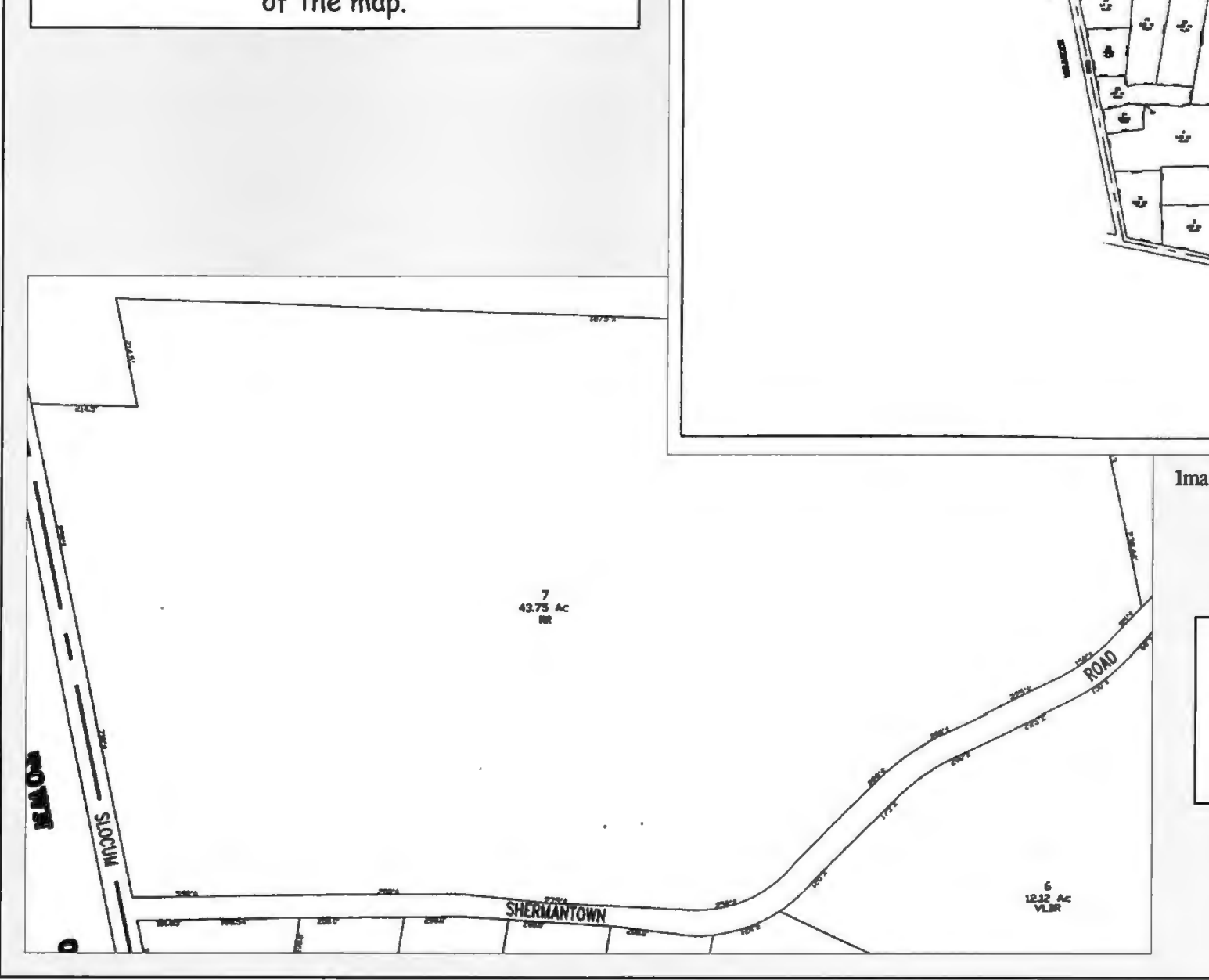

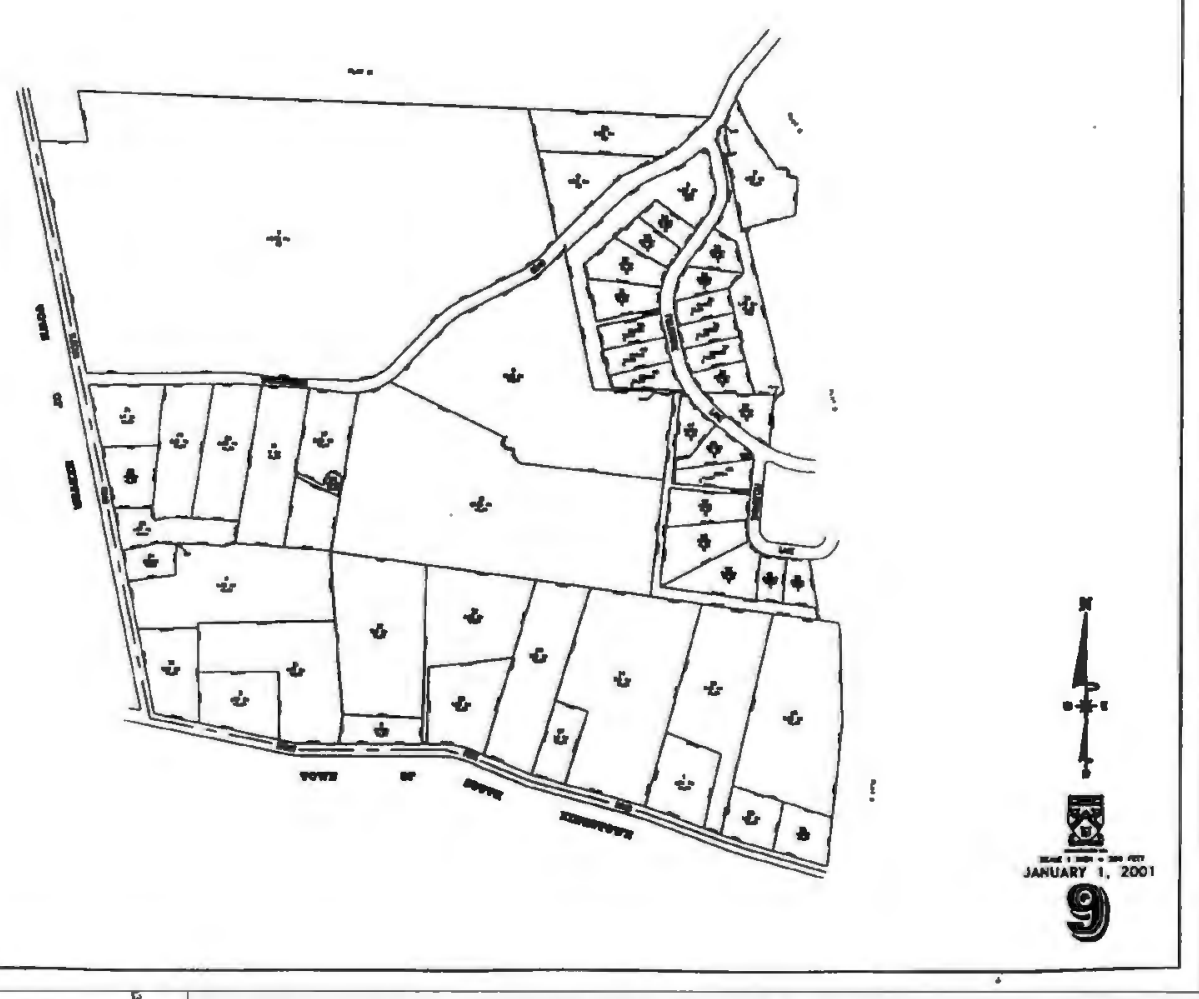

mage Source: North Kingstown Town Planner's Office

To the left is a "blow-up" of assessor's plat 9, lot 7 This particular municipality includes the lot number. the acreage of the lot, the current zoning designation, and approximate measurements along the perimeter of the lot. 


\section{Section V. Maps of Importance for Site Analysis}

As the field of site planning becomes more comprehensive, more and more aspects about the site for which a project is proposed are being included in the initial analysis of a potential project site. It is becoming increasingly more important to plan for the impacts that a land development project will have on the natural environment, as well as the effects the natural environment will have on the development project.

\section{Minimal Site Disturbance}

Plan reviewers should strive to enforce planning and construction practices that support the minimal disturbance of the natural and cultural resources found on the site.

Site planning for minimal disturbance should be the norm, and to ensure that the proper site analysis is being done initially, the site plan reviewer should be familiar with the mapping and diagramming techniques that land developers should be using during the planning and design phases of project development.

As the diagram to the far right illustrates, site analysis is the culmination of analyzing the attributes that are present on a sight before any development related disturbance occurs.
These attributes may be of a physical nature, including analysis of topography, hydrology, soils, or climate. They may be of a biological nature, including analysis of vegetation and wildlife, or they may be of a cultural nature, including such attributes as historic structures, utilities, or visual quality.

These attributes should all be mapped and analyzed for their importance to the sight and the surrounding context. Combining all of the attributes that are deemed important or significant with those that cause limitations for development, will produce a map of suitable areas on the site for development to occur. This is called the land development suitability map, and is the "final product" of the site analysis process.

Further detailed information regarding site inventory and analysis, including guidelines for sighting structures on-site with minimal impact is available in the Conservation Development Manual (Flinker, et al.), as well as several publications by Randall Arendt (see sources for full citations).

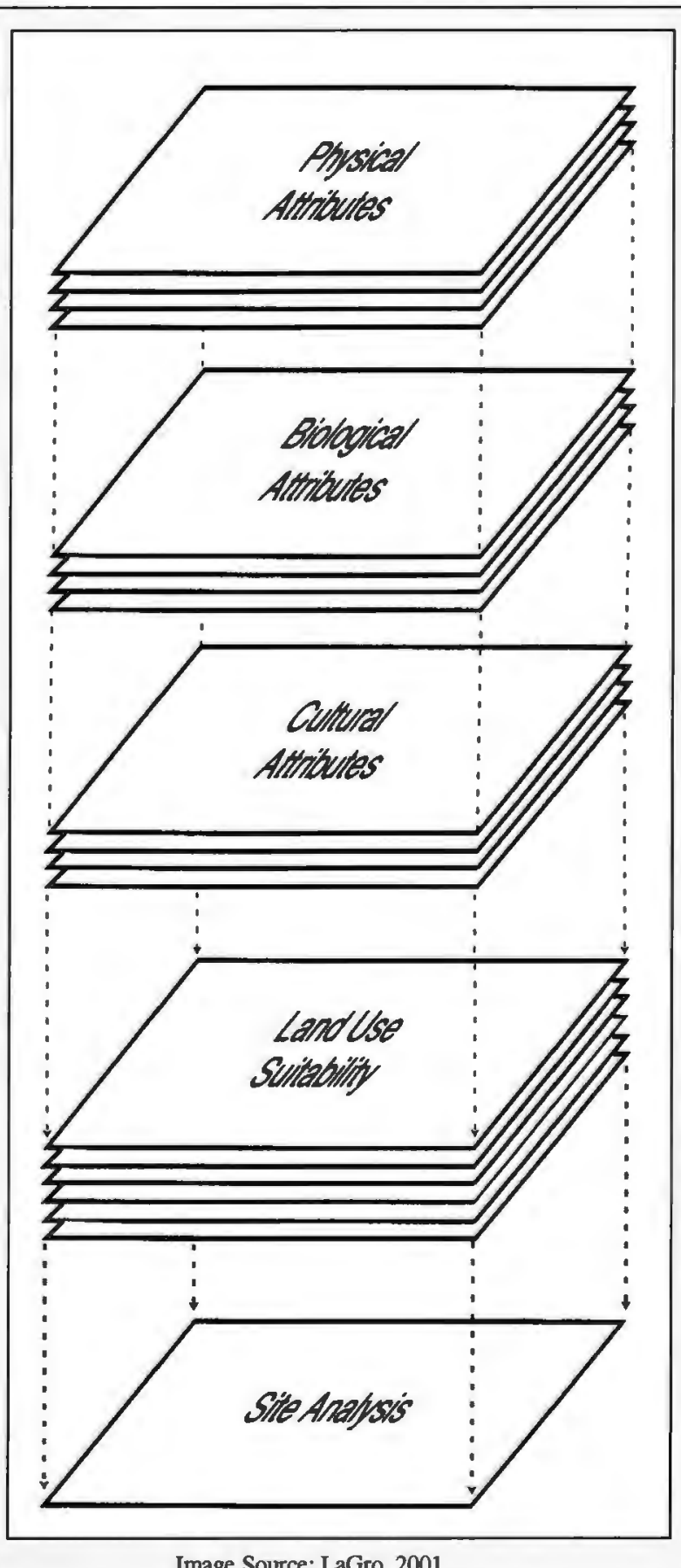

Image Source: LaGro, 2001
The following is an example set of these analyses taken from a land development project in nearby Connecticut. These analyses should be done in most land development projects, and it is the reviewers right to request these plans if it will improve the quality of the review.

If the land developer that the reviewers are dealing with on a particular project did not go through the following analyses, the reviewer should be attentive to the design elements of the proposed development, and carefully consider how it will effect any physical, natural or cultural attributes found on the site.

If you are confident that a complete and thorough analysis of the sight has been done and the land developer can produce documentation and maps to prove that this is true, you can then go forward with your review knowing that the design of the development is based on a sound analysis of the attributes found on the sight.

The plans should be a positive representation of the analysis that was done for the site.

The following set of site analysis maps was chosen simply as an example of what types of issues and maps go into the process of site analysis, and what types of maps land development plan reviewers can expect from developers. 


\section{Section V. Maps of Importance for Site Analysis}

Slope Analysis is done by analyzing the slopes that are present on the selected site, and grouping them into categories that represent different constraints to development.

For example, slopes are classified according to some of the constraint characteristics described previously on pages 9 and 10 of this handbook.

To the right is an example of a slope analysis map, representing four distinct categories of slope percentages. Percent of slope is a common representation of slope in site analysis, because it can be broken down into distinct categories which represent specific limitations to development.

In analyzing this particular map, the reviewer would hope to see the development that is planned for the sight be concentrated in the white and light gray areas of the site, with minimal disturbance to the steeper slopes (the black and dark gray areas) during the

development process. Of course, the white and gray areas may have other constraints as you will see in the following pages.

Municipal Officials responsible for development plan review should become accustomed to seeing this type of slope analysis from developers and begin to consider making it a requirement. Slope should be weighed heavily into considerations about where roads and other engineered aspects of a project are to be located, as to respect the minimal disturbance practice discussed earlier in the handbook.

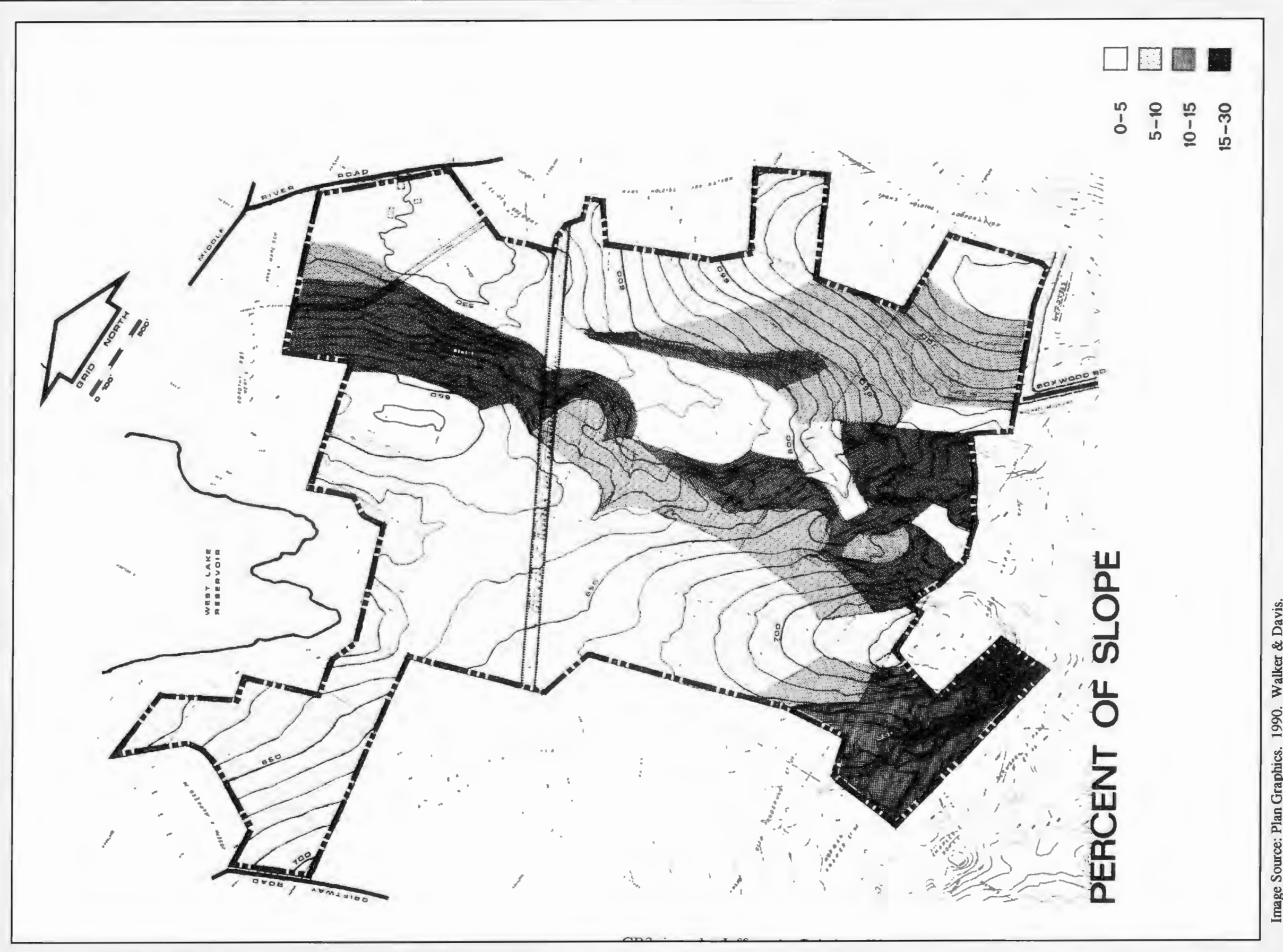




\section{Section V. Maps of Importance for Site Analysis}

Soils Analysis is a very important component of site analysis because soils represent so many different potential constraints to development. Soils can be too compact for development or too loosely compacted to support a structure. They can percolate too quickly or too slowly, be too close to the water table, or be too near the underlying bedrock to support development.

This particular soils analysis map groups soils with like characteristics into categories by a predetermined set of physical traits, including geological composition and structural features.

There are six categories represented on this map, each representing specific constraints to development. Although these specific constraints are not listed here, they can be researched easily through the Rhode Island Soil Survey or other soils science reference books. For example, densely compacted soils will create problems for drainage, and exposed bedrock creates problems for building foundations and footings for proposed structures.

Although this map is grouped by certain physical attributes of soil types, soils analysis can group categories based on a variety of features. Included in theses are depth to the seasonal high water table (also called the soil hydrologic group), permeability and infiltration rates (important in sighting individual sewage disposal systems), or it could directly categorize constraints to development in groups such as low, moderate, considerable, and high.

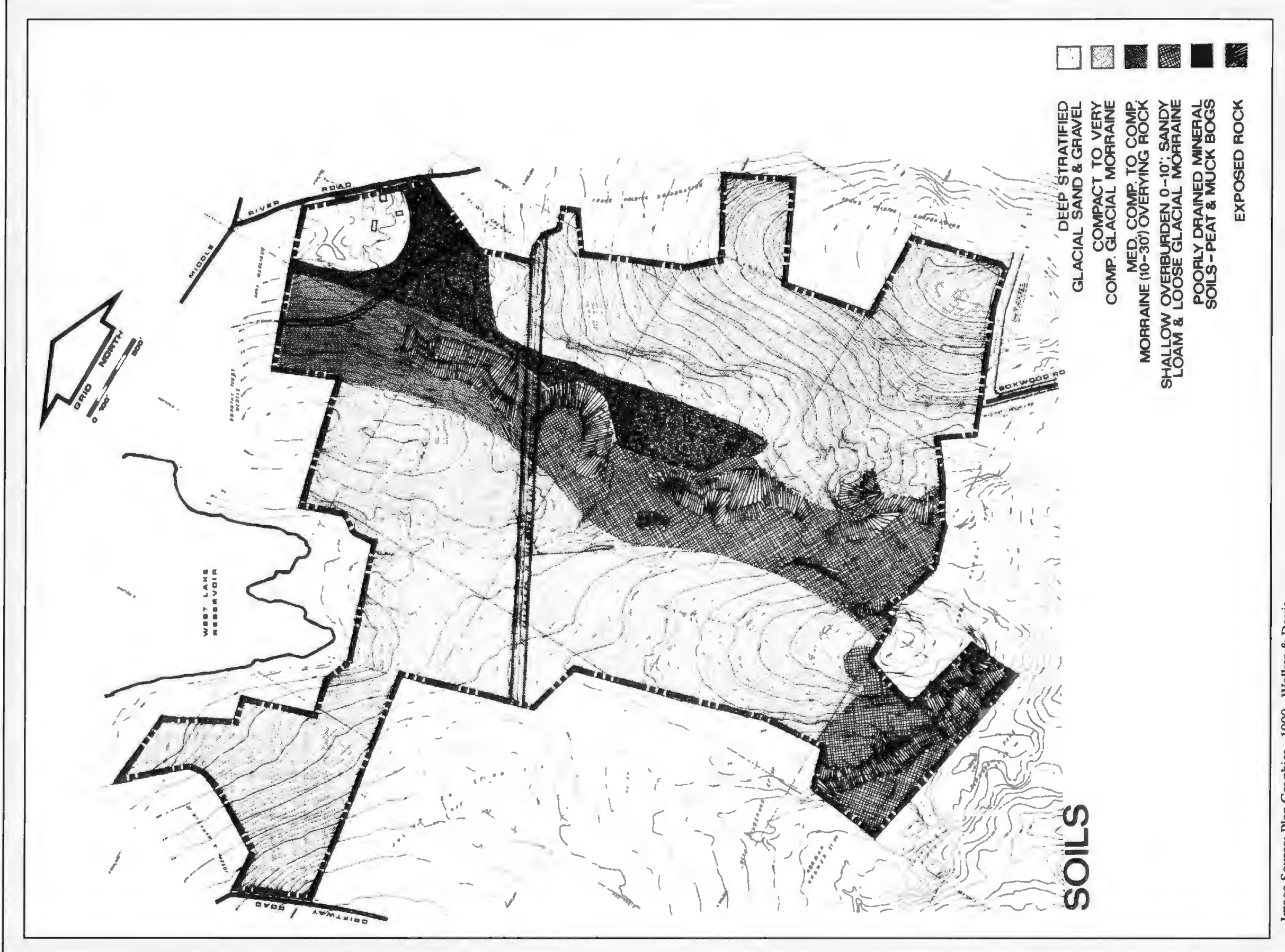




\section{Section V. Maps of Importance for Site Analysis}

\section{Elevation and Drainage Analysis}

represents how water will move through the

site during a weather event. This type of

analysis is primarily used for determining the

direction of the overland flow of water during a

weather event, and figuring how to properly

manage stormwater while having a minimal

impact on the existing hydrology of the site.

The main components of this map were briefly explained is Section III of this handbook, but this map illustrates how these site features

relate to each other and to the water that moves through the site.

The categories found in the legend represent areas of land that are within the stated elevation category. Naturally, water will flow downhill (from the higher elevations to the lower) through the site, or from the dark areas to the lighter areas. Notice in the figure that water sheds from some areas and accumulates in others

In general, water flows perpendicular to the contour lines on a topographic map, feeding smaller streams and other surface water bodies.

Water flow is a crucial issue to consider in land development planning, as small changes to the natural movement of water on your site can have serious impacts on neighboring properties, or even on a regional basis. Managing water flow properly is important during construction to minimize sediment runoff and loading to surface waters, and in the future to ensure that the hydrologic cycle of the site and region is not impeded by the new development.

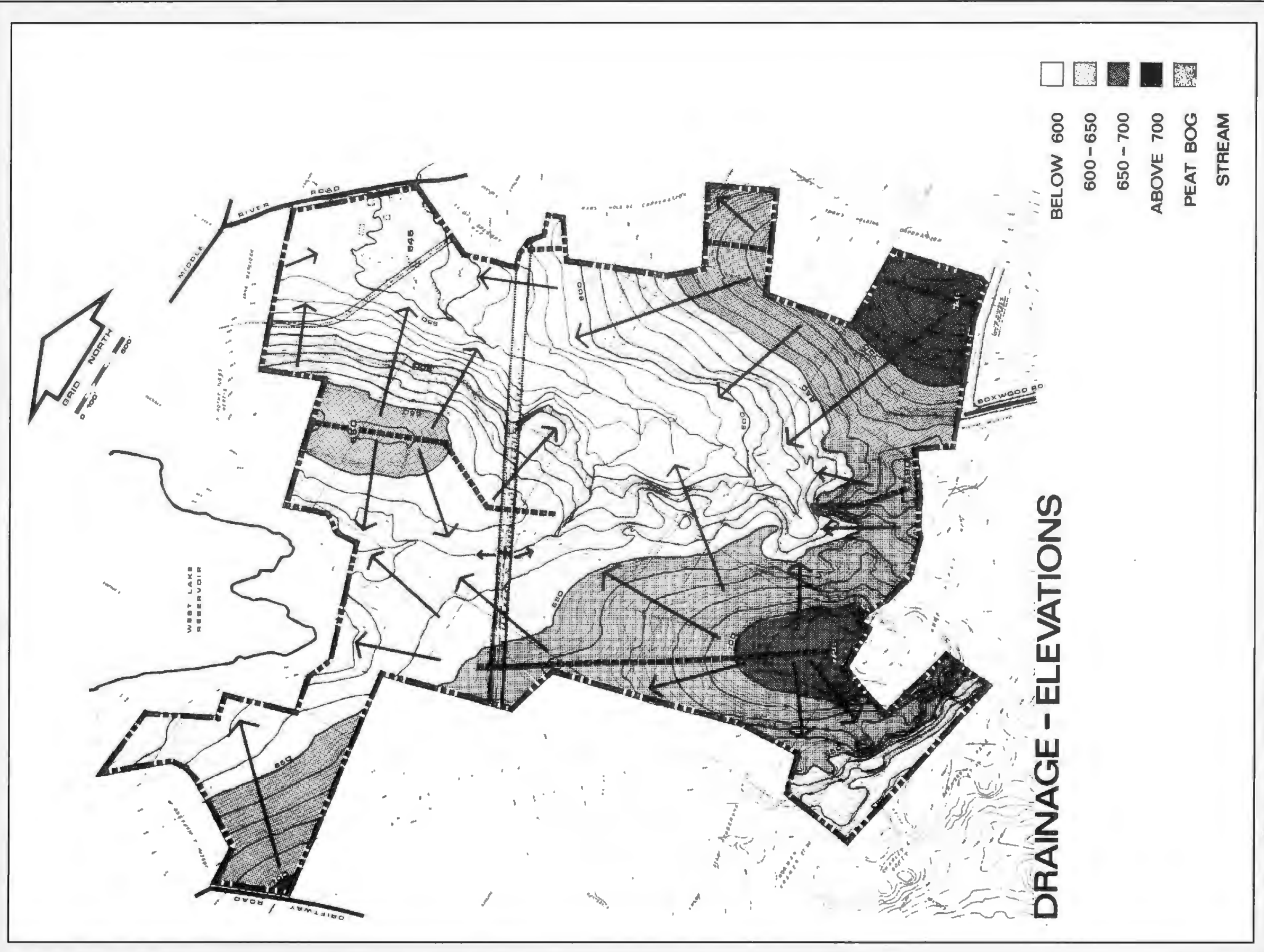




\section{Section V. Maps of Importance for Site Analysis}

\section{Existing Vegetative Cover Analysis is}

important when dealing with areas of the landscape that are environmentally sensitive and require minimal site disturbance, or where stands of existing trees are naturally or culturally significant.

To the right is an example of an existing vegetation survey. Note that the individual species of trees that are found are differentiated from one another based on the ecotypes in which they are found. Species differ whether the area is wetland, a riparian zone, or upland. The open areas that are present on site are mapped as well.

This particular map does not identify "specimen trees", as another that may be encountered from another project would. There are many different ways to illustrate existing vegetation on a map, this example represents some important features but not others.

Although the analysis in the figure to the right is limited only to the potential development site, it is important for the plan reviewer to consider vegetative cover off-site, as well.

The reviewer should examine issues of connectivity between vegetated areas on and off-site as a means of protecting the biodiversity of the region. Also, maintaining vegetative buffers around riparian zones and wetlands protect these important environmental features from sedimentation caused by overland water flow.

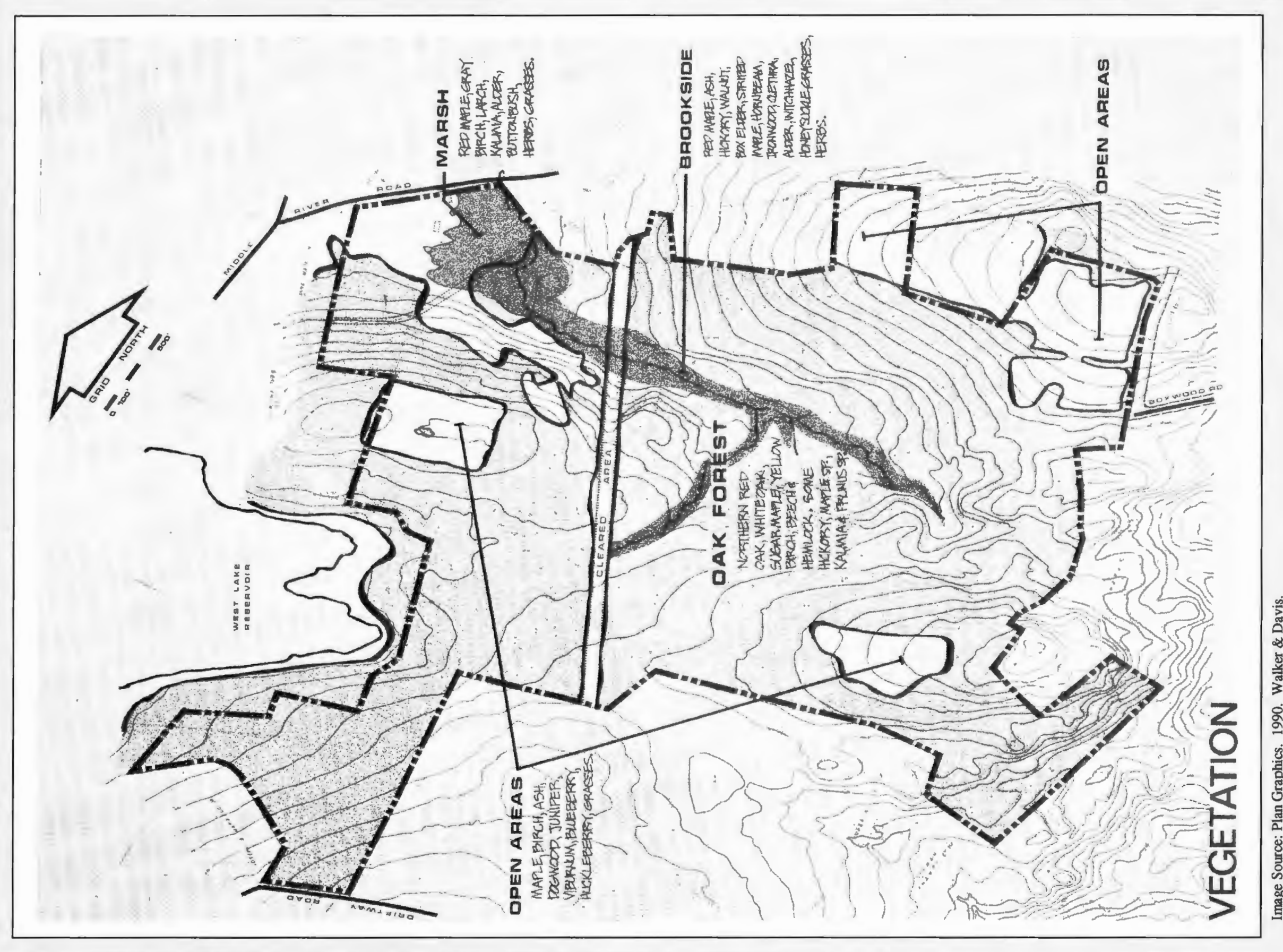




\section{Section V. Maps of Importance for Site Analysis}

\section{Climatological Analysis is important to} consider when designing and orientating a land development project on a selected site.

Depending on the context in which the project is to be constructed, maximizing or minimizing a building's exposure to prevailing winds and sunlight can greatly reduce the need for the expensive heating and cooling of the structures thereafter.

In Rhode Island, it would be sensible to maximize wind exposure in the summer months to naturally cool the structure, whereas during the winter months it would be most beneficial to reduce a structure's exposure to the chilling northeasterly winds.

Seasonal wind and sun exposure analysis can not only be used to guide the orientation of individual structures throughout a project, but also effect which types of landscaping and other physical aspects should be incorporated at integral locations throughout the project site.

The gradient and aspect of slopes are also important when analyzing the climatalogical features of a site. Here in the Northern Hemisphere, South facing slopes receive more direct sunlight than north facing slopes in all seasons, keeping them warmer throughout the year.

In the example to the right, prevailing winds, sun exposure and slope analysis are combined in a map representing the overall climate of the site.

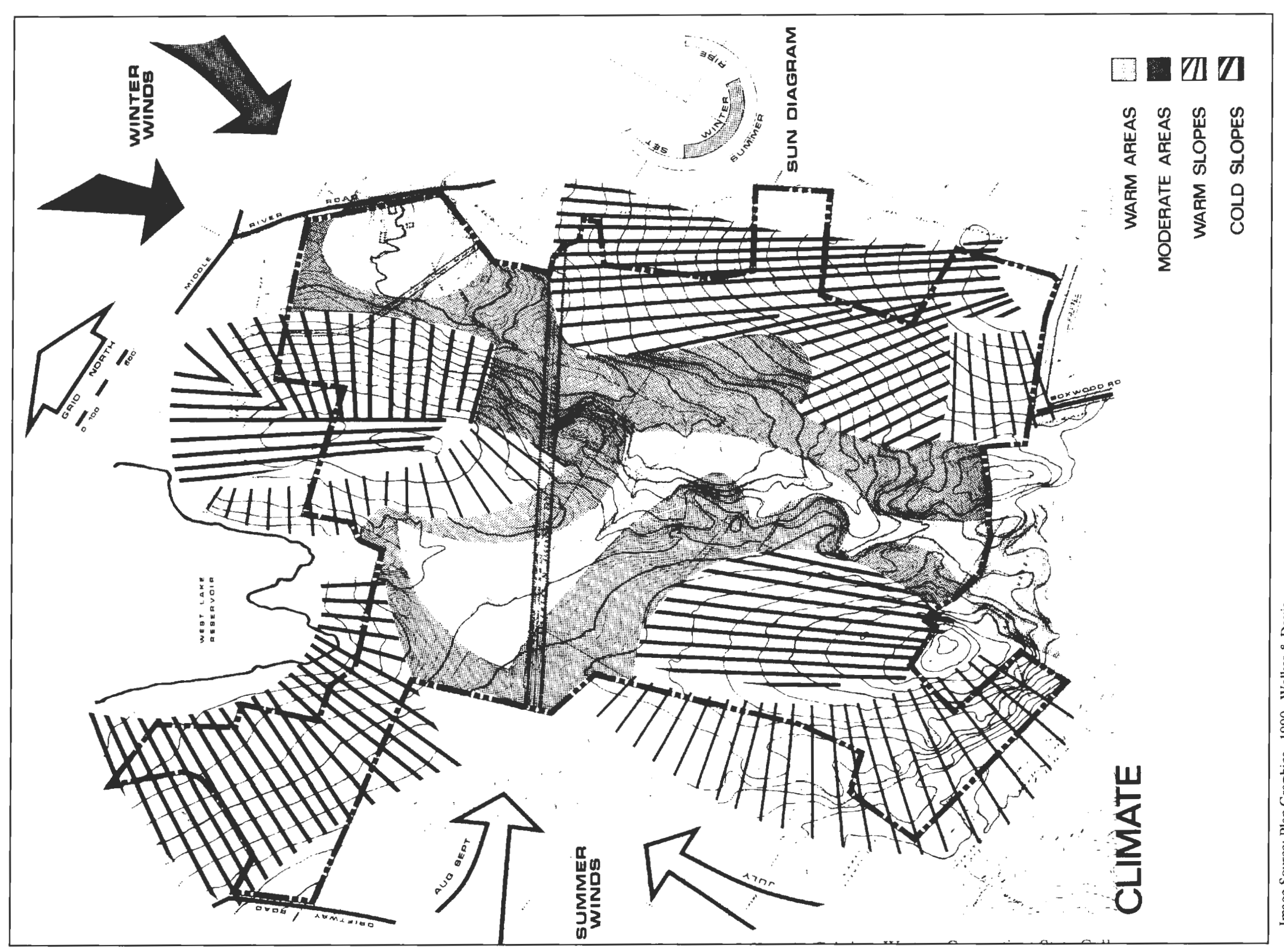




\section{Section V. Maps of Importance for Site Analysis}

\section{Visual Impact Analysis is another}

important aspect of planning land development projects. The visual quality of the site itself, and the visible off-site features can be important to the success of a development project (LaGro, 2001). View corridors and the visual quality of natural and cultural features should be considered both from the site to the existing surroundings, as well as from off-site locations to the project site.

Natural and Cultural features can have both positive and negative effects on aesthetic interpretation: features such as water bodies, rock outcrops, stonewalls, and historic buildings add to the aesthetic quality of a project site, while others such as power lines, roadways and railways are considered negatively.

Highpoints in elevation on sites where the topography is variable create particularly important aesthetically sensitive areas because the opportunity for views is greatest here. Topography is a very important physical characteristic when considering viewsheds, because hills and valleys can create aesthetic opportunities, but development in the wrong locations can detract significantly from the overall aesthetic quality of a site.

Access to the site is also depicted in the figure to the right, so the reader can understand how the specific aesthetic components of the site will relate to the overall flow of human activity.

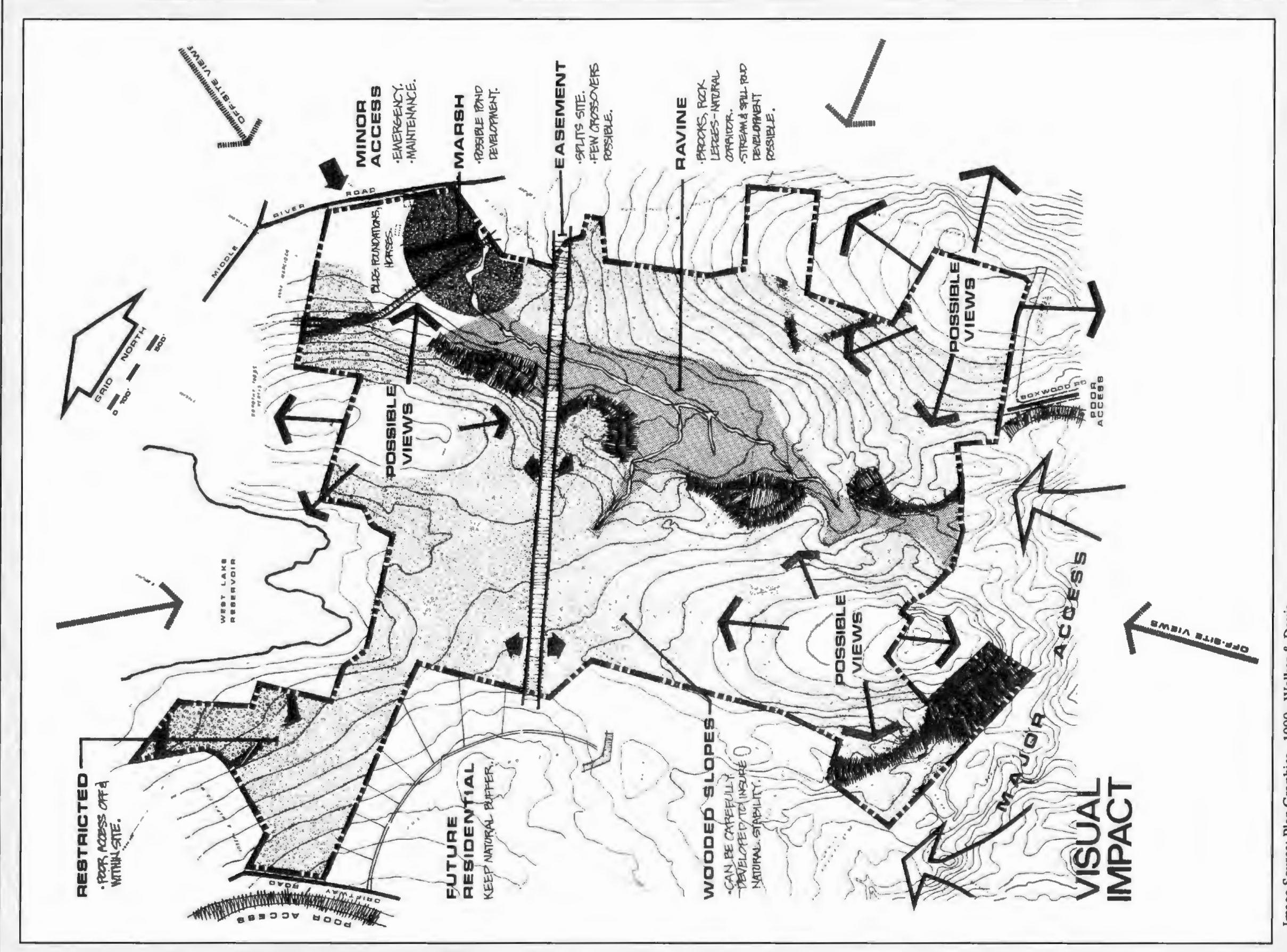




\section{Section V. Maps of Importance for Site Analysis}

Assessing Potential for Development is the final step in site analysis. Development potential can be broken down into many categories including the ones that were used in the example to the right. The example to the right has four categories ranging from very good to poor.

These categories are created by compounding the characteristics of the site that have been analyzed throughout this section, and either including or excluding areas for development based on those characteristics. For example, the large white area depicted on this map has a low percent slope, favorable soils, no particular aesthetic value, etc. Therefore it is deemed a very good area for potential development.

Working with all of the resources described thus far in this handbook, the developer and the land development plan reviewer can all make informed decisions regarding the suitability of the potential project for the site that has been selected.

In addition to site suitability, the sighting of individual structures and roadways should be based on this analysis.

It is intuitive that the majority of disturbance that will take place during this development will occur in the areas marked as very good or good on the site development potential map, leaving those areas designated as fair or poor in their natural state, or as close to their natural state as is possible under the current set of conditions.

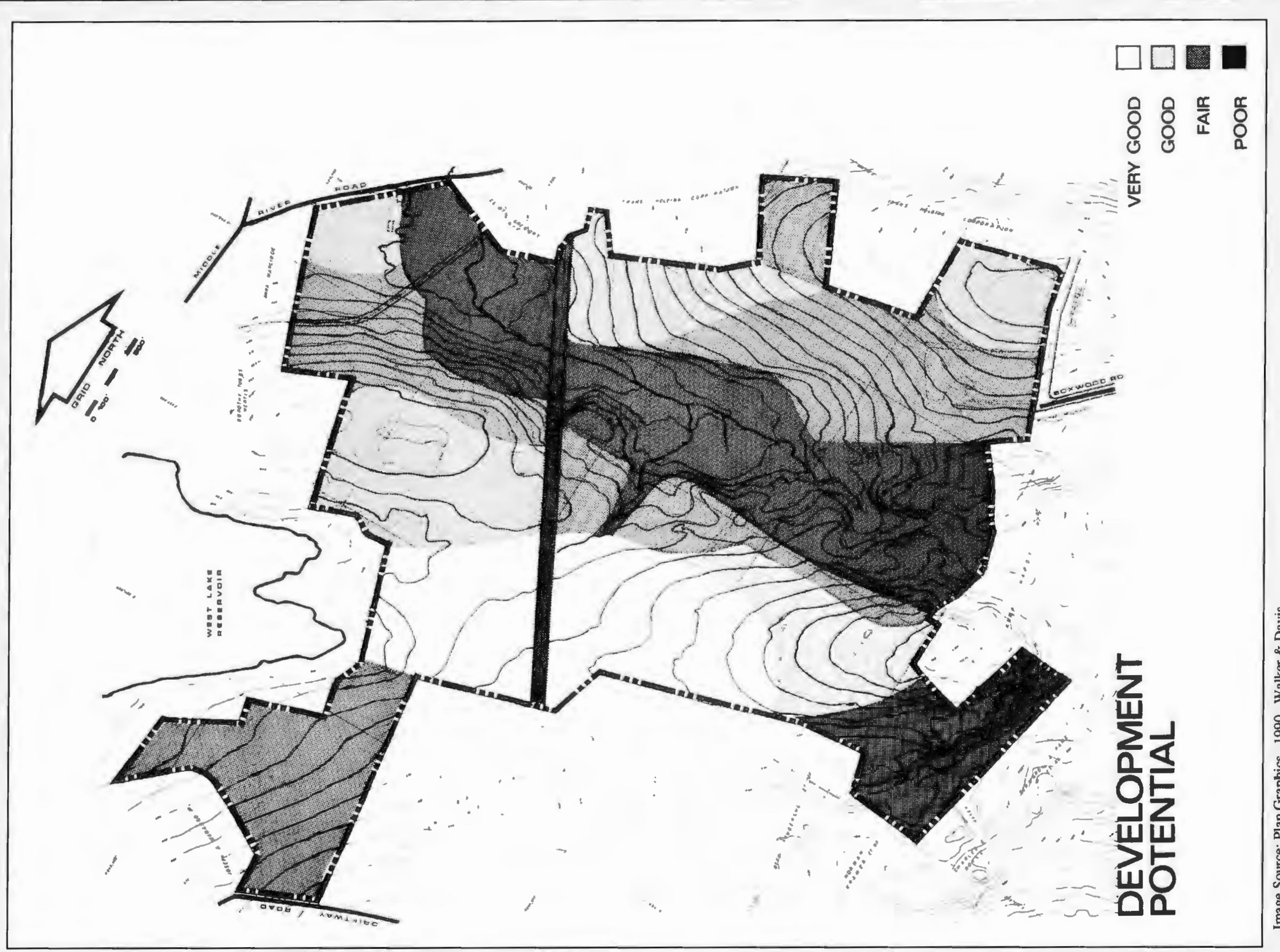




\section{Section VI. Reading Land Development Plans}

Now that we have a good understanding of what resources should go into the formulation and design of good land development plans, we will explore an actual set of plans and their components in detail, discussing what to look for during the review process.

In this section, you will be introduced to the different components of land development plans, familiarized with common language and symbols, as well as prompted to think about certain issues and concepts related to the associated drawing.

Generally, a legend is given which encompasses the meanings of the symbology that is used throughout a set of plans. This helps to orient the new reader to the symbols typically used by the engineer who has produced the development plans and also lets the experienced reader know what features to expect to find on the plans.

The two sample legends to the right are representative of those that would be found within a set of land development plans. The symbols used vary greatly with the type of project that is proposed for the site.

Plans for developments where existing development is already present will include such features as existing structures, rights-ofway, utilities, etc., in addition to symbology for the new development. Proposed development plans for relatively undeveloped land (such as the following example) contain a somewhat different set of symbols related to new development.

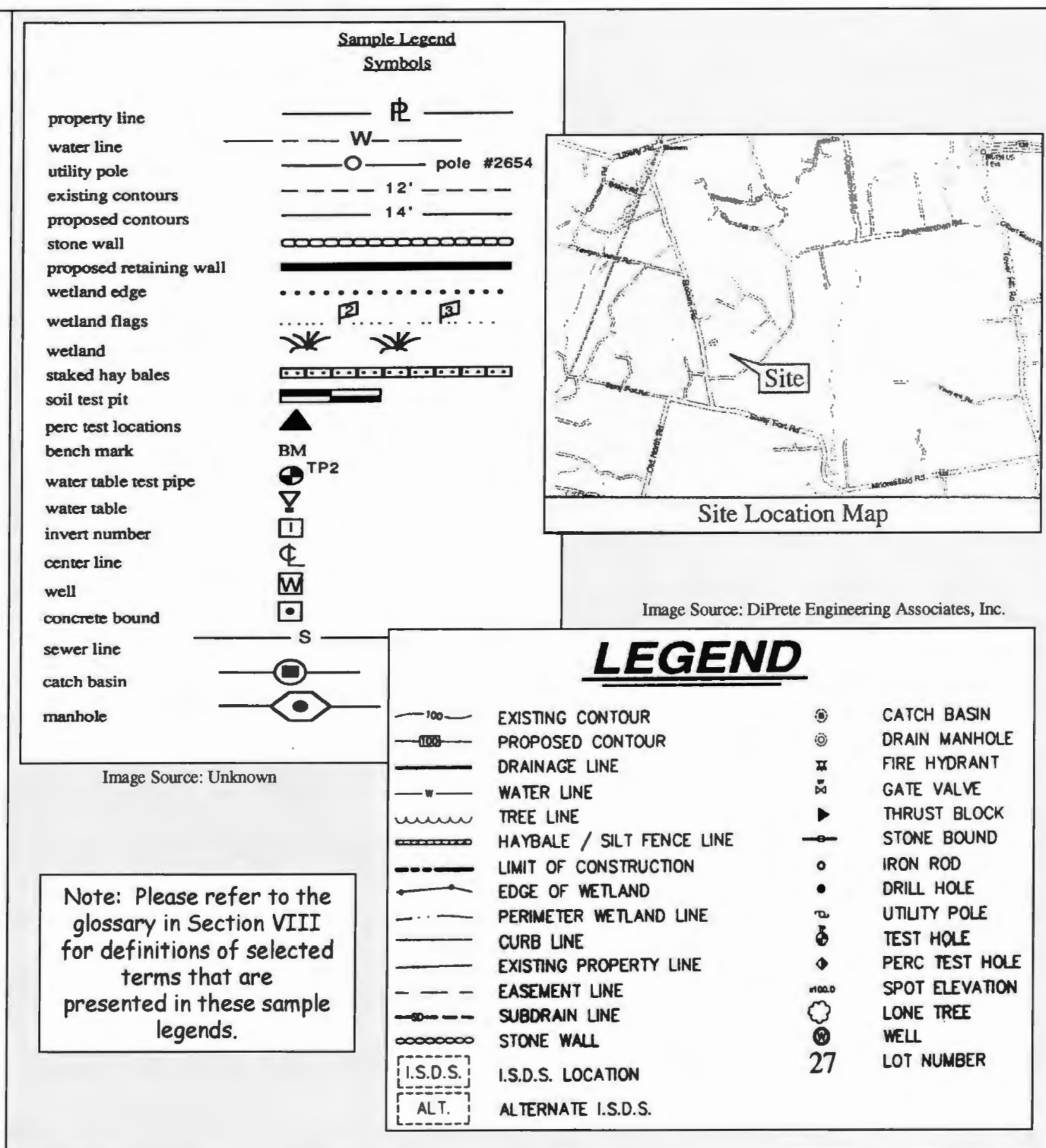

All of the skills you have already been introduced to thus far in this manual will become useful in analyzing the land development plans included in this section.

The following set of site plans has been chosen simply as a typical complete set of plans that might be encountered by Rhode Island municipal officials in the land development plan review process.

The plans are for a relatively small subdivision, consisting of only 18 lots, located in at the intersection of Slocum and Shermantown Roads in North Kingstown (see locus map to left).

This particular site contains many constraints to development, such as wetlands, stonewalls, historic foundations and cemeteries, among others.

This set of plans is a preliminary submittal for a major subdivision, so recall the process from pages 3,4 and 5 of this handbook when thinking about what type of review should be taking place here.

This section is generally set up as follows:

The full page of the plan is shown and you are prompted to recognize specified terms and symbols relating to that particular page. Next, certain features and sections of the page have been expanded to show greater detail and enhance readability. Finally, the entire page is shown again, and you are prompted to consider several important questions relating to the current page. 


\section{Section VI. Reading Land Development Plans}

\section{Existing Conditions Plan}

Recognize these terms and symbols:

Soils Symbols \& Delineation

Site Boundary

2-foot contour interval topographic lines

Stonewalls

Historic Foundations

Flagged Wetland Edge

Approximate Edge of Floodplain

Test Boring Markers

Cemeteries

Development Limitations District

Calculations

Soils Information

General Notes

\section{$\sqrt{ }$}

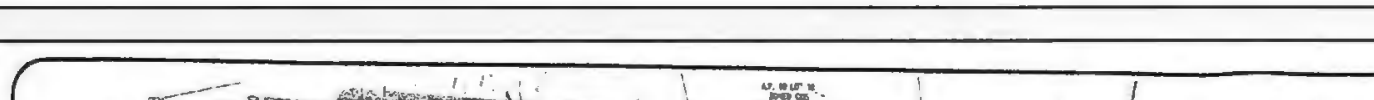

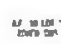

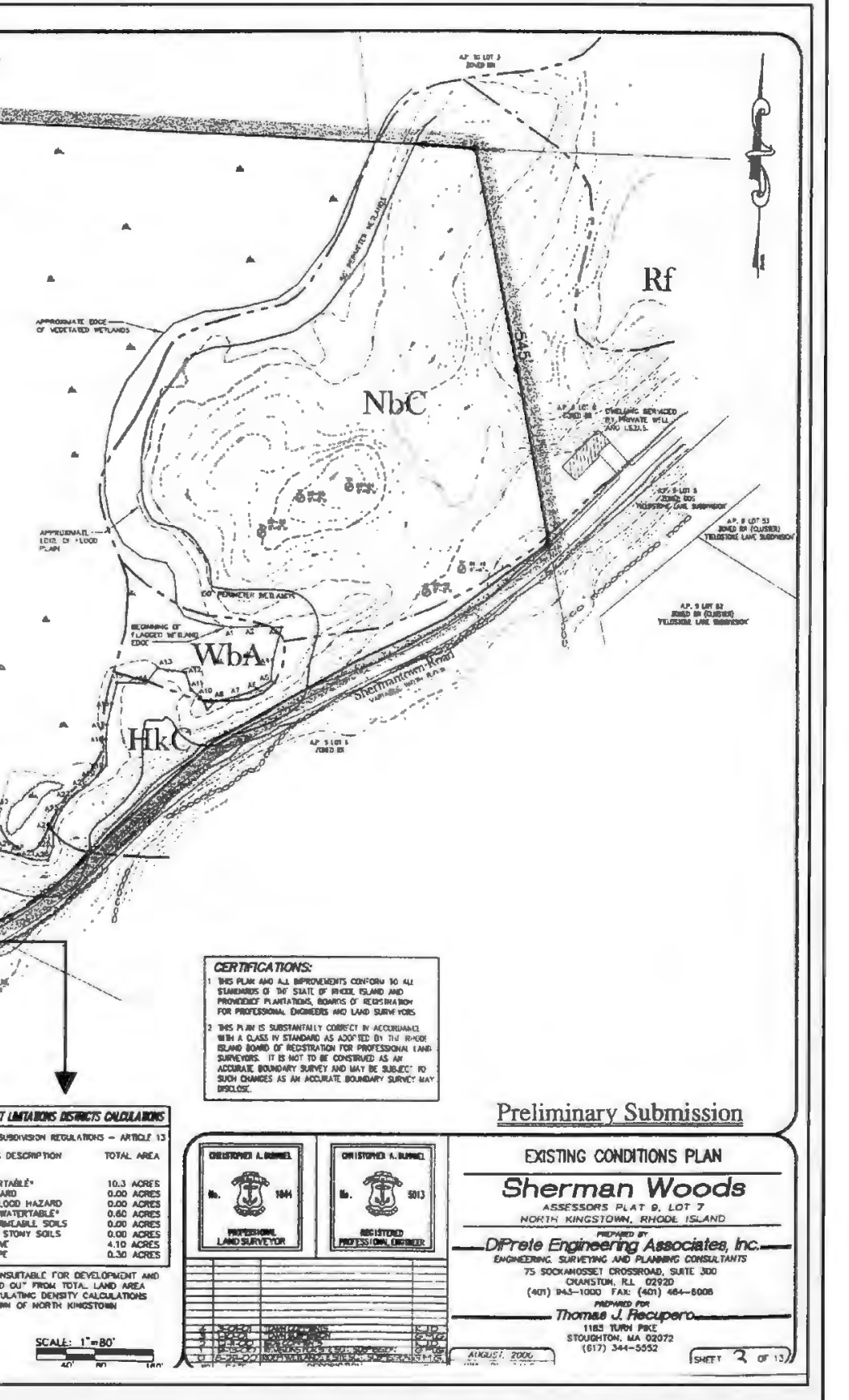

Image Source: DiPrete Engineering Associates, Inc. 


\section{Section VI. Reading Land Development Plans}

\section{Existing Conditions Plan (continued)}

Particular aspects of the Existing Conditions Plan have been "blown up" here for easier readability.

Flagged Wetland Edge

Approximate Edge of Floodplain

2-foot ontour interval topographic lines

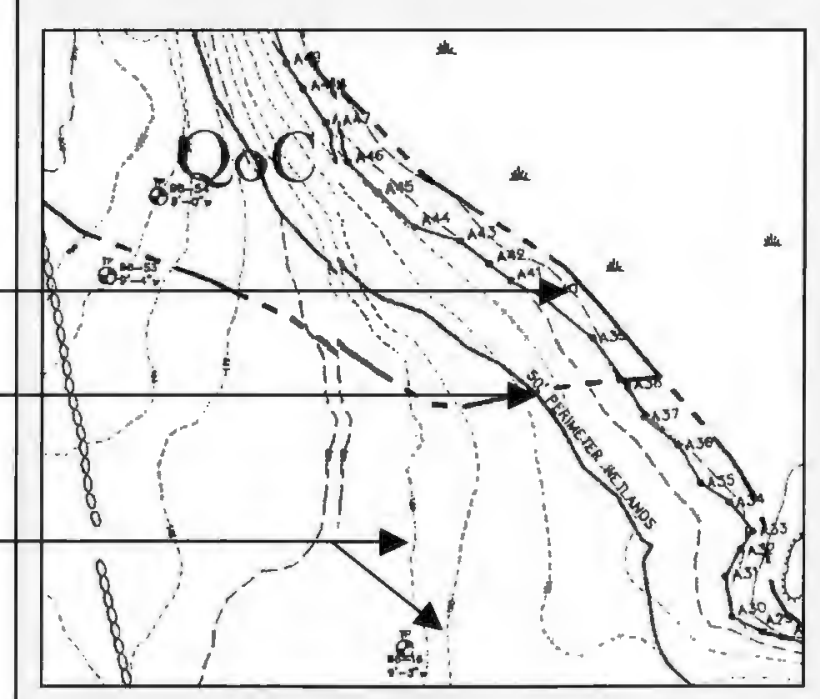

Soils Information \& Development Limitations District Calculations General Notes

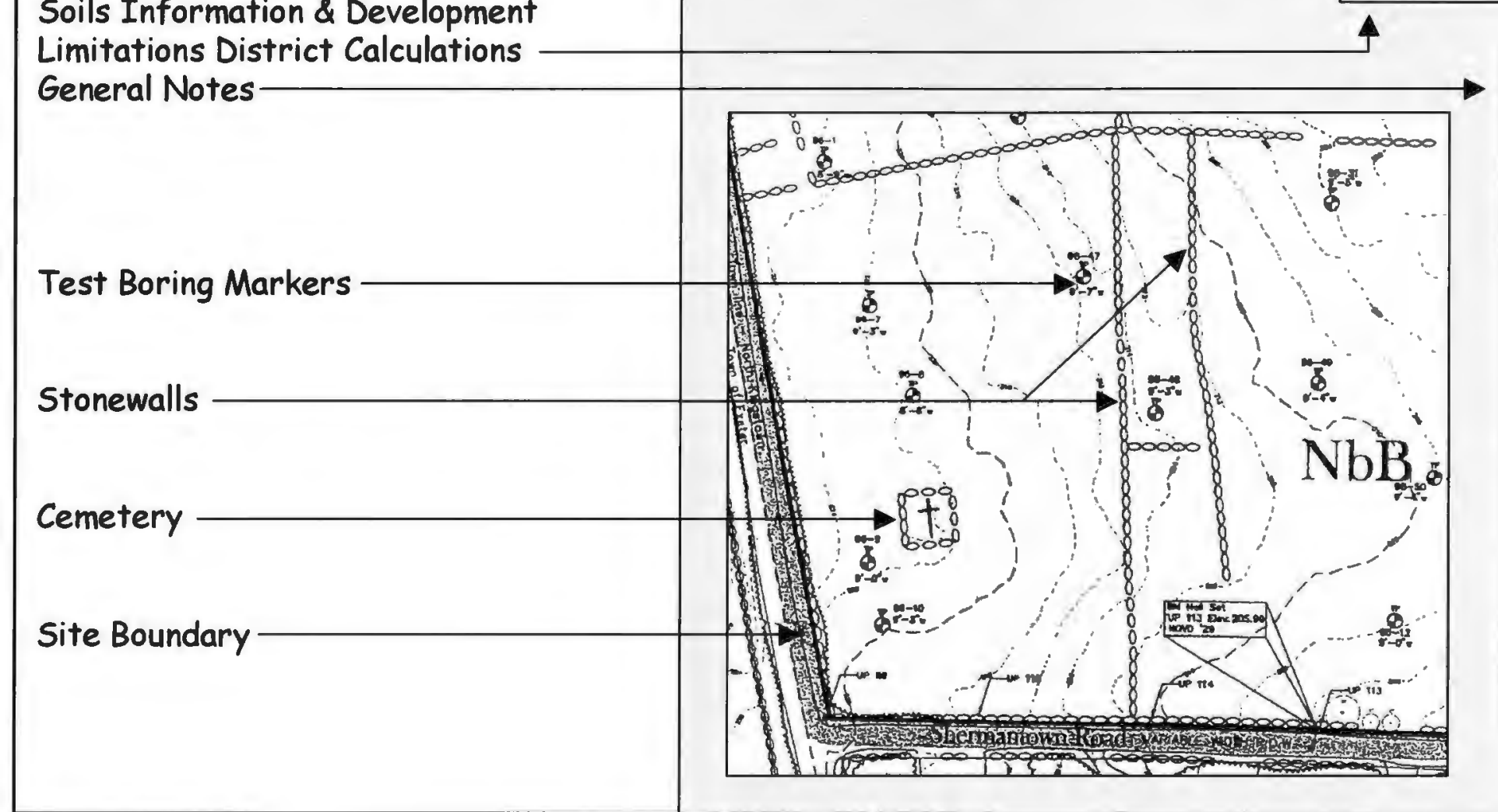

\begin{tabular}{|c|c|}
\hline & 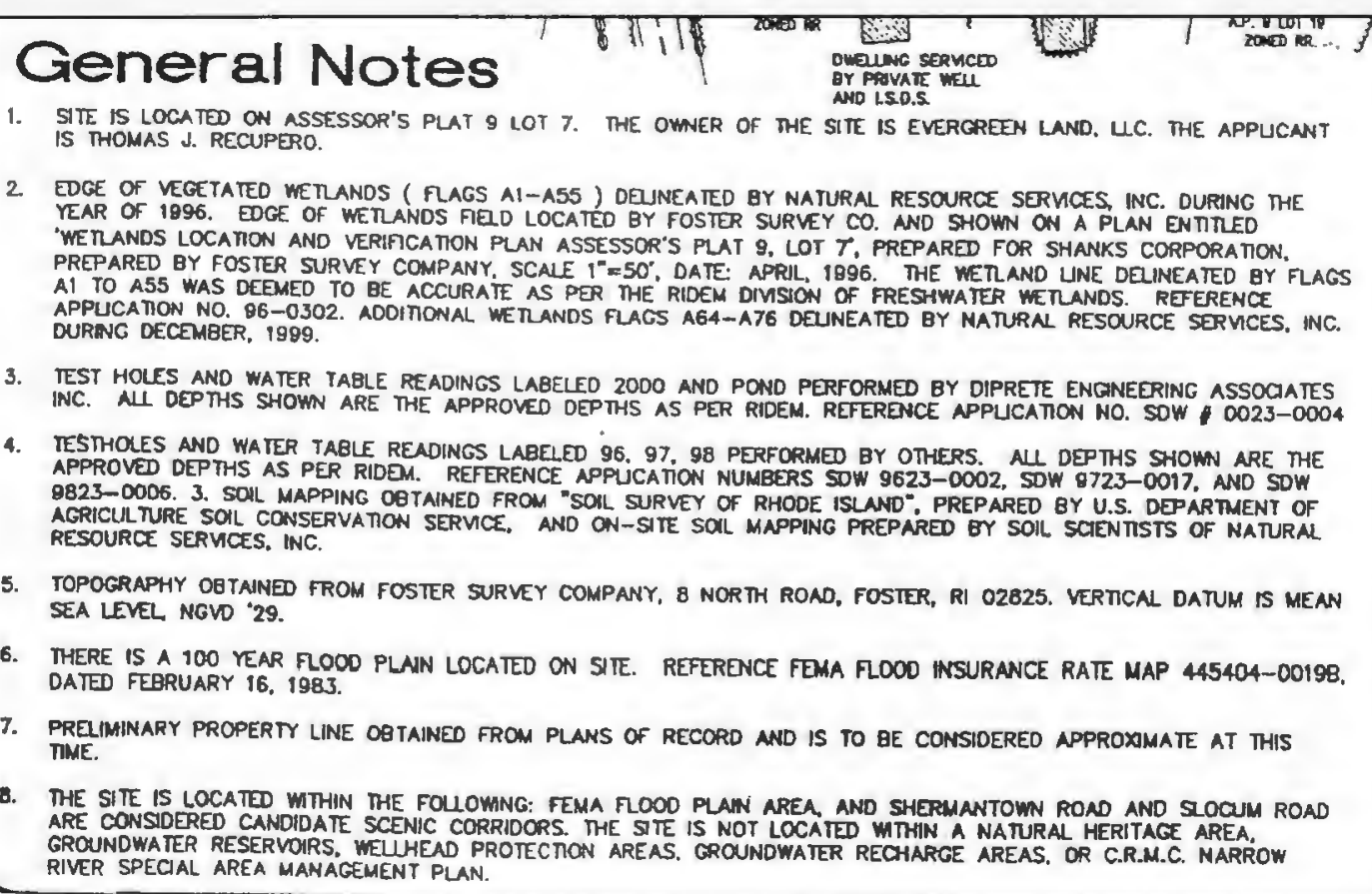 \\
\hline
\end{tabular}




\section{Section VI. Reading Land Development Plans}

\section{Existing Conditions Plan (continued)}

\section{Consider these questions:}

Are all on-site natural features represented in the appropriate detail?

Are all on-site cultural features represented in the appropriate detail? How will water flow on this site? How does the site relate to adjacent properties?

Where is the best place on-site for access (entrance \& exit)?

Where is the best place for sighting structures and roadways?

Where are the wetlands on site?

What is the difference between the demarcated wetland and floodplain boundary?

Where is the 50' buffer around the wetlands?

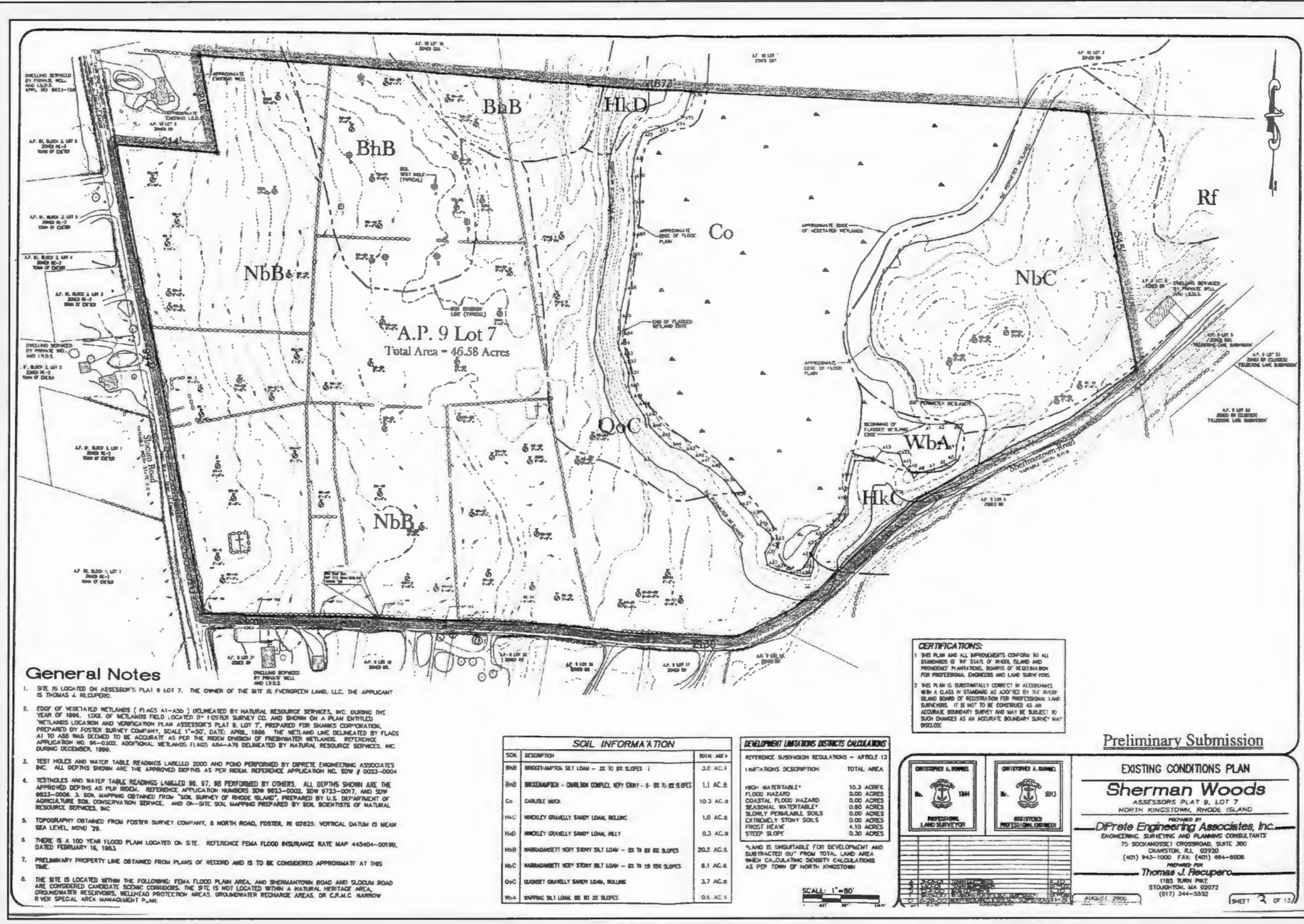




\section{Section VI. Reading Land Development Plans}

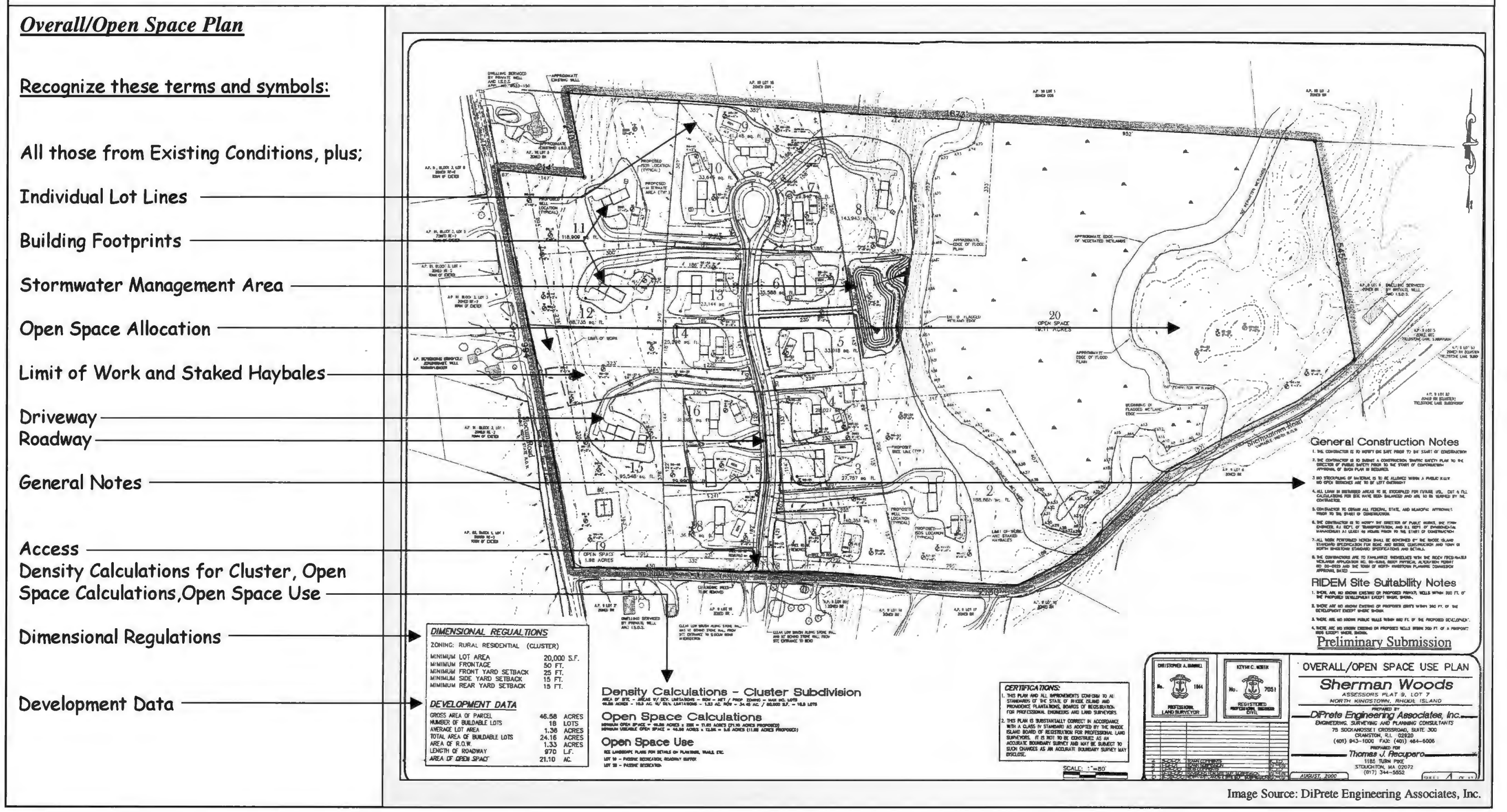




\section{Section VI. Reading Land Development Plans}

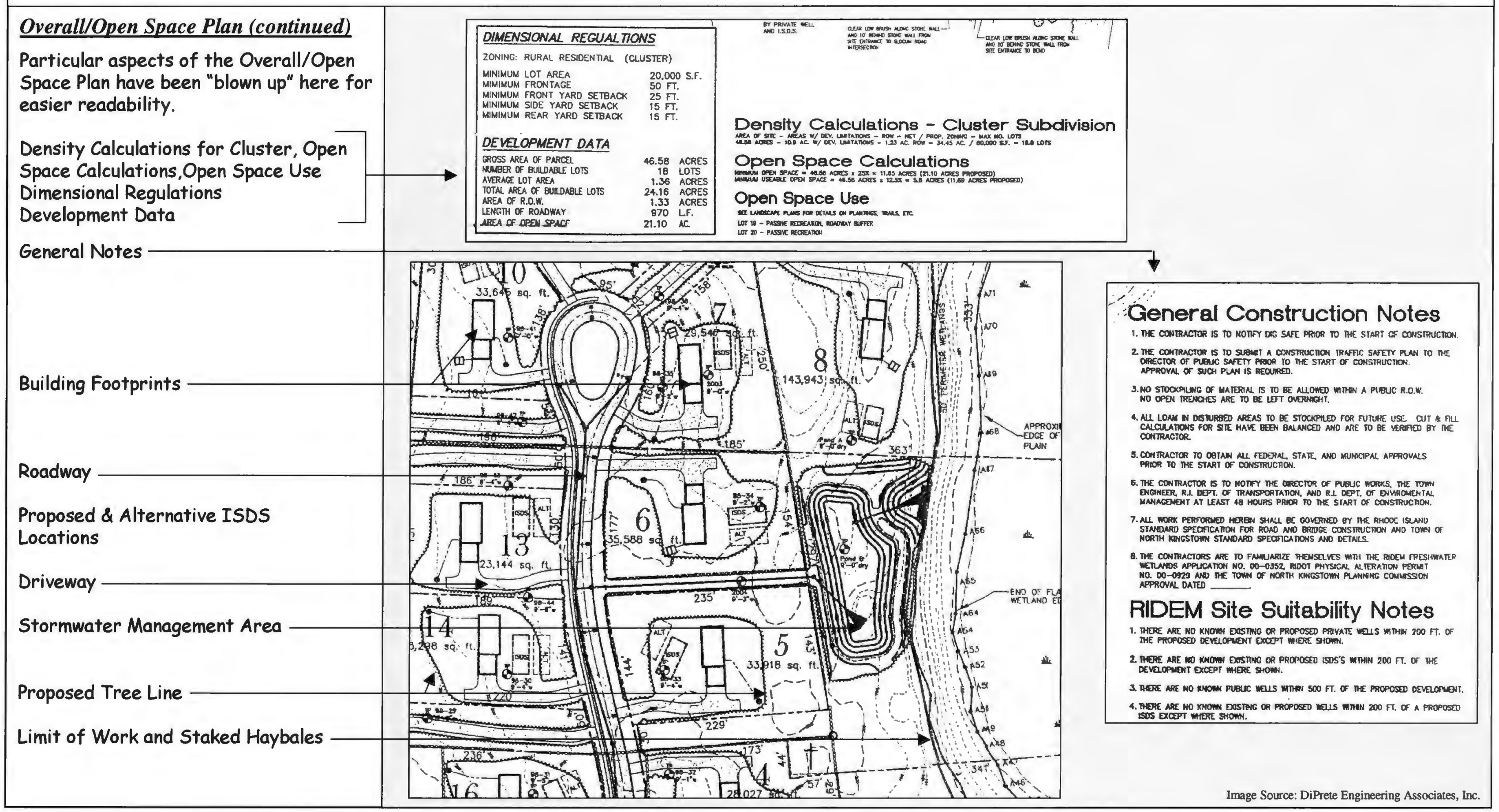




\section{Section VI. Reading Land Development Plans}

\section{Overall/Open Space Plan (continued)}

\section{Consider these questions}

What sight analysis was done to achieve this design?

Is this development consistent with the comprehensive plan?

Consistent with subdivision regulations? Consistent with the zoning ordinance (minimum lot sizes \& setbacks, etc.)? Does the access point(s) make sense? How is the open space configured, does it make sense?

How are the houses orientated, does this make sense? Is this based on wind/sun exposure analysis?

Is the ISDS sighted properly? What kinds of analysis is this based on?

Is the length of paved surface minimized (imperviousness minimized)?

How will this design effect water flow on site?

Where will the stormwater go, does this make sense?

Does the limit of work respect the natural features of the sight?

Does lot size accurately reflect buildable land?

Does development minimize impact to cultural resources? Is Open Space managed correctly?

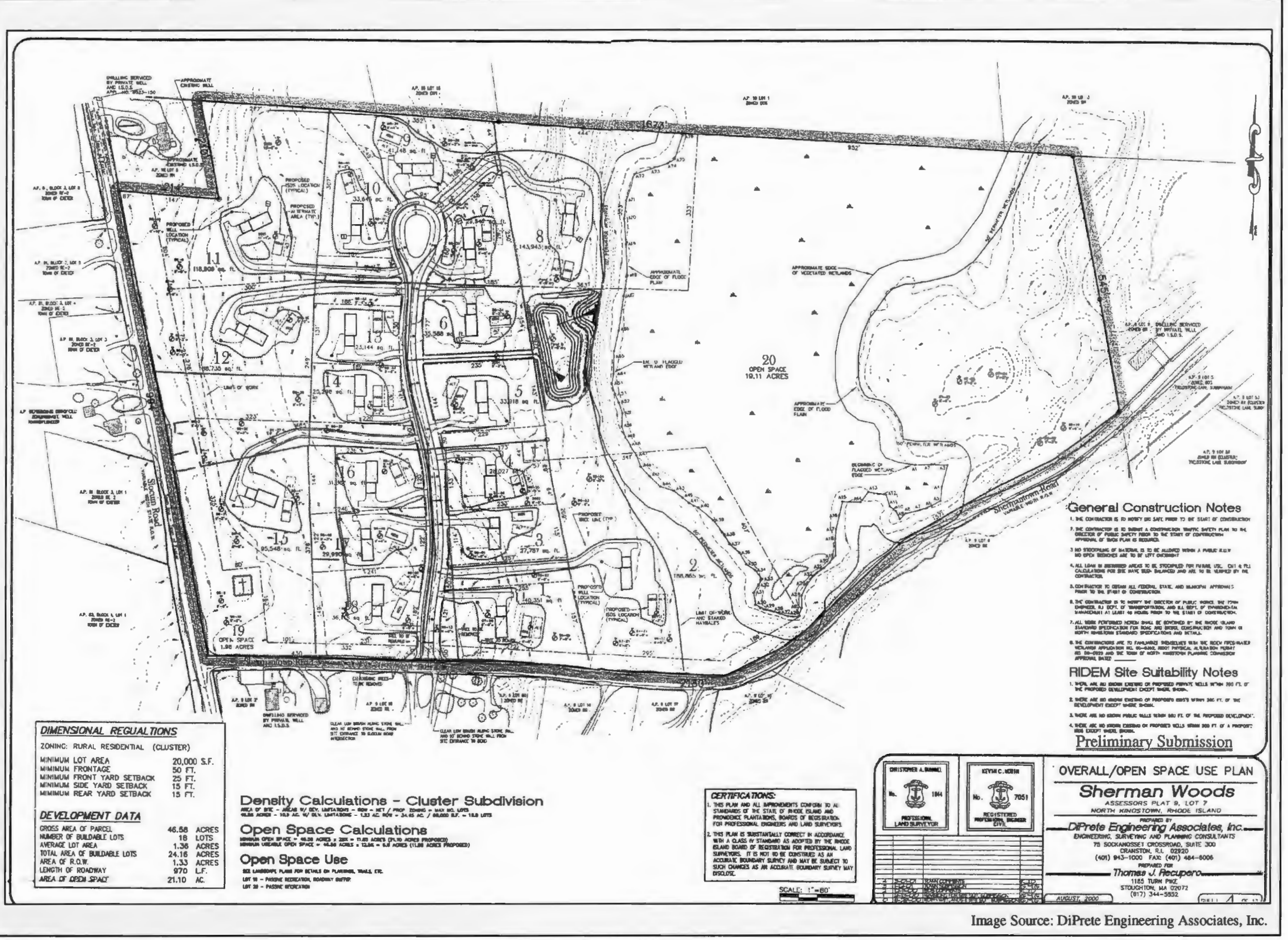




\section{Section VI. Reading Land Development Plans}

\section{Landscape Plan "South"}

Recognize these terms and symbols

All those from the Overall/Open Space Plan, plus:

\section{Match Line}

Shrubs -

Stonewall Breaks

Proposed Tree Line

Coniferous Trees -

Proposed Limit of Work

Deciduous Trees

Work Descriptions

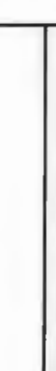

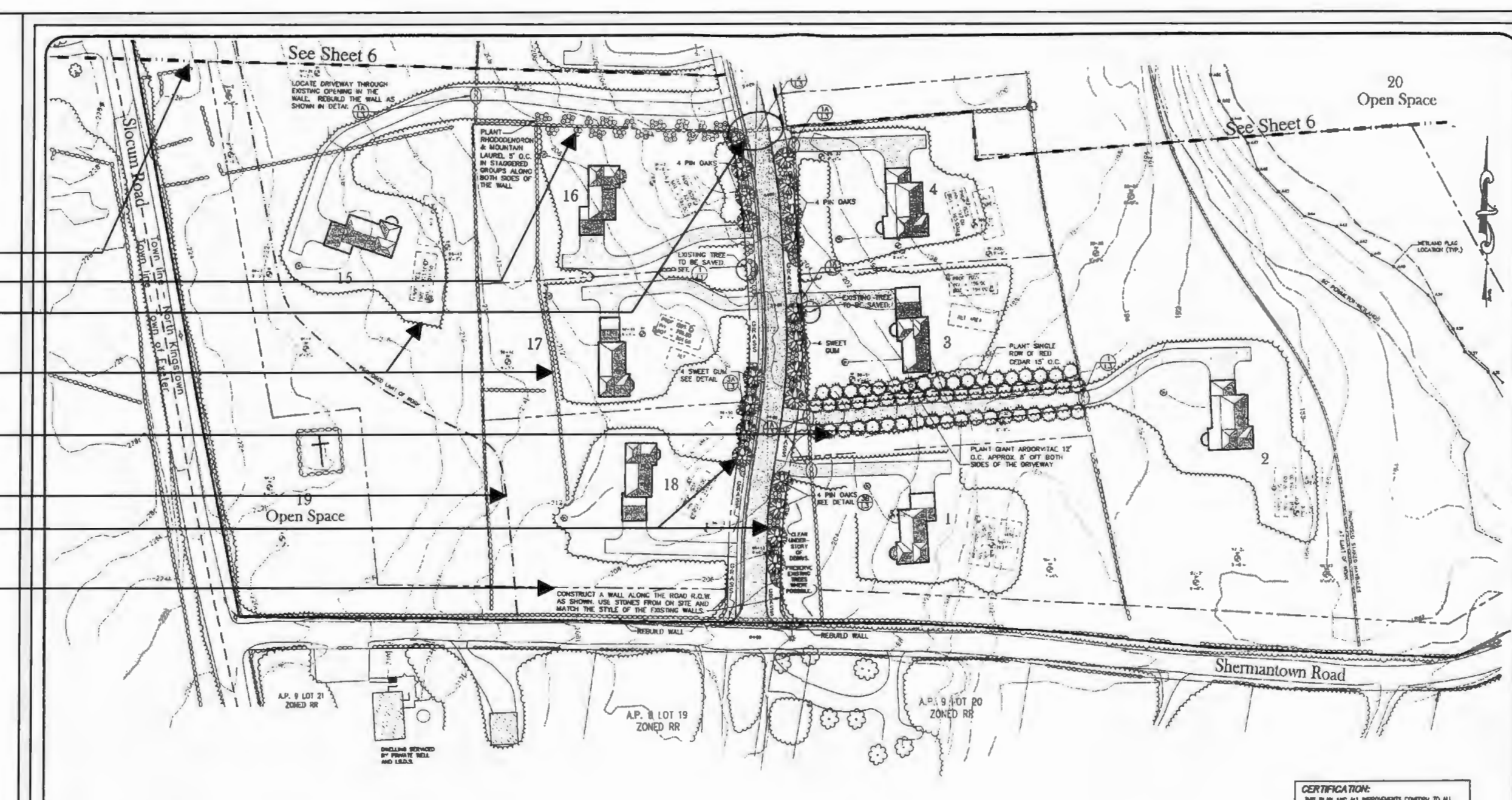

$$
D G
$$

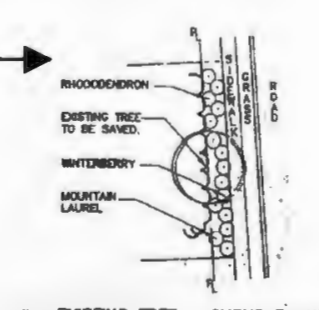

(11) DOSTING REE - SHRUB PLANTING DETAL

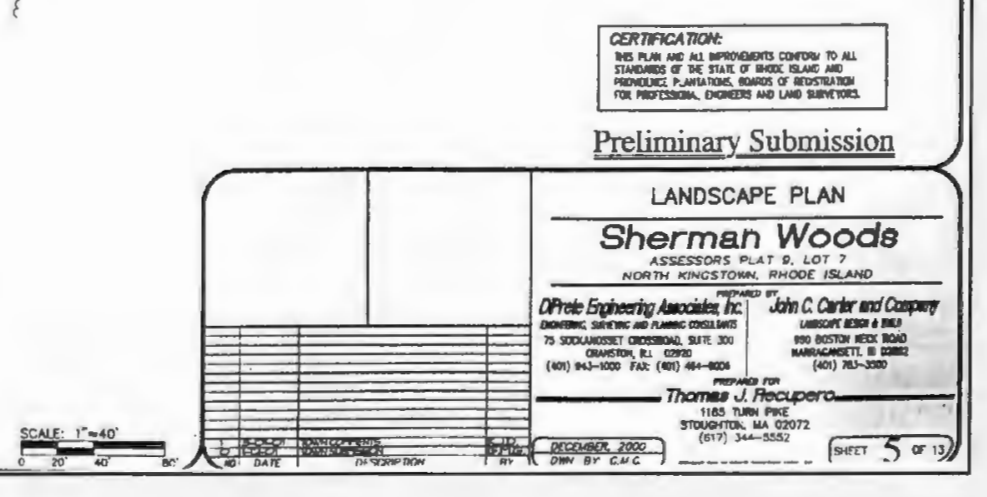




\section{Section VI. Reading Land Development Plans}

\section{Landscape Plan South (continued)}

Particular aspects of the Landscape Plan have been "blown up" here for easier

readability.

Stonewall Breaks

Existing Tree to be Saved

Proposed Tree Line

Coniferous Trees

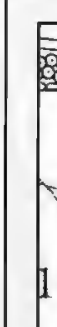

Deciduous Trees

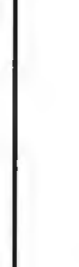

Work Descriptions

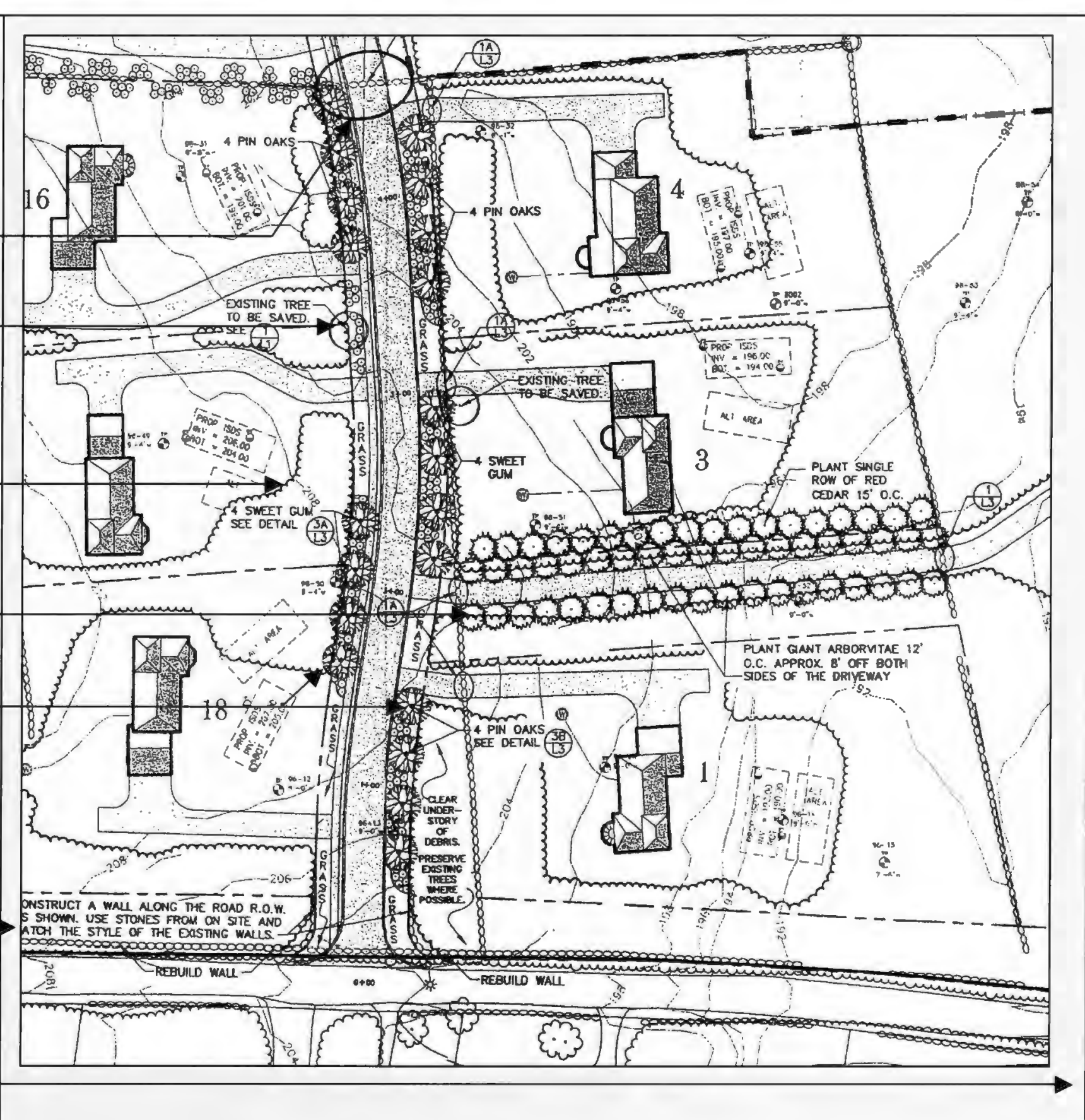

.

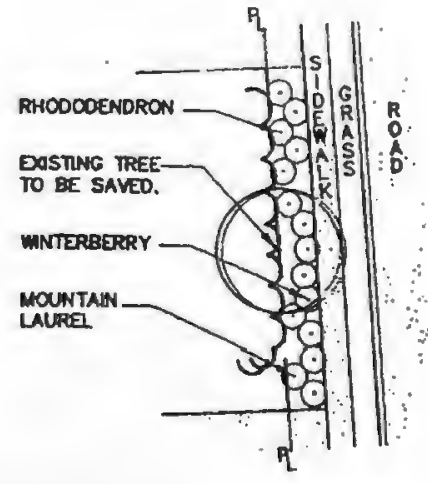

EXISTING TREE - SHRUB PLANTING DETAIL SCNE: $1^{\circ}=20^{\circ}-0^{\circ}$ 


\section{Section VI. Reading Land Development Plans}

\section{Landscape Plan "North" (continued)}

Consider these questions

*For All Landscape Plans Pp. 33-36*

Is the natural vegetation left undisturbed wherever possible?

Does this plan support the minimal disturbance principle?

Is the landscaping properly used to buffer aesthetically?

Is the landscaping properly used to buffer wind and sun exposure?

Will there be proper buffering of stormwater management areas?

What species are used?

Are the species correct for the application?

Are they consistent with URI's list of sustainable and non-invasive species?

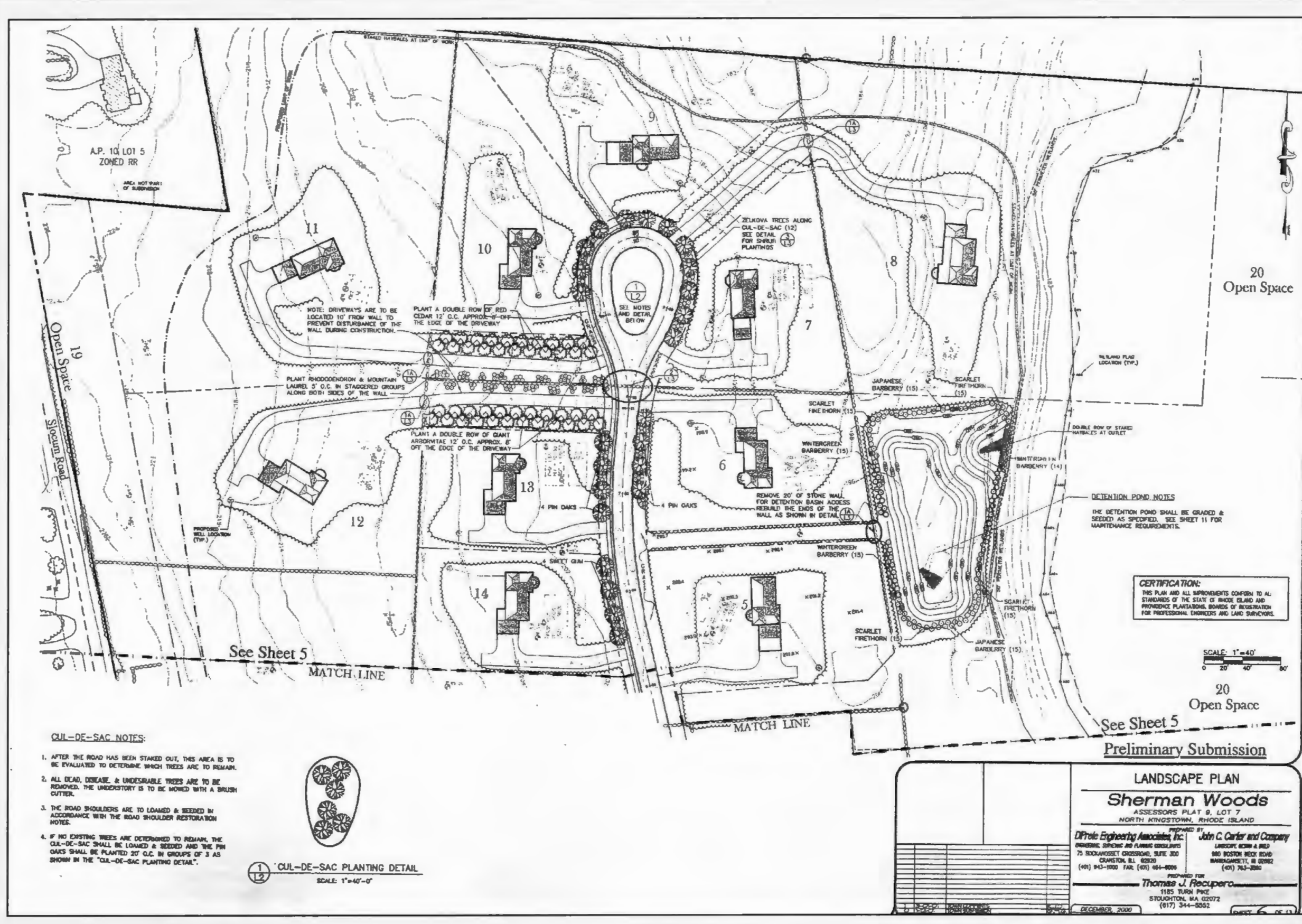




\section{Section VI. Reading Land Development Plans}

Landscape Plan "North"(continued)

Particular aspects of the Landscape Plan have been "blown up" here for easier readability.

Cul-de-sac Notes$$
\mathrm{Cu}
$$

Cul-de-sac Detail

Detention Pond Elevations

Notes and Descriptions

\section{CUL-DE-SAC NOTES:}

1. AFTER THE ROAD HAS BEEN STAKED OUT. THS AREA IS TO
BE EVAUUATED TO DETERMHEE WHICH TREES ARE TO REMAIN.

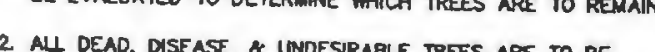
ALL DEAD. DSEASE \& UNOESIRABLE TREES AFE TO BE
REMOOED. THE UNDERSTORY IS TO BE MOWED MTH A BRUS 3. THE ROAD SHOULERS AAE TO LOAUED \& SESDED IN
ACCORDANCE. WTH THE ROAO SHOULDER RESTORATON
NOTES.

4. IF NO EXSTING IREES ARE DETERMANED TO REMAN, THE OAKS SHAIL SE PLI BE LOAMED \& SEEDED AND WHE PIN SHOWN WN THE "CAR-OE-SAC PLANING DETAR-"

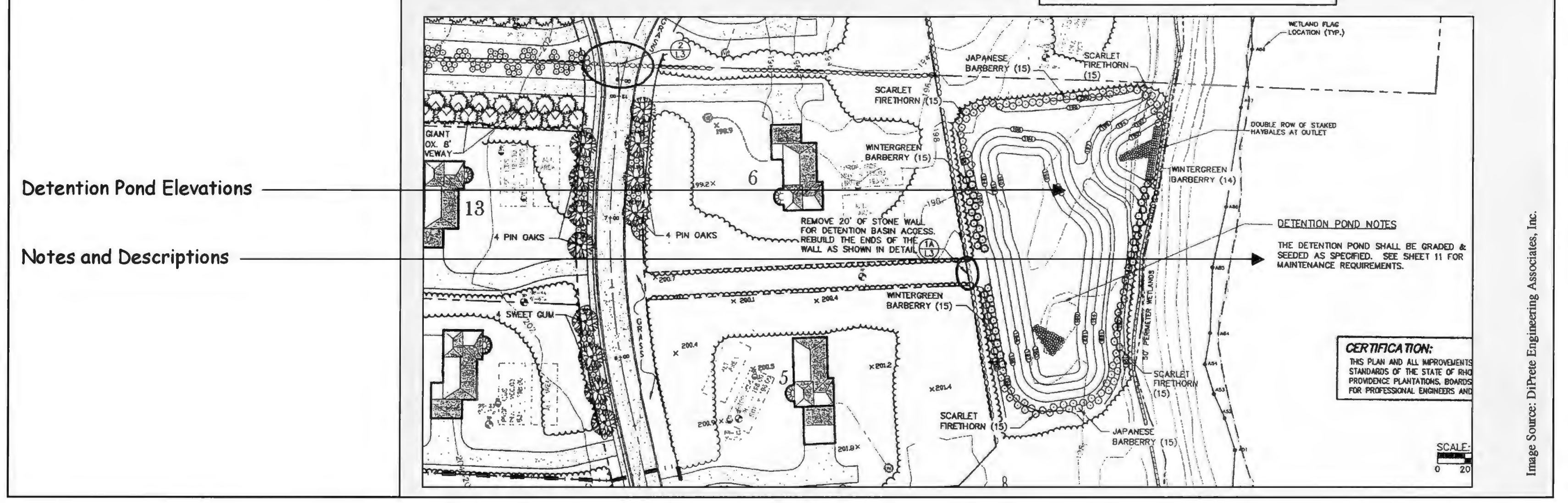




\section{Section VI. Reading Land Development Plans}

\section{Landscape Details}

Recognize these terms and symbols

Landscape Construction Notes

The Plant Schedule

Stonewall Restoration Treatment Details for driveways \& roadways and associated notes

Tree Planting Details and Associated Notes

Shrub Planting Details and Associated Notes

Roadside Planting Details and Associated Notes

\section{Consider these questions}

Are the construction notes consistent with the town's regulations and requirements?

Do the construction notes meet all expectations and respect minimal disturbance practices?

Does the maintenance and warranty plan meet expectations?

Does the plant schedule respect sustainable and non-invasive species? Are the trees to be planted big enough to survive?

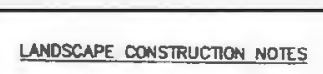

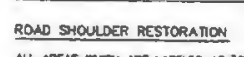

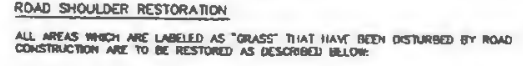

1.

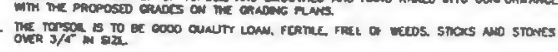

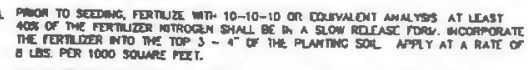

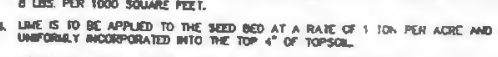

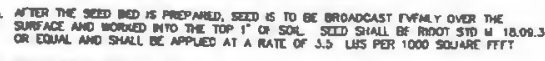

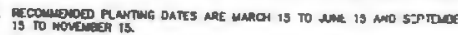

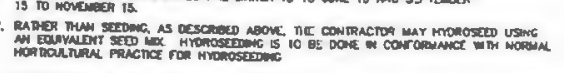

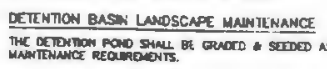

Penmec

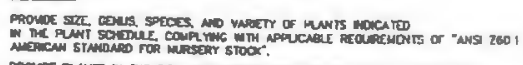

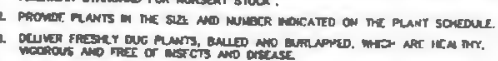

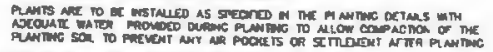

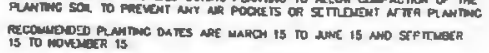

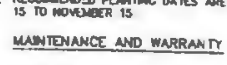

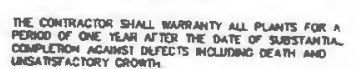

2.

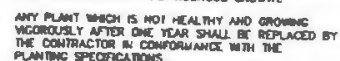

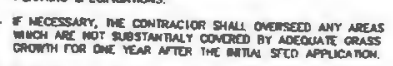

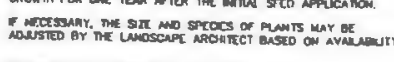

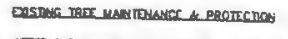

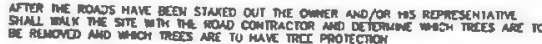

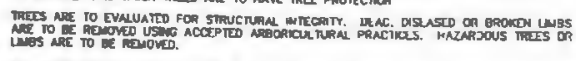

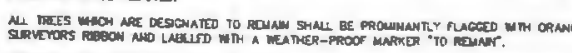
D.

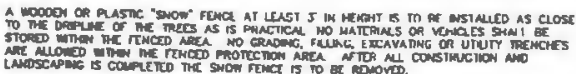

-
-

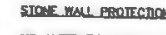

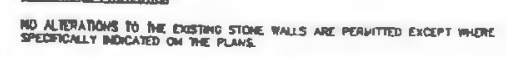
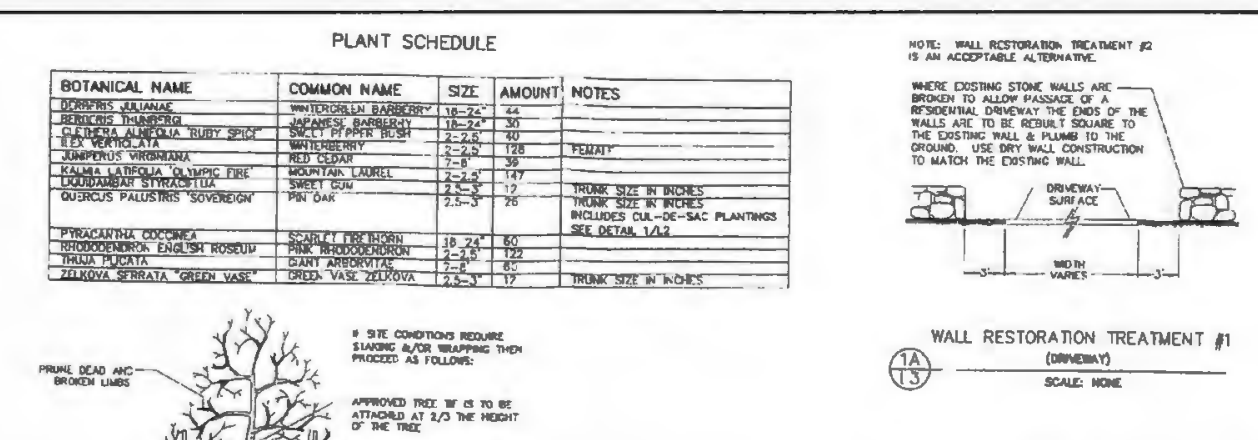

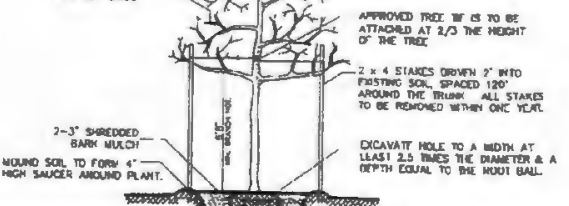

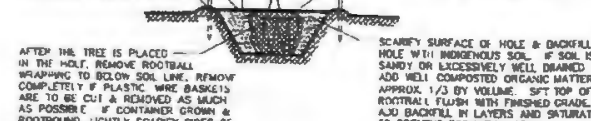

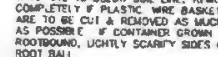

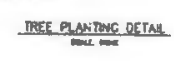

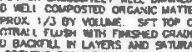

$$
\text { (1) }
$$

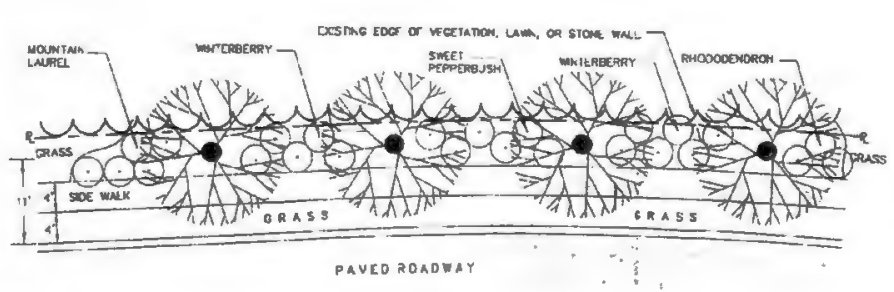

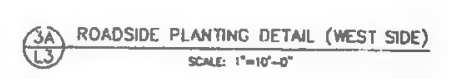

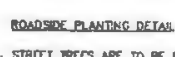

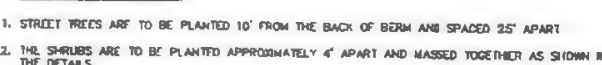

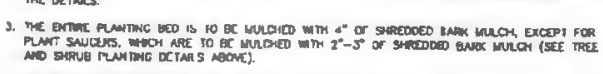

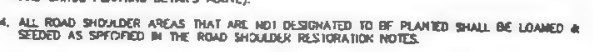

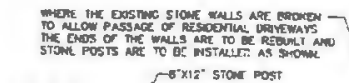

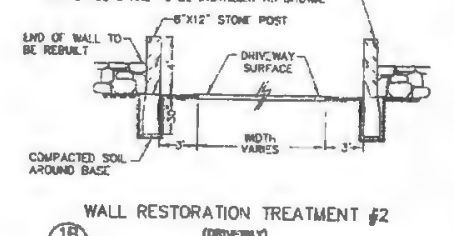

(1A) $\frac{\text { WALL RESTORA TON TREATMENT " }}{\text { (13) }}$

$\left(\frac{18}{13}\right)^{\text {WALL RESTORATION REATMENT }}$

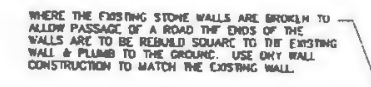

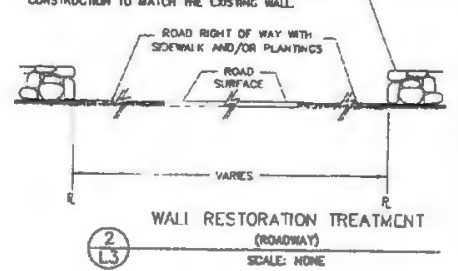

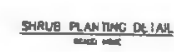

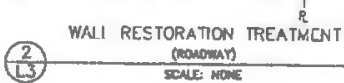

ave roackat

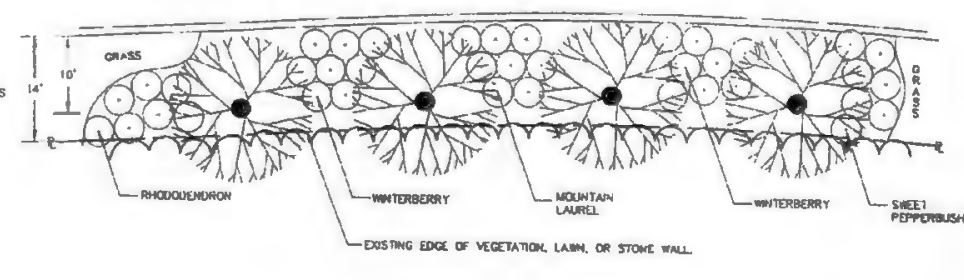

(38) ROAOSIDE PLANTNG DETALL (LAST SDE)

Preliminary Submission

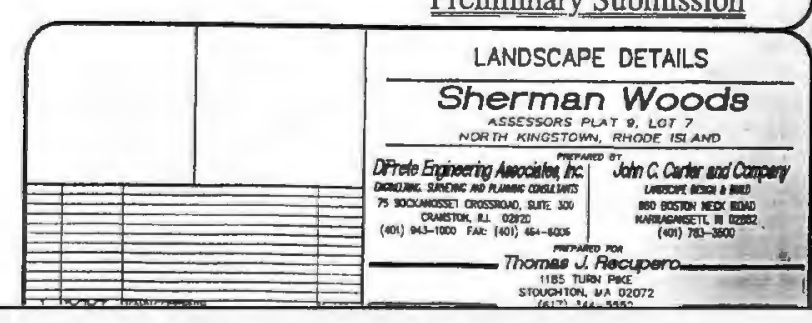

Image Source: Diprete Engineering Associates, Inc. 


\section{Section VI. Reading Land Development Plans}

\section{Landscape Details (continued)}

Particular aspects of the Landscape Details have been "blown up" here for easier readability.

Road Shoulder Restoration \& Detention Basin Landscape Maintenance

$\longrightarrow$

The Plant Schedule Planting/Maintenance \& Warranty

\section{Existing Tree Maintenance \&} Protection/Stone Wall Protection

\section{LANOSCAPE CONSTRUCTION NOTES}

ROAD SHOULDER RESTORATON

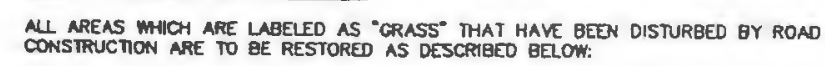

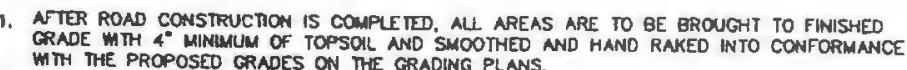

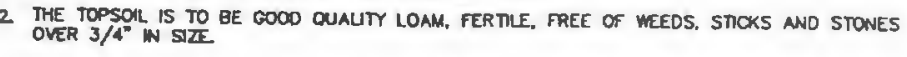

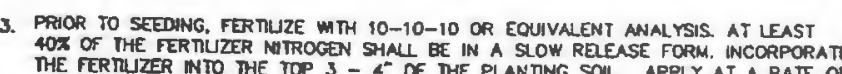

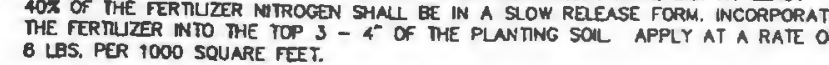

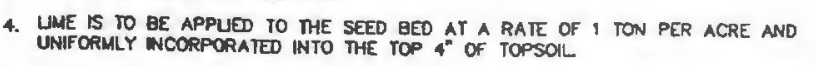

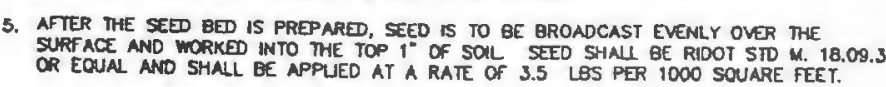

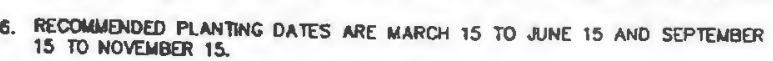

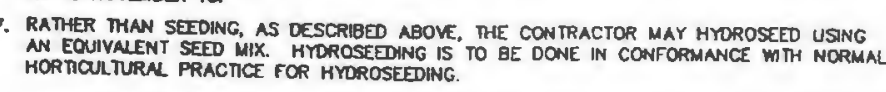
OETENTON BASN LANDSCAPE MANTENANCE

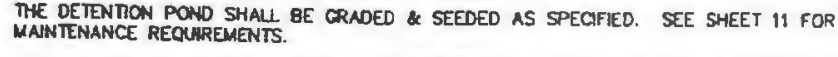

EXISTNG TREE HANIENANGE \& PROTECTON

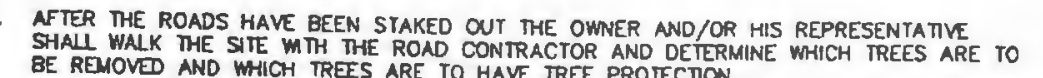

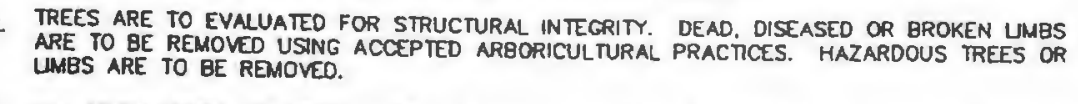

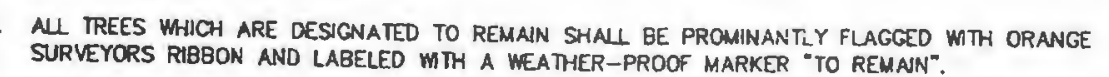

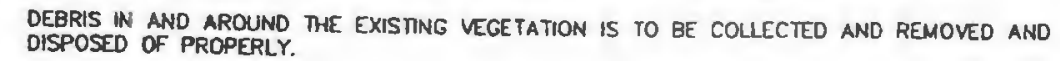

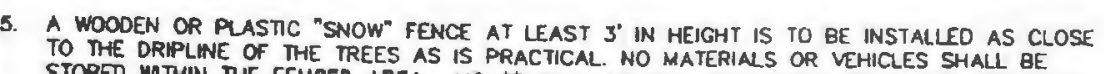

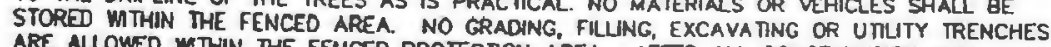

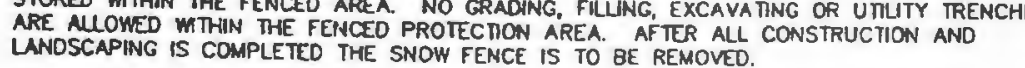

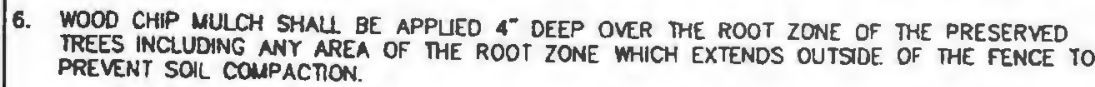
STONE WALL PBOTECTON

NO ALTERATONS TO MEE EXISTNG STONE WALS ARE PERMITED EXCEPT MHERE
SPECIFCALY WOICATED ON THE PLANS.
PLANT SCHEDULE

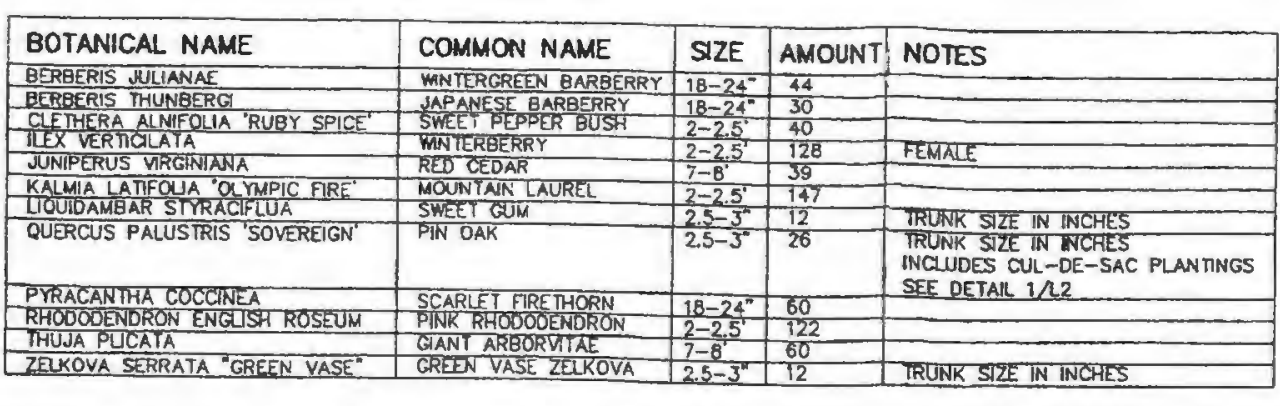

PLANTING

1. PROMDE SIZE, GeNus, SPECIES, and VARIETY OF PLaNTS INOICATED

IN THE PLANT SCHEDULE, COMPLYNA MTH APPLICABLE REQUIREMENTS OF -ANSI Z60.1

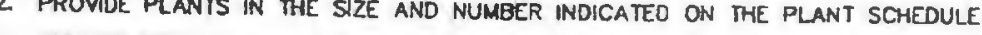
DEUVER FRESHLY DUG PLANTS, BALIED AND BURLAPPED, WHICH ARE HEALTHY,

4 PUNTS

PLANTS ARE TO BE INSTALLED AS SPECFFED IN THE PLANTING DETALS WITH
ADEQUATE WATER PROMDED DURING PLANTING TO PLANTING SOIL TO PREVENT ANY AIR PLCCKETS OR SETLLOMENT AFTER PLANINGG.

5. RECOMMENDED PLANTING DATES ARE MARCH 15 TO MNE 15 ANO SEPTEMBER
15 TO NOVEMBER 15. MAINTENANCE AND WARRANTY

1. THE CONTRACTOR SHALL WARRANT ALL PLANTS FOR A PERIPD OF ONE YEAR AETER THE DATE OF SUBSTANTAAL
COMPLTION AGANST OEFECTS INCLUDING DEATH AND UNSATSFACTORY GROWTH.

2. AFTER PLANTNG. ADEQUATE WATER SHALL BE PROMDED
TO ENSURE HEALTHY AND MGOROUS GROWTH.

3. ANY PLANT WHICH IS NOT HENL THY ANO GROMNG

VIGOROUSTY AFTER ONE YEAR SHALL BE REPLACED BY PLANTING SPECIRTCATONS.

4. IF NECESSARY, JHE CONTRACTOR SHALL OVERSEED ANY AREAS GROWTH FOR ONE YEAR AFTER THE INITIN SEED APPUCA TON.

5. IF NECESSARY, THE SSZE ANO SPECIES DF PLANTS MAY DE
AD NSTED BY THE LANDSCAPE ARCHITECT BASED ON AYNIIS 


\section{Section VI. Reading Land Development Plans}

\section{Grading Plan}

Recognize these terms and symbols

Existing Topographic Contours

Proposed Home Elevations: "T.F." and "slab" elevations

Proposed New Grade Elevations

Individual Sewage Disposal System (ISDS): "inv." and "bot" elevations

Alternate ISDS Location. Garage Floor Elevation: "G.F."

\section{Proposed Well Location}

Location of Stockpiles.$$
\text { a }
$$

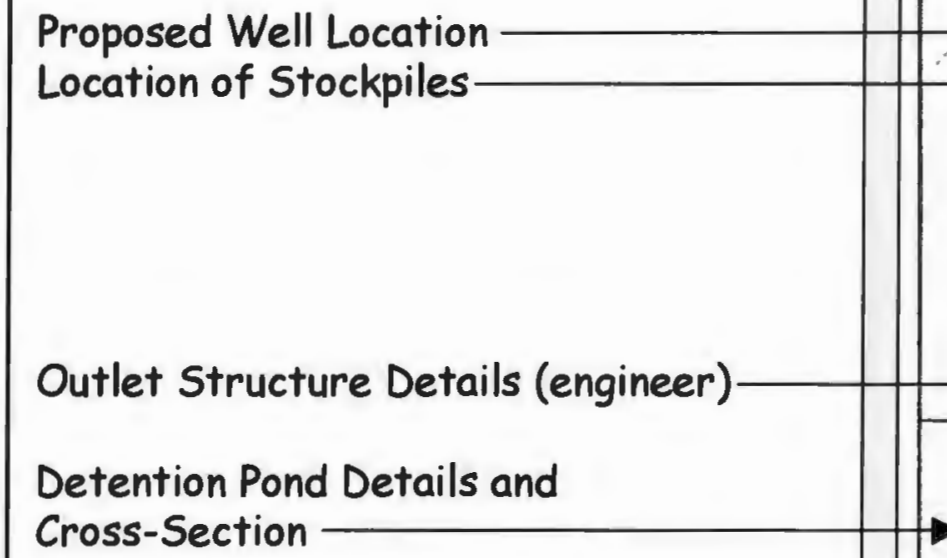

\section{Cross-Section}

Rip-rap apron details, Water quality outlet details, Private drywell detail, and Fire protection cistern locations (on following pages)

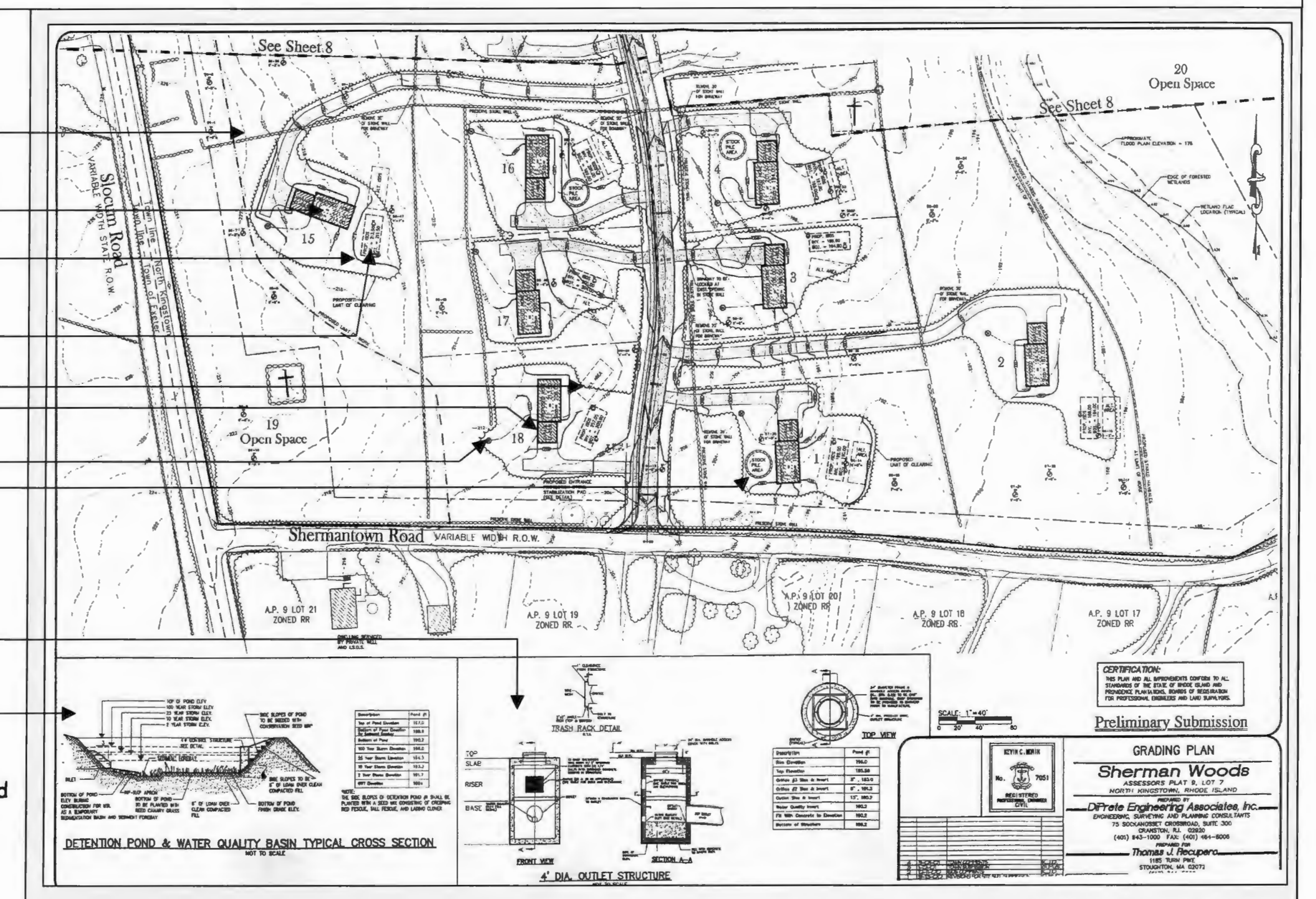

Image Source: DiPrete Engineering Associates, Inc. 


\section{Section VI. Reading Land Development Plans}

\section{Grading Plan (continued)}

Recognize these terms and symbols (cont'd)

Fire Protection Cistern Location

\section{Consider these questions}

Are the proposed grade changes necessary?

Do they support the minimal disturbance practices?

Do the proposed locations of wells, ISDS and drywells make sense?

How will the grade changes affect water flow on-site?

How will the grade changes affect water flow off-site?

Will the stormwater management System use gravity or require pumping? Is individual house runoff managed in any way?

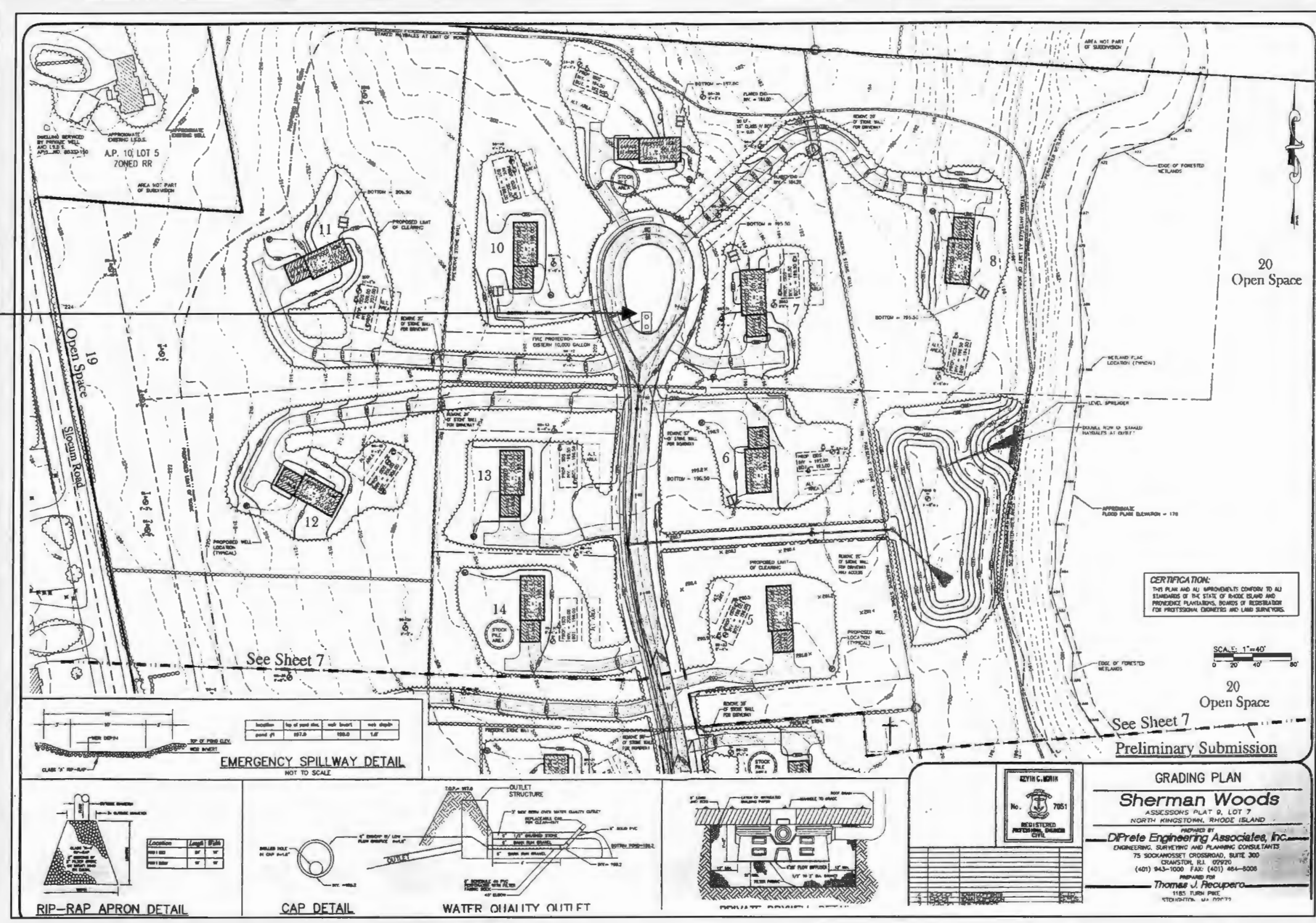




\section{Section VI. Reading Land Development Plans}

\section{Grading Plan (continued)}

Some aspects of the Grading Plan have been "blown up" here for easier readability.

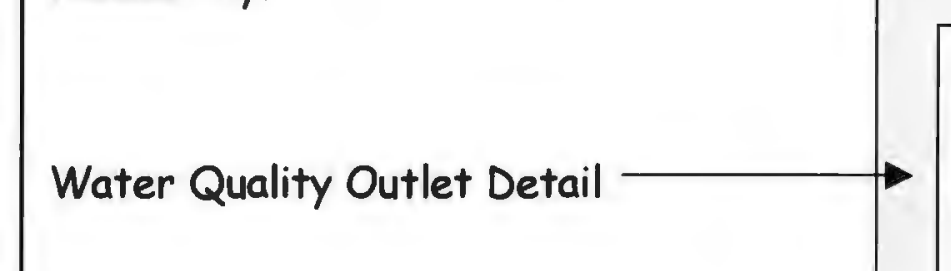

Rip-Rap Apron Detail

Detention Pond Cross-Section

\section{Private Drywell Detail}

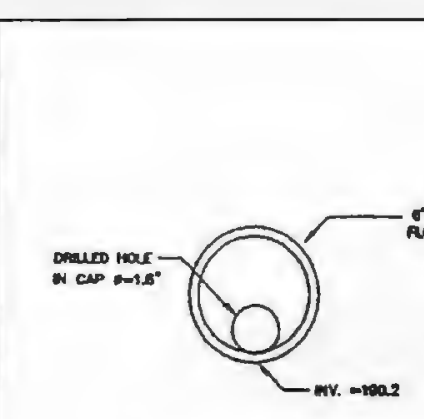

CAP DETAIL
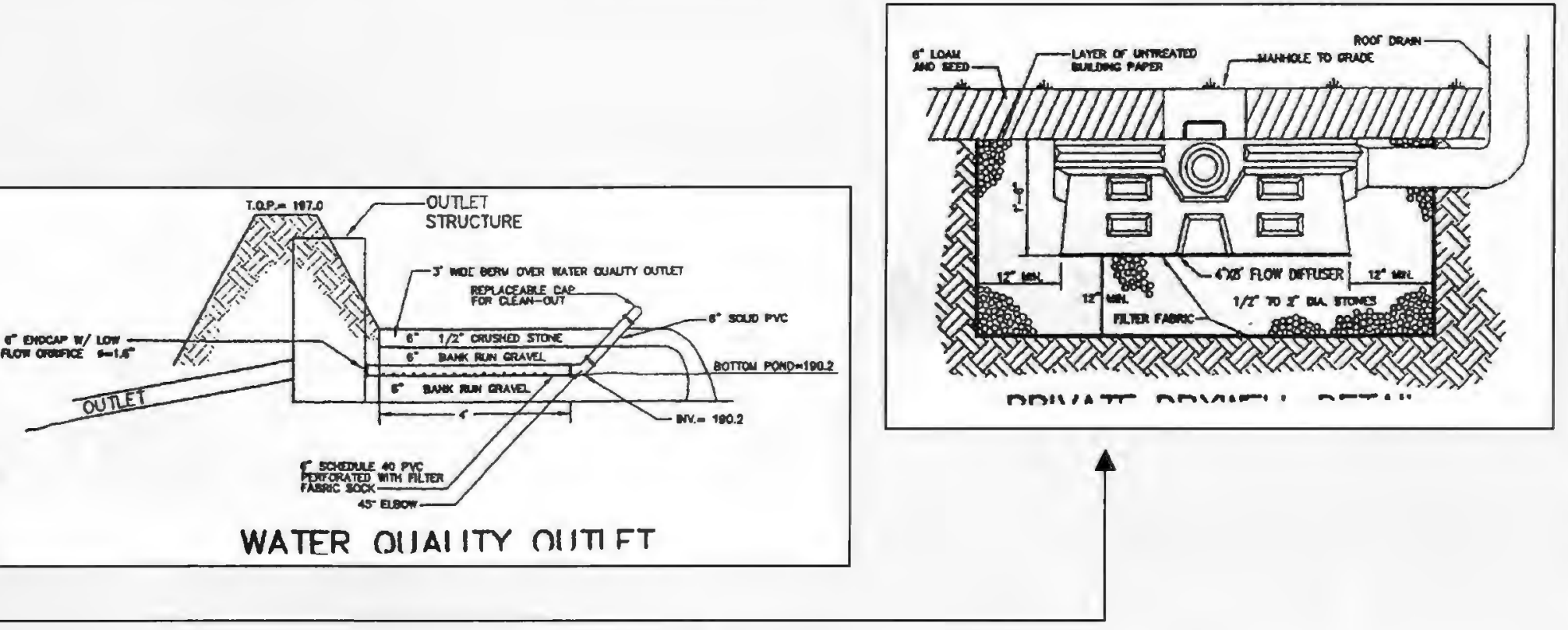

De (1)

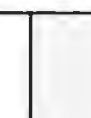

.

opmentans

$+2$




\section{Section VI. Reading Land Development Plans}

\section{Grading Plan (continued)}

The grading plan is such an important piece of the overall land development that it requires a bit of extra attention.

The figure below is a "blown-up" section of the grading plan on the previous page, for the purpose of observing and explaining the detailed information contained therein.

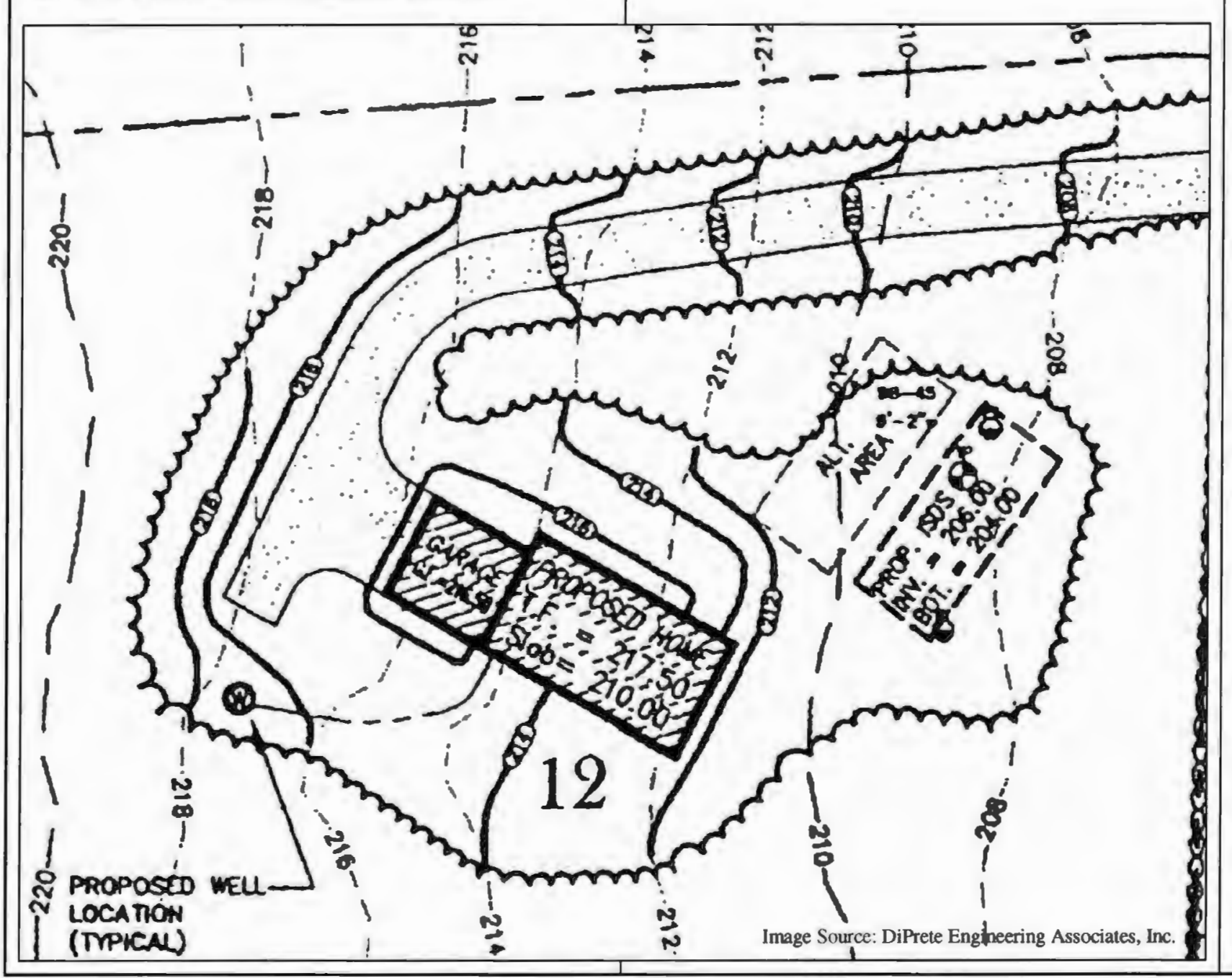

The largest function of the grading plan is to observe the changes in topography that are proposed in a land development project and how the existing and proposed topography relate to the proposed structures and

infrastructure systems such as stormwater management, wastewater management, and water supply systems.
As the sample grading legend to the righ shows, and is exemplified in the figure to the left, existing contours are shown as dashed lines (as we discussed in the understanding topography section), and changes to the existing contours are shown as solid, darker, heavier lines on the plan.

Notice that the proposed contours (the darker lines) originate and terminate on the existing contour lines and show the corresponding elevation on them, as do the existing contours. This represents the changes, and the shape of said changes that are proposed to the existing topography of the site.

Typically, grade alterations are made to accommodate roads and individual driveways, such that the proposed grading lines are perpendicular to the proposed right of way. This can be observed in the figure to the left, as well as throughout the grading plans on pages 39 and 40.

Grade alterations are also made to ensure proper overland water flow away from structures such as houses. This requires grade changes that roughly mimic the shape of the footprint of the proposed structure, moving from higher elevations at the footprint to lower elevations as they move away. These proposed grade changes can also be observed in the figure to the left

The figure to the right is a sample of the different symbols and abbreviations may be found on Grading Plans, although all are not necessarily found on those included here.
For a complete and comprehensive explanation of the different aspects of grading and formulating Grading Plans, consult the Land Development Handbook by Dewberry and Davis, which is fully referenced at the conclusion of this handbook.

\begin{tabular}{|c|c|}
\hline$\frac{(24)}{24}-\cdots--$ & $\begin{array}{l}\text { EXISTING CONTOUR } \\
\text { PROPOSED CONTOUR }\end{array}$ \\
\hline$x(24.21)$ & EXISTING SPOT ELEVATION \\
\hline$\times 24.71$ & PROPOSED SPOT ELEVATION \\
\hline FFE & FINISHED FLOOR ELEVATION \\
\hline TW/BW & TOP OF WALLBOTTOM OF WALL \\
\hline TC/BC & TOP OF CURB/BOTTOM OF CURB \\
\hline TS/BS & TOP OF STAIR/BOTTOM OF STAIR \\
\hline BF & BOTTOM OF FOOTING \\
\hline HPRP & HIGH POINT/LOW POINT \\
\hline HPS & HIGH POINT OF SWALE \\
\hline TF or RE & TOP OF FRAME OR RIM ELEVATION \\
\hline INV.EL & INVERT ELEVATION \\
\hline$\square \mathrm{CB}$ & EXISTING CATCH BASIN \\
\hline$\square \mathrm{CB}$ & PROPOSED CATCH BASIN \\
\hline ODI & EXISTING DRAIN INLET \\
\hline$O D I$ & PROPOSED DRAIN INLET \\
\hline $\mathrm{OMH}$ & EXISTING MANHOLE \\
\hline$\bullet$ MH & PROPOSED MANHOLE \\
\hline DAD & PROPOSED AREA DRAIN \\
\hline CIP & CAST IRON PIPE \\
\hline ACP & REINFORCED CONCRETE PIPE \\
\hline CMP & CORRUGATED METAL PIPE \\
\hline VCP & VITRIFIED CLAY PIPE \\
\hline PVC & POLYVINYL CHLORIDE (PLASTIC) PIPE \\
\hline STA. $0+00$ & STATION POINT \\
\hline - R- - - & PROPERTY Y LINE \\
\hline CLL & CONTRACT LIMIT UNE \\
\hline 2 & CENTER LINE \\
\hline a & CENTER LINE OF SWALE \\
\hline
\end{tabular}

Image Source: Strom, 1998 


\section{Section VI. Reading Land Development Plans}

\section{Plan and Profile}

Much of the content of this particular plan should be reviewed by the town engineer for particular specification compliance with town regulations and standards. Still, there issues with which a board or commission member should be concerned.

\section{Recognize these terms and symbols}

The overall shape and flow of the street system (Plan view)

Location of lot frontages

Profile view of proposed changes to grade where the road will be located

\section{Consider these questions}

Did the engineer make a thorough review of all measurements and town

requirements?

What comments did the engineer have? Does the road system make sense with respect to minimal disturbance practices?

Do the grade changes respect minimal disturbance of the natural grade?

*though it is a difficult skill to develop, a trained reader of these plans can imagine how the altered topography will look*

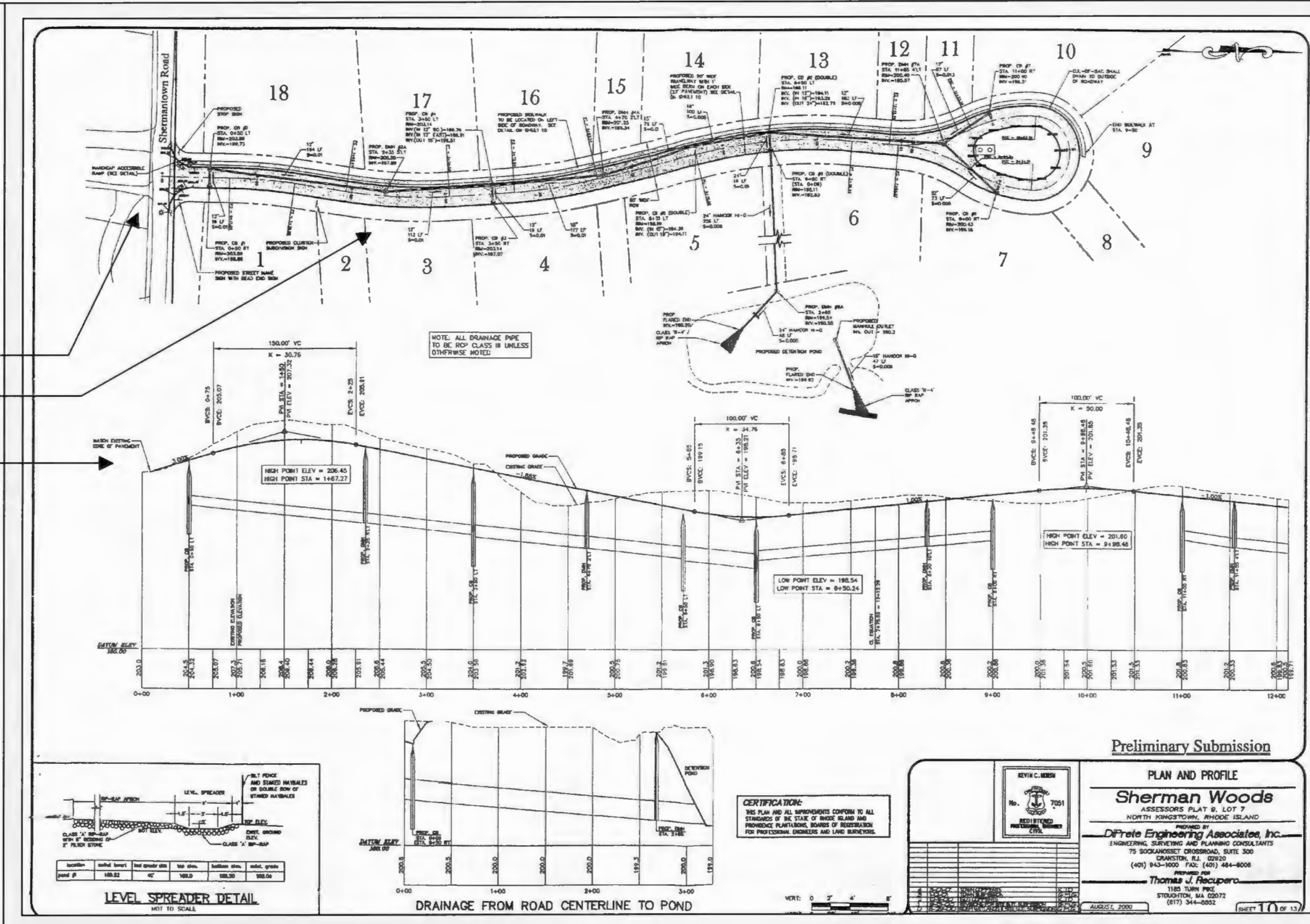




\section{Section VI. Reading Land Development Plans}

\section{Engineering Detail Sheet}

This is another plan that will generally be reviewed by the town engineer for compliance with town regulations and standards. Although many of the figures in this plan are of a strictly technical nature dealing with prefabricated parts for the drainage and roadway systems, there are many important issues that deal with planning present here.

\section{Recognize these terms and symbols}

\section{Erosion controls}

Road and sidewalk construction profile

Notes: sequence \&staging of land disturbing activities

Non-structural measures

Establishment of vegetative cover

Structural measures

Maintenance short-term/long-term

Consider these questions

Are erosion controls adequate and do

they meet expectations?

Is the roadway reduced from the standard to minimize imperviousness?

Do all notes and schedules meet town requirements and expectations?

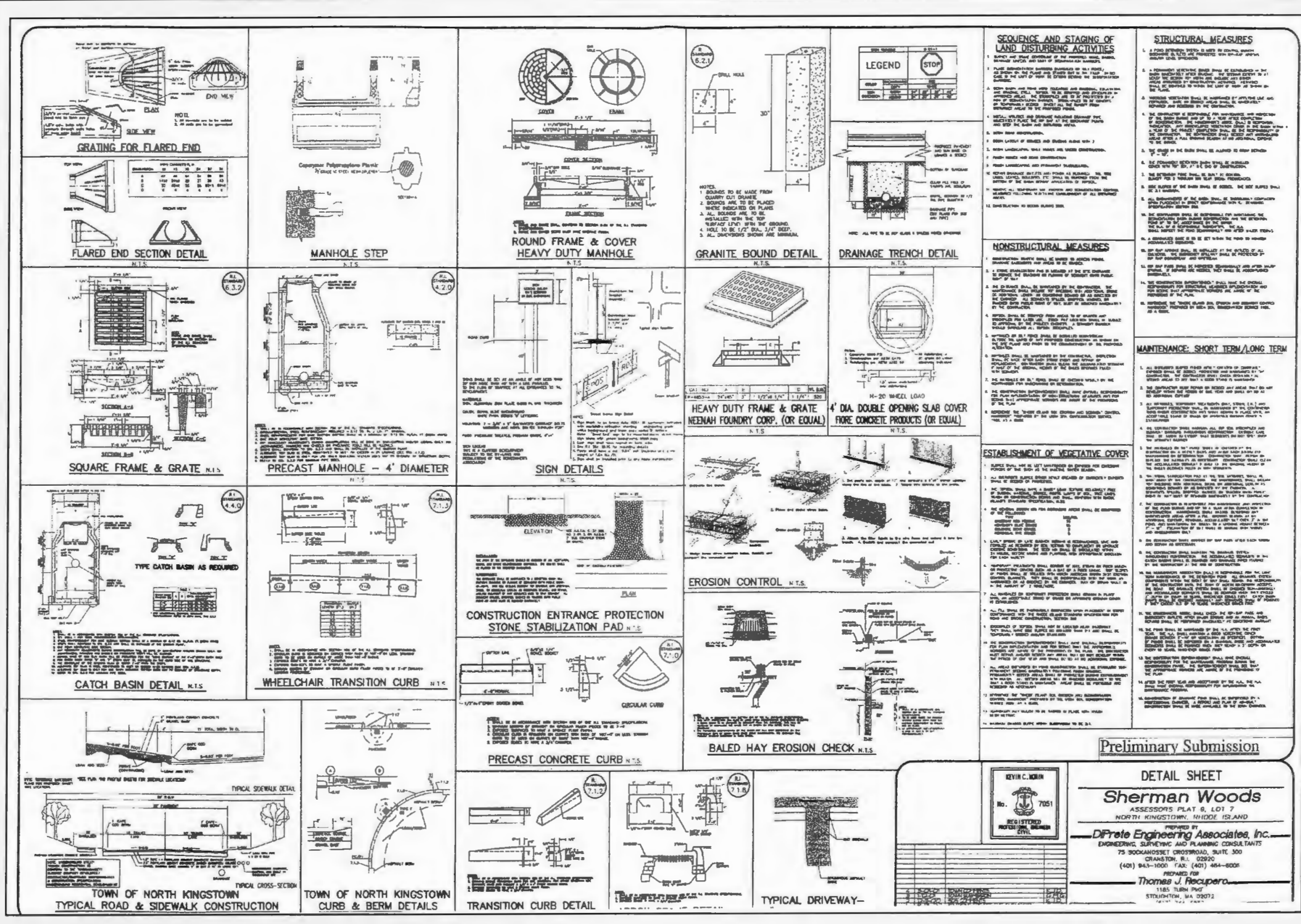




\section{Section VI. Reading Land Development Plans}

\section{Engineering Detail Sheet (continued)}

Particular aspects of the Grading Plan have been "blown up" here for easier readability, including Notes for:

Establishment of Vegetative Cover

\section{ESTABUSAMENT OF VECETATIVE COVER}

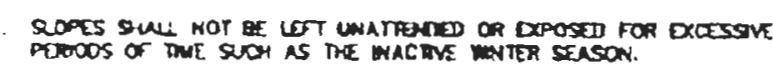

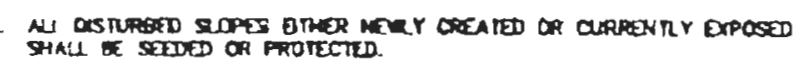

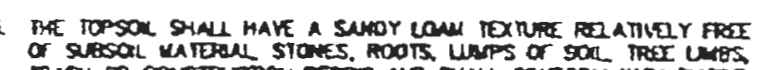

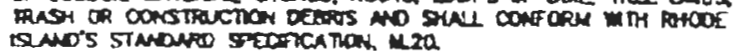

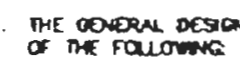

Areus STALL Ex commesed

oetrive rad rescure

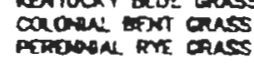<smiles>C1[As]=[As]1</smiles>

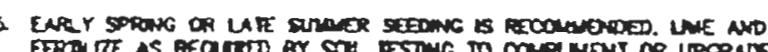

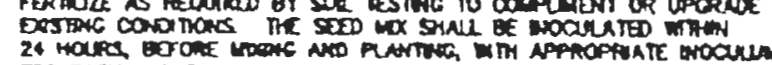

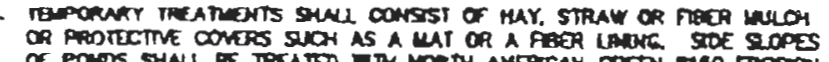

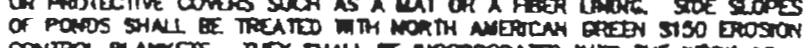

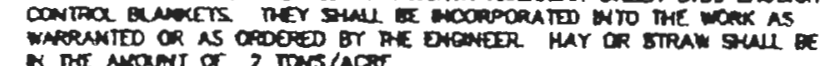

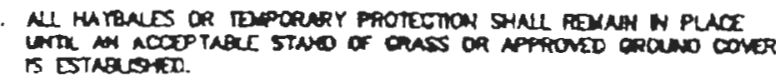

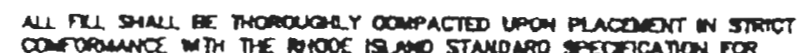

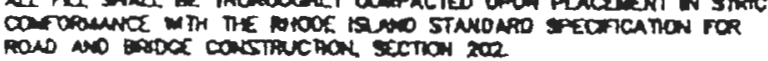

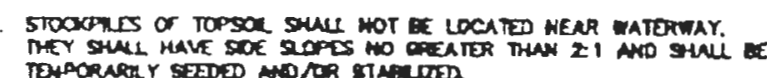

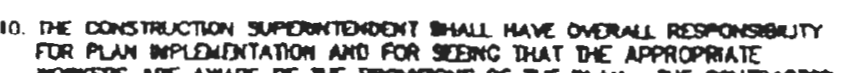

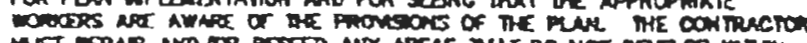

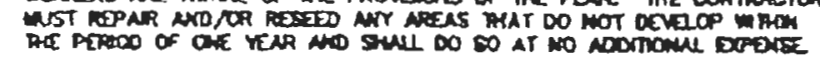

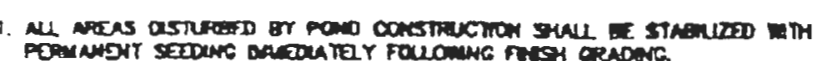

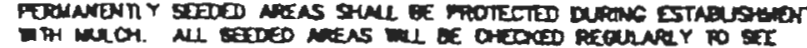

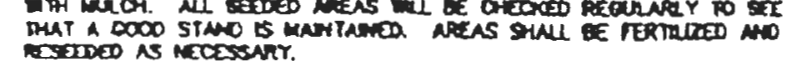

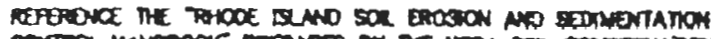

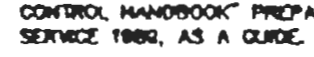

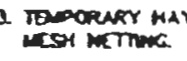

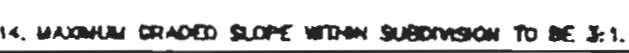

\section{NONSTRUCTURAL MEASURES}

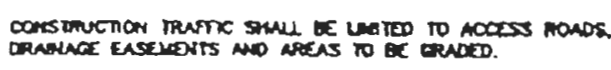

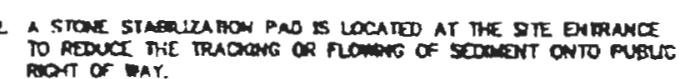

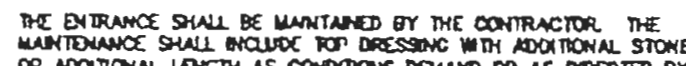

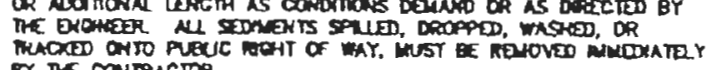

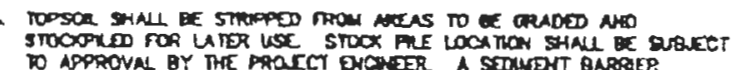

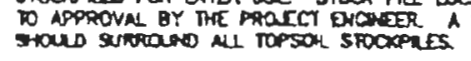

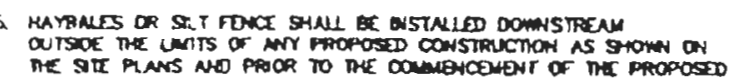

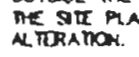

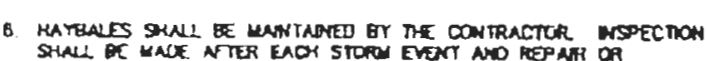

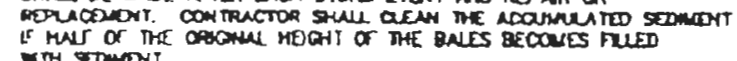

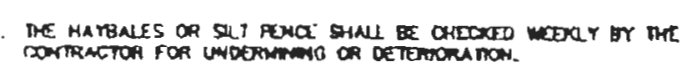

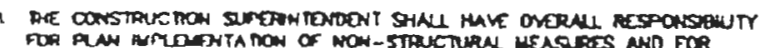

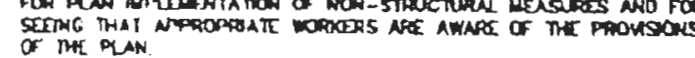

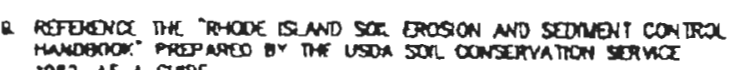

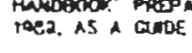

SEQUENCE AND STAGNG OF LAND DISTURBING ACTIVITES

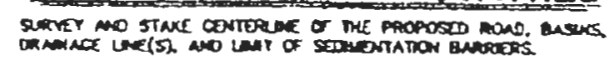

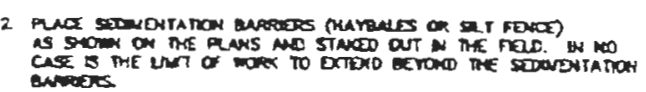

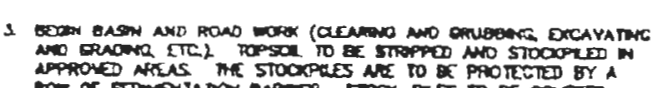

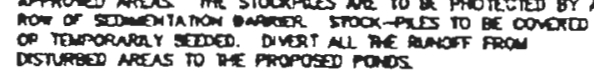

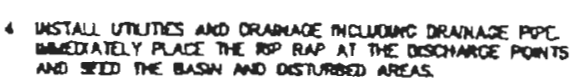

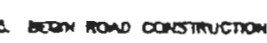

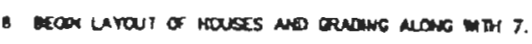

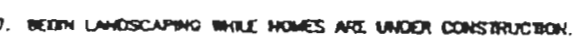

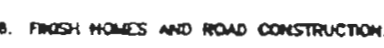

2.

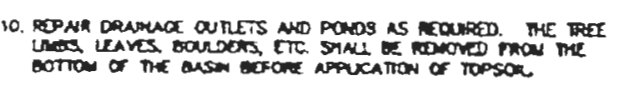

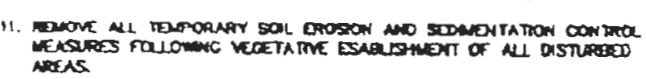

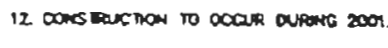




\section{Section VI. Reading Land Development Plans}

Engineering Detail Sheet (continued)

Additional aspects of the Grading Plan have been "blown up" here for easier readability, including Notes for:

Structural Measures

Maintenance: Short Term/Long Term

\section{SIRUCTURAL MEASURES}

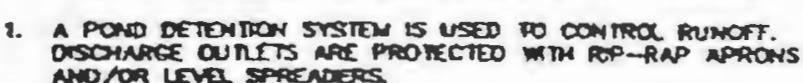

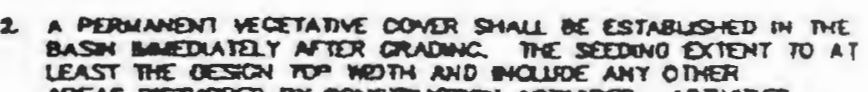

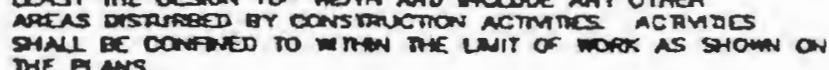

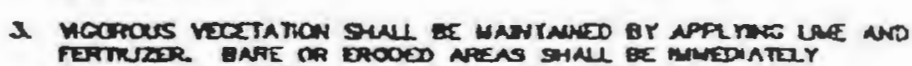

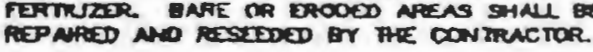

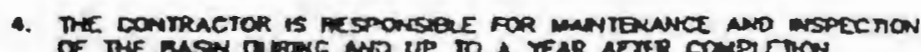

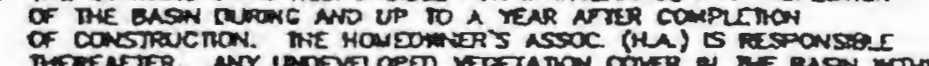

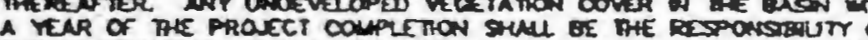
Dre C To Mie onter

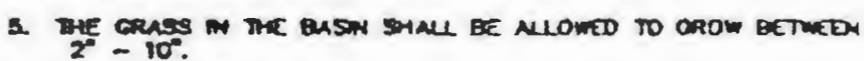

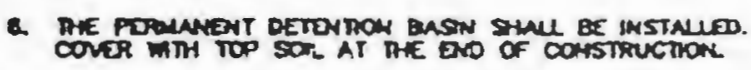

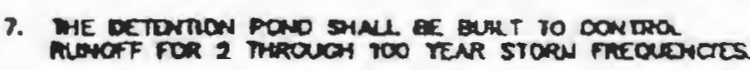

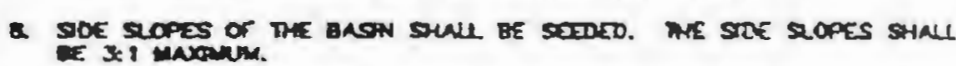

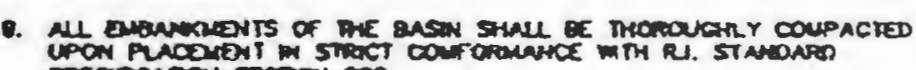
SFEOncanow section 202

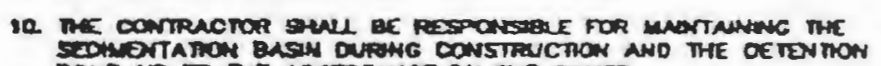

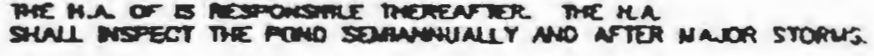

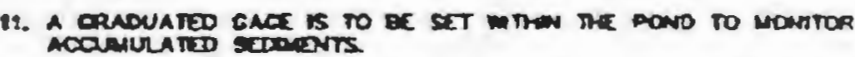

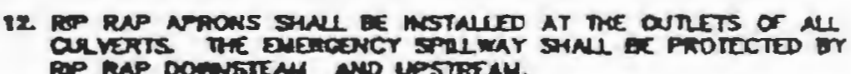

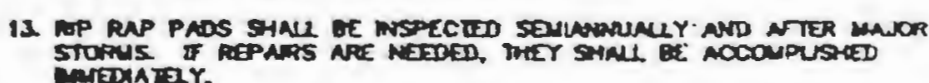

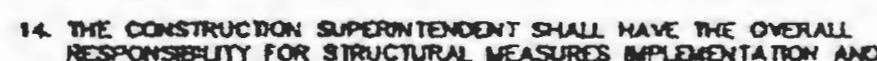

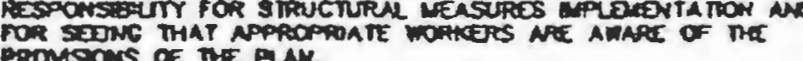

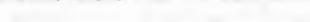

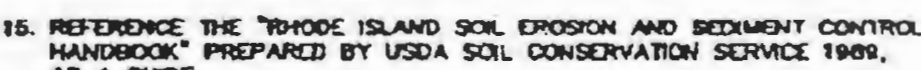
AS A A OUIOE
MANTENANCE: SHORT TERN LONG TERM

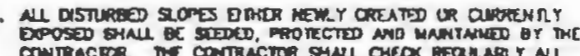

Dent

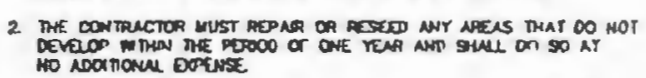

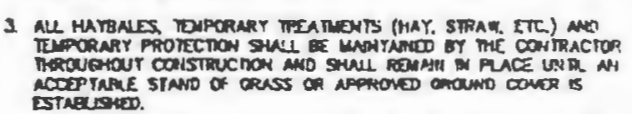

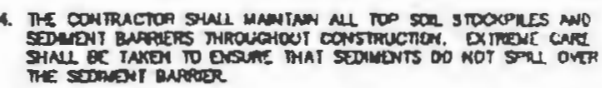

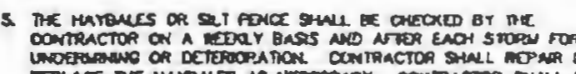

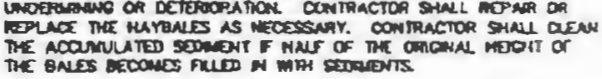

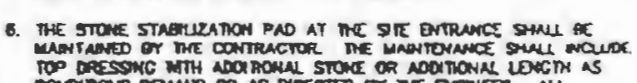

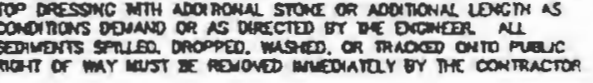

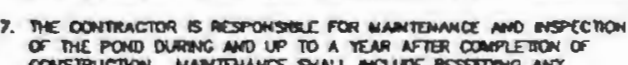

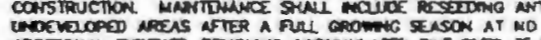

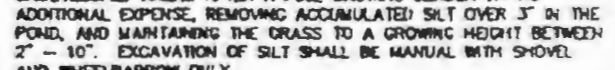

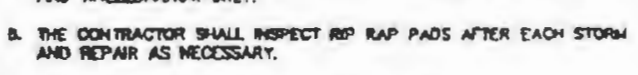

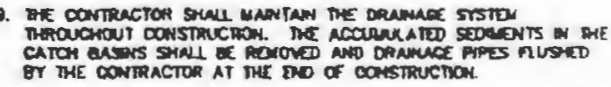

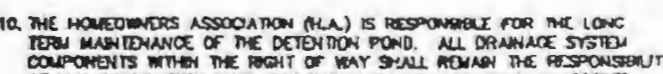

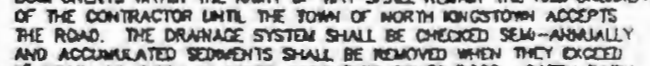

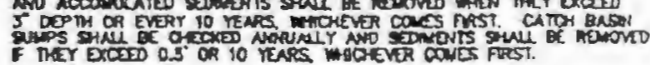

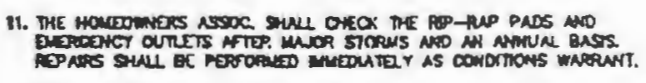

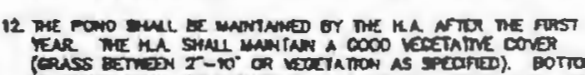

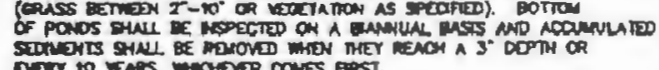

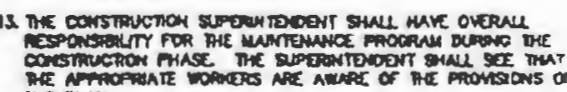

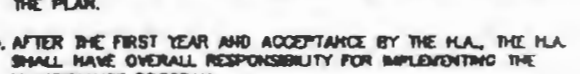

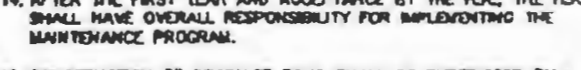

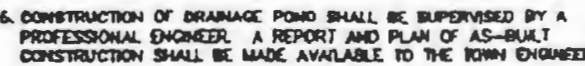




\section{Section VI. Reading Land Development Plans}

\section{Engineering Detail Sheet (continued)}

Additional aspects of the Grading Plan have been "blown up" here for easier readability.

Typical Road \& Sidewalk Construction Detail

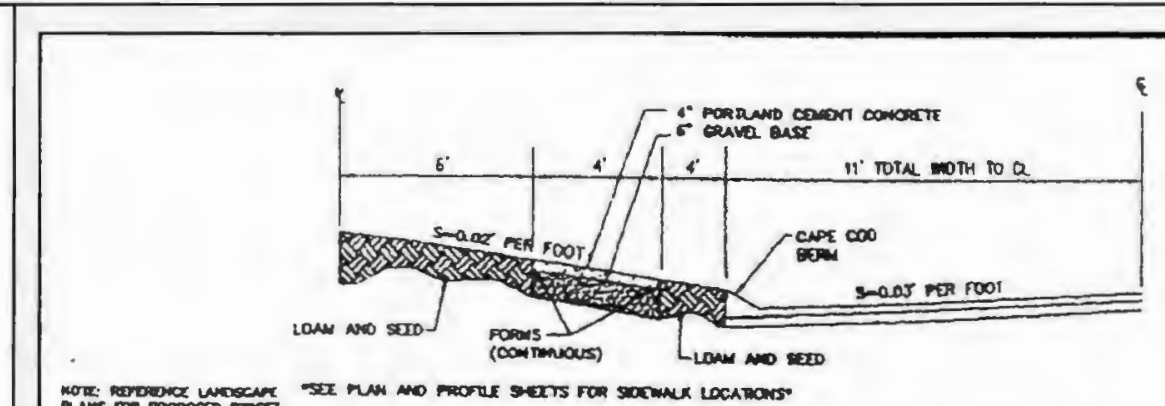

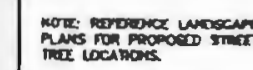

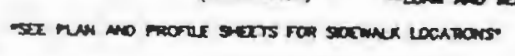
TPICAL SIDEWALK OETAL
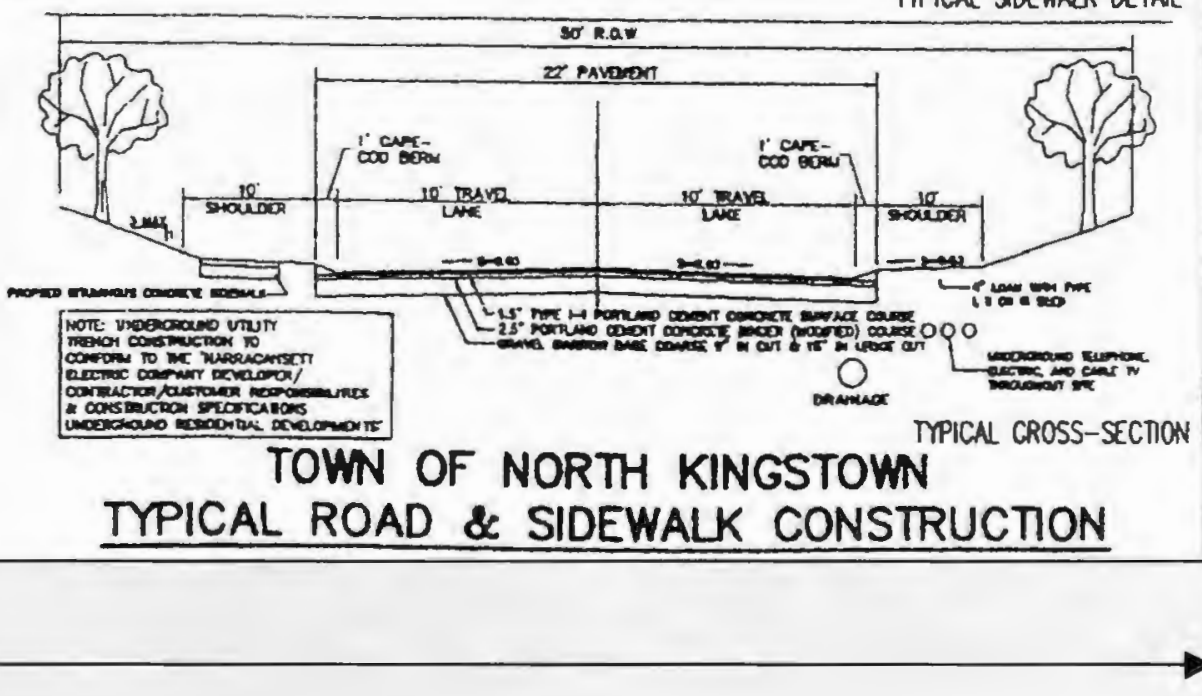

Erosion Controls

Baled Hay Erosion Check Detail

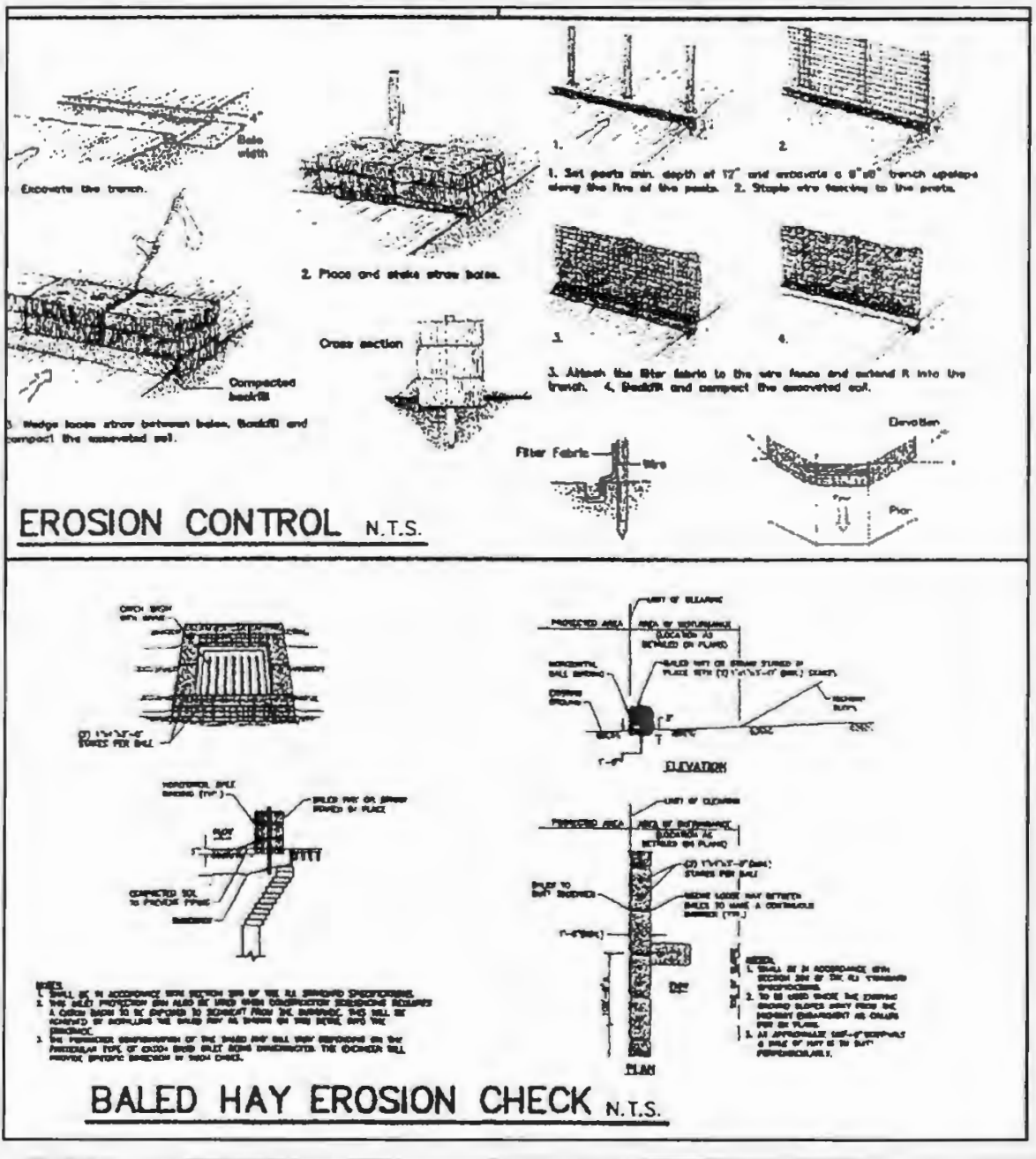




\section{Section VI. Reading Land Development Plans}

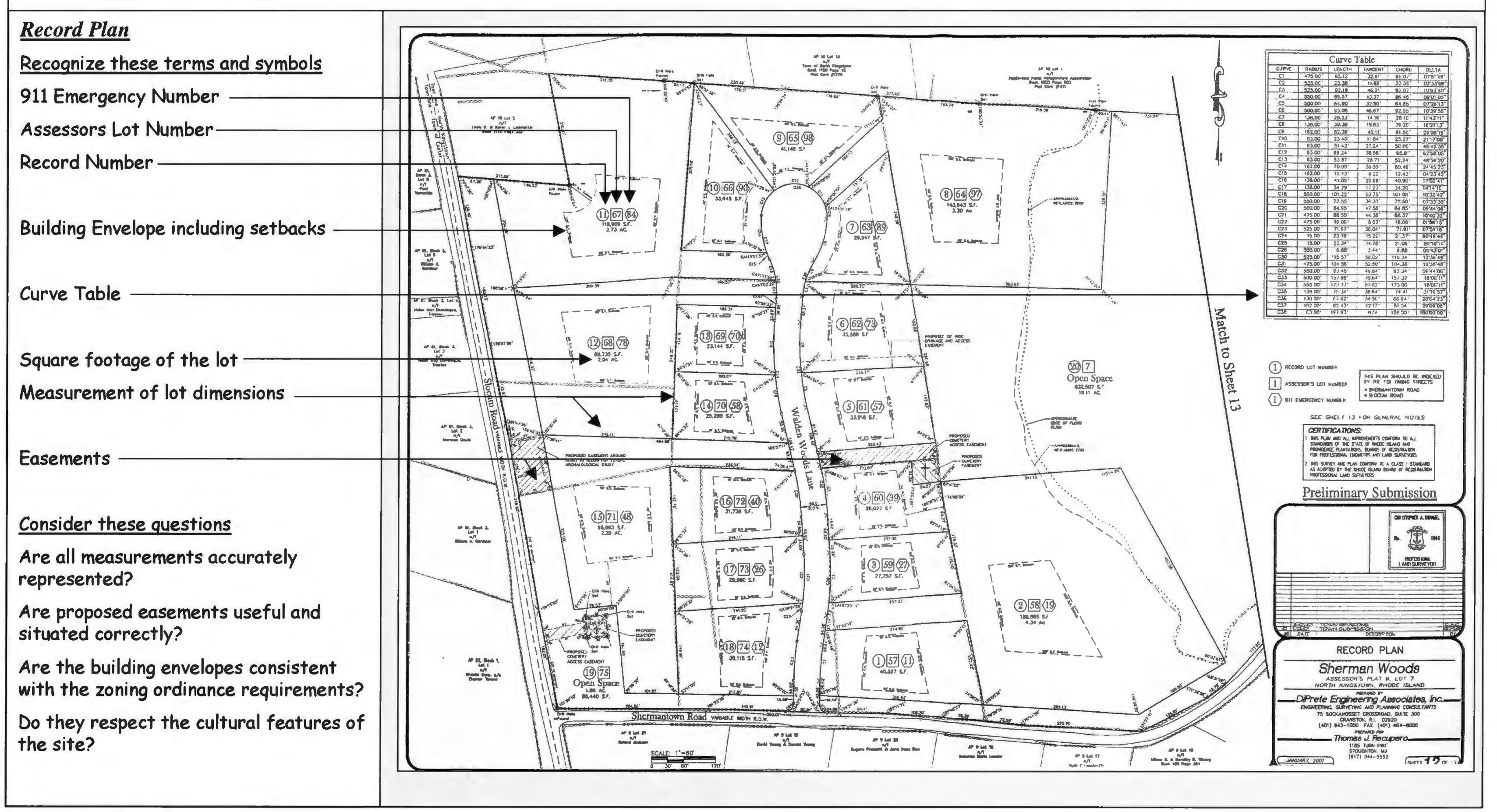




\section{Section VI. Reading Land Development Plans}

\section{Record Plan (continued)}

This is the eastern section of the development record plan. The record plan for the remainder of the site (though it is all open space), general notes and references are present here.
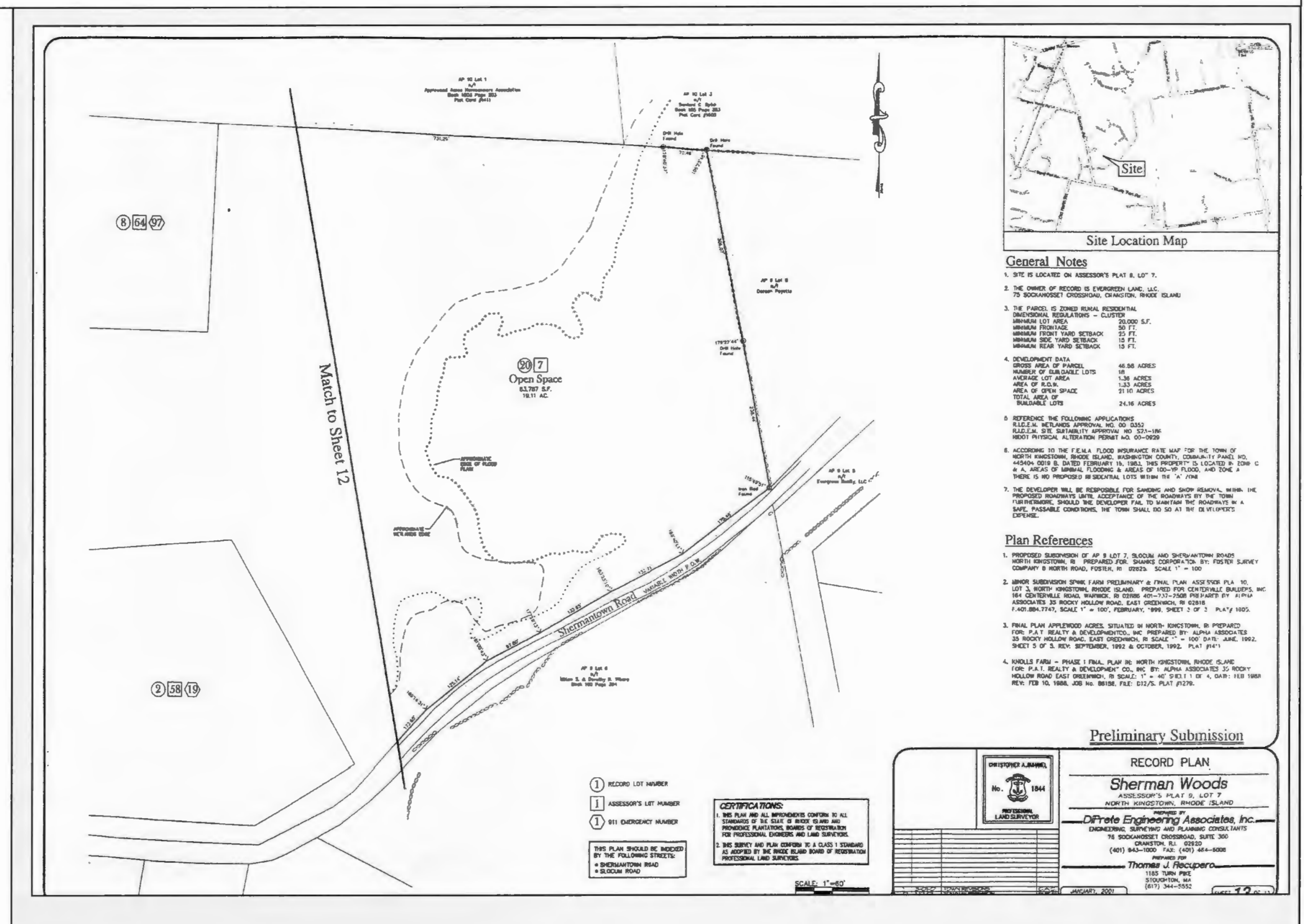


\section{Section VI. Reading Land Development Plans}

\section{Record Plan (continued)}

Some aspects of the Grading Plan have been "blown up" here for easier readability.

\section{Survey Measurements}

911, Assessor's \& Record Numbers Lot Area (S.F. and Acres) Building Envelope Lot Line

General Notes \& Plan References

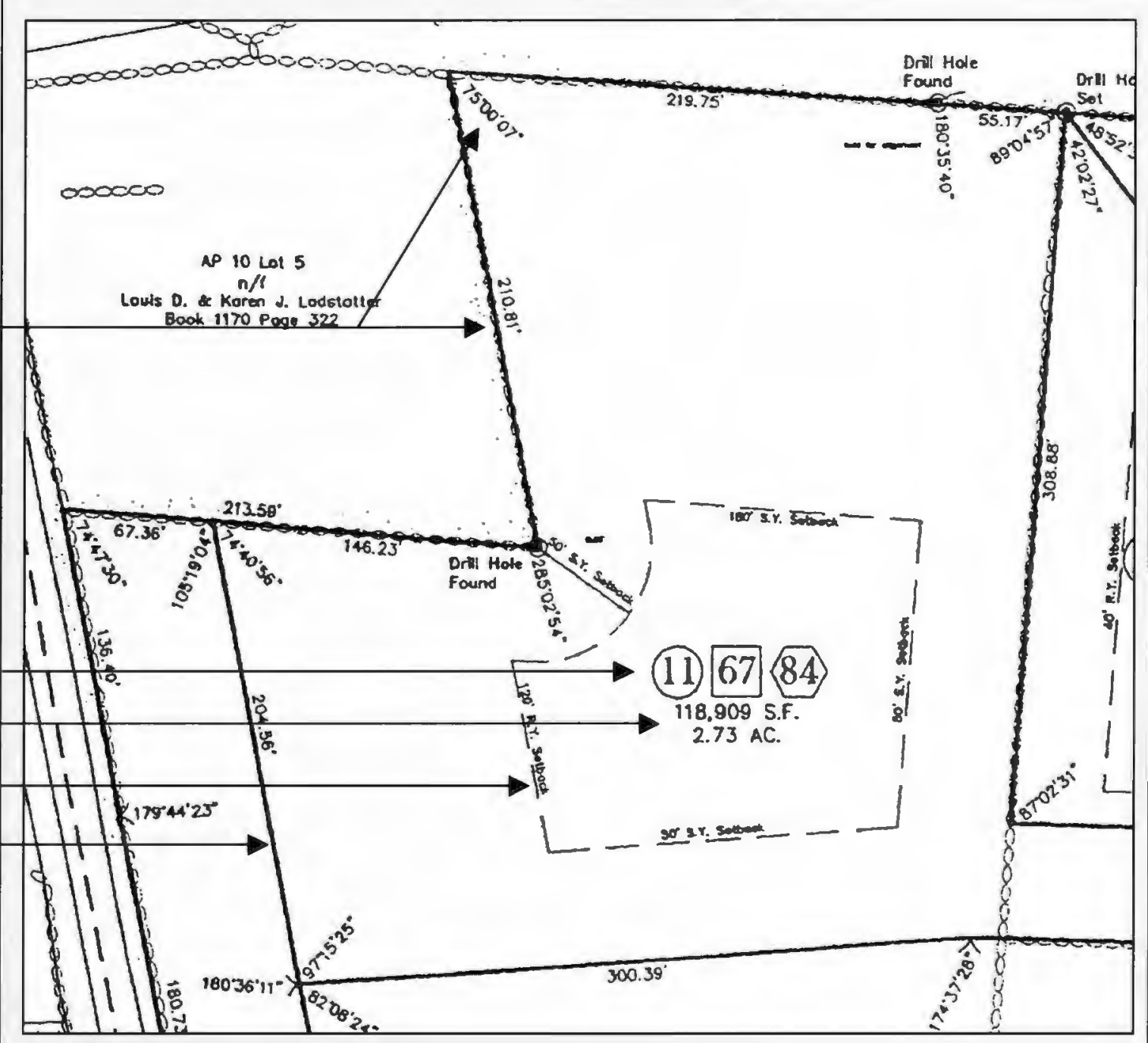

General Notes

1. SITE II LOCATEO ON ASSESSOR'S PLAT 9. LOT ?

2. THE OMNER OF RECORO IS VIERGRERN LAND, LCC,

3. THE PARCE IS ZONED RURAL RESIDENTAL

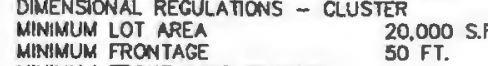

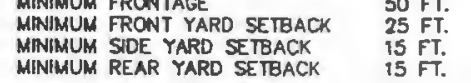

4. DEVELOPEENT DATA

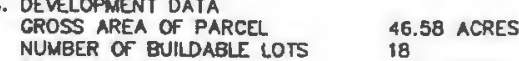

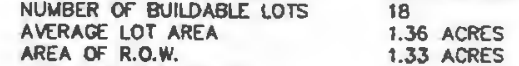

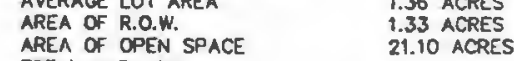

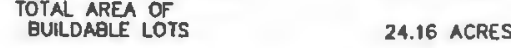

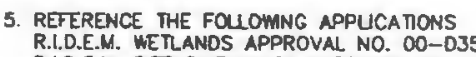

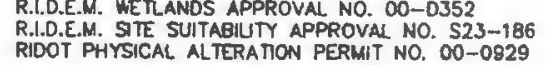

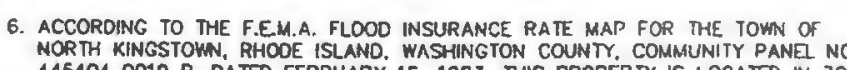

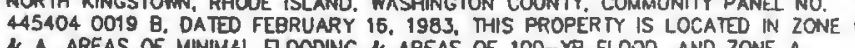
THERE IS NO PROPOSLO RESDOENTAL LOTS WITHN THE 'A' ZONE.

7. THE OEVELOPER MLL BE RESPOSBELE FOR SANONG ANO SNOW REMOVAL MTTHIN TME FURTHERMORE, SHOULO THE DEVELOOER FAL TO MAANTAN THE ROAOWASS IN A

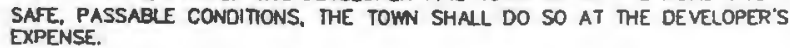

Plan References

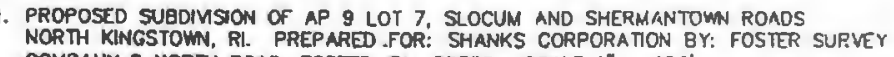

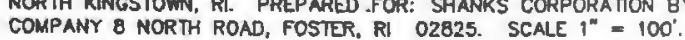

2. MINOR SUBDIUSOON SPNNK FARM PREUMINARY \& FINAL PLAN, ASSESSOR PLAT 10.

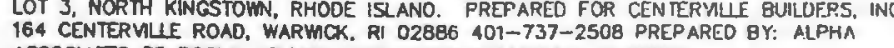

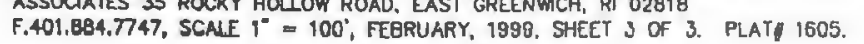

3. FINAL PLAN APPLIFOOD ACRES, STIUATED IN NORTH KIESTOWN, RR PREPARED

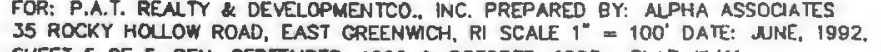
SHEET 5 OF 5. REV: SEPPEABER. 1992 \& OC OCOBER, 1992. PLAT MA11.

4. KNOLLS FARA - PHASE I INA PLAN IN: NORTH KINGSTOWN. RHOOE ISLANO

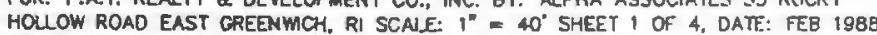
REV: FEB 10, 1988, J09 NO. B6158, FLLE; D12/S. PLAT J1279. 
The final topic to be addressed in this manual is the site visit, the actual physical visitation by the land development plan reviewers to the project site for the purposes of thoroughly understanding the relationship between the site, the proposed project, and it's surroundings. This is also commonly known as a "site inspection".

Site visits may be conducted by a group (meaning the reviewing body and interested members of the public), an individual, or be done by videotape to be shown at a later public meeting.

Site visitation should no longer be an option, but rather be mandatory when reviewing land development projects. It is absolutely essential that reviewers see the site to ensure that the"paper record" of maps and plans is accurate.

\section{SITE VISITATION PROCESS AND STANDARDS IN RHODE ISLAND}

When conducting a site visit, it is very important that you and your colleagues understand and obey the guidelines and requirements that are set for you by the laws governing the State of Rhode Island. The following is a short list of factors to consider when holding a site visit:

1. Always retain the permission of the owner of the property and/or the applicant before attempting a site visit.
2. Obey Open Meetings Law if the group visiting a site represents a quorum of a public body. In this case the site visit is a public meeting, and you must:

- Provide proper notice of the site visit/meeting

- Keep minutes of the site inspection and read into the record at the next public hearing

3. Maintain due process in decision-making by being fair and impartial, and providing all information gathered during a site inspection to the public

4. Avoid ex parte contacts, which are those communications that occur outside the public forum with anyone who may have an interest in the decision of the pending project application

Further information regarding the legalities of site visits are available in the "Making Good Land-Use Decisions" manual from Grow

Smart R.I., and from the Planning

Commissioners Journal website a www.plannersweb.com under Ethics and The Planning Commission.

\section{MAKING GENERAL OBSERVATIONS FOR FIELD REVIEW}

When making observations during a site visit, you are beginning the process of field review, which is really taking all of the information presented to you in all of the maps, figures, plans and other documentation explained in this handbook thus far, and relating it to the site and the proposed project.

Many of the questions posed while reviewing site plans will be relevant when touring the site where the development will potentially be.

\section{GROUND-PROOFING MAPS}

Observing the relationship between how elements of a project are mapped on paper and how they are laid out on the site can greatly influence the impression a potential project has on a reviewer. Here are a few pointers on what to observe when walking a site:

Observing Survevor's Markers. Surveyors will mark out the location of all structures and roadways using a series of stakes and flags. These markers can be used to orient the reviewer to the footprints of the buildings and locations of roads to assess how they will relate to the site as well as their surroundings. Try to visualize the project in built form by referencing the marked stakes and flags.
Observing the Wetland Edge. The edge of all wetlands found on site are flagged by a state licensed wetlands scientist, are either approved or relocated upon inspection by the RIDEM Division of Wetlands. They are then located by a professional surveyor so that they can be mapped and shown on the site plans. These marks can be observed in the field as a series of numbered blue "surveyor's tape" flags either staked into the ground or tied to tree limbs.

\section{Cataloguing significant natural and cultural}

resources. If any significant natural or cultural resources that were not previously identified are observed during the site visit, it is important that they are catalogued by the field review team, and addressed at the next meeting with the applicant. All resources that are protected by law or are deemed important by the town officials should be addressed, and the applicant should be held responsible for protecting said resources, both during the planning and construction phases of the project. 


\section{Section VIII: Glossary of Common Planning \& Zoning Terms}

Accessory Use: A use of land or of a building or portion thereof customarily incidental and subordinate to the principal use of the land or building, and located on the same lot with such principal use.

Administrative Officer: The municipal official designated by the local regulations to administer the land development and subdivision regulations and to coordinate with local boards and commissions, municipal staff and state agencies. The administrative officer may be a member of, or the chair, of the planning board, or an appointed official of the municipality.

Administrative Subdivision: Re-subdivision of existing lots which yields no additional lots for development, and involves no creation or extension of streets. The re-subdivision only involves divisions, mergers, mergers and division, or adjustments of boundaries of existing lots.

Board of Appeal: The local review authority for appeals of actions of the administrative officer and the planning board on matters of land development or subdivision, which shall be the local zoning board of review constituted as the board of appeal.

Buildable Lot: A lot where construction for the use(s) permitted on the site under the local zoning ordinance is considered practicable by the planning board, considering the physical constraints to development of the site as well as the requirements of the pertinent federal, state and local regulations.

Certificate of Completeness: A notice issued by the administrative officer informing an applicant that the application is complete and meets the requirements of the municipality's regulations, and that the applicant may proceed with the approval process.

Consistency with the Comprehensive Plan: A requirement of all local land use regulations which means that all these regulations and subsequent actions are in accordance with the public policies arrived at through detailed study and analysis and adopted by the municipality as the comprehensive community plan.

Developer: The legal or beneficial owner or owners of a lot or of any land included in a proposed development including the holder of an option or contract to purchase, or other persons having enforceable proprietary interests in such land.

Enabling Act: The legislative act authorizing a governmental agency to do something that previously could not be done.
Environmental Constraints: Natural features, resources, or land characteristics that are sensitive to change and may require conservation measures or the application of special development techniques to prevent degradation of the site, or may require limited development, or in certain instances, may preclude development.

FEMA: The Federal Emergency Management Agency.

Final Plan: The final stage of land development and subdivision review.

Flood Plain: The channel and the relatively flat area adjoining the channel of a natural stream or river that has been or may be covered by floodwater.

ISDS: Individual sewage disposal system.

Land Use: A description of how land is occupied or utilized.

Major Land Development Plan: Any land development plan not classified as a minor land development plan.

Major Subdivision: Any subdivision not classified as either an administrative subdivision or a minor subdivision.

Master Plan: An overall plan for a proposed project site outlining general, rather than detailed, development intentions. It describes the basic parameters of a major development proposal, rather than giving full engineering details. Required in major land development or major subdivision review.

Minor Land Development Plan: A development plan for a residential project as defined in local regulations, provided that the development does not require waivers or modifications as specified in this act. All nonresidential land development projects are considered major land development plans.

Minor Subdivision: A plan for a subdivision of land consisting of five (5) or fewer units or lots, provided that the subdivision does not require waivers or modifications as specified in this chapter.

Parcel: A lot, or contiguous group of lots in single ownership or under single control, and usually considered a unit for purposes of development. Also referred to as a tract.

Permitted Use: Any use allowed in a zoning district and subject to the restrictions applicable to that zoning district. 


\section{Section VIII: Glossary of Common Planning \& Zoning Terms}

Planning Board: The official planning agency of a municipality, whether designated as the plan commission, planning commission, plan board, or as otherwise known.

Police Power, the: The general governmental power to protect the general health, safety, morals and general welfare of the citizenry.

Preliminary Plan: The required stage of land development and subdivision review which requires detailed engineered drawings and all required state and federal permits.

Public Informational Meeting: A meeting of the planning board or governing body preceded by a notice, open to the public and at which the public is heard.

RIGIS: The Rhode Island Geographic Information System.

RIGL: The General Laws for the State of Rhode Island

SHWT: Seasonally high water table.

Slope: The degree of deviation of a surface from the horizontal, usually expressed in percent or degrees.

Special Use Permit: A permit issued by the proper governmental authority that must be acquired before a special exception use can be constructed.

Stormwater Detention: A provision for storage of storm water runoff and the controlled release of the runoff during and after a flood or storm.

Stormwater Retention: A provision for storage of storm water runoff.

Subdivision: The division or re-division, of a lot, tract or parcel of land into two or more lots, tracts, or parcels. Any adjustment to existing lot lines of a recorded lot by any means is considered a subdivision. All re-subdivision activity is considered a subdivision. The division of property for purposes of financing constitutes a subdivision.

Technical Review Committee: A committee appointed by the planning board for the purpose of reviewing, commenting, and making recommendations to the planning board with respect to approval of land development and subdivision applications.

Topography: The configuration of a surface area showing relative elevations. USGS: The United States Geological Survey.

Water Table: The uppermost bound of a groundwater aquifer
Well: Mechanism for extracting groundwater to the surface for human use

Zoning: The dividing of a municipality into districts and the establishment of regulations governing the use, placement, spacing, and size of land and buildings.

Zoning Map: The map or maps that are part of the zoning ordinance and delineate the boundaries of zone districts. 


\section{References}

Arendt, Randall G. 1999. Growing Greener: Putting Conservation into Local Plans and Ordinances. Washington, DC: Island Press

Arendt, Randall G. 1996. Conservation Design for Subdivisions: A Practical Guide to Creating Open Space Networks. Washington, DC: Island Press

Association of New Jersey Environmental Commissions Resource Center. Undated. Site Plan Review: Procedures for Environmental Analysis. Mendham, NJ

Brewer, William E., and Charles P. Alter. 1988. The Complete Manual of Land Planning and Development. Englewood Cliffs, NJ: Prentice-Hall, Inc.

Callahan, Keane, et. al. 1993. An Inland Wetland Commissioner's Guide to Site Plan Review. Hartford, CT: Connecticut Department of Environmental Protection.

Center for Watershed Protection. 1998. Better Sight Design: A Handbook for Changing Development Rules in Your Community. Ellicott City, MD

Chandler, Michael, Milton Herd, and Jewell Emswiller. 1992. Planning Commission Basics: an Introduction. Workshop given at the APA National Conference, Washington Hilton.

Department of the State of New York. Undated. Local Government Technical Series: Site Development Plan Review, Procedures and Guidelines.

Dewberry, Sydney O., and John S. Matusik. 1996. Land Development Handbook: Planning, Engineering \& Surveying. New York, NY: McGraw Hill

Ewing, Reid. 1996. Best Development Practices. Chicago, IL: APA Planners Press

Herkimer-Oneida Counties Comprehensive Planning Program. Planning \& Design Manual:A Handbook on Reviewing Site Plans for Municipal Officials. Utica, NY

Huntington, Stuart H. Not Dated. A Guide to Common Planning and Zoning Procedures. Ames, lowa: Iowa State University, University Extension.

Iowa State University, University Extension. 1995. Subdivision Review Manual. Ames, Iowa

lowa State University, University Extension. 1995. Glossary of Common Planning and Zoning Terms. Ames, Iowa
Jarvis, Frederick D. 1993. Site Planning and Community Design for Great Neighborhoods. Washington, DC: Home Builder Press.

LaGro, James A. 2001. Site Analysis: Linking Program and Concept in land planning and Design. New York, NY: John Wiley \& Sons, Inc.

Lembeck, Stanford M., George W. Fasic, and Olev Taremae. 1998. Trainer's Manual: Public Course in Subdivision Review. Pennsylvania Municipal Planning Education Institute.

Listoken, David, and Carole Walker. 1989. The Subdivision and Site Plan Handbook. Rutgers University Center for Urban Policy Research

Lynch, Kevin, and Gary Hack. 1984. Site Planning. Cambridge, MA: MIT Press

Marsh, Willliam. 1998. Landscape Planning: Environmental Applications. New York, NY: John Wiley \& Sons, Inc.

Massachusetts Association of Conservation Commissions. 2000. Fundamentals for Conservation Commissions: A Comprehensive Training Course. Belmont, MA

New Hampshire of Comprehensive Planning. 1976. The Land Book: The Challenge of Making Wise Community Development Decisions.

New Hampshire Office of State Planning. 1999. Data Requirements for Site Review: Guidance for Panning Boards. Concord, NH

RI Statewide Planning Program, URI Cooperative Extension, Town of Glocester, Providence Water. 2000. Training Program for Glocester Town Officials: Roles and Responsibilities of Boards and Councils in Community Development.

Strom, Steven, and Kurt Nathan. 1998. Site Engineering for Landscape Architects. New York, NY: John Wiley \& Sons, Inc.

Walker, Theodore D., and David A. Davis. 1990. Plan Graphics. John Wiley \& Sons Inc., New York

Winter, Thomas C., Judson W. Harvey, O. Lehn Franke, and William M. Alley. 1998. Ground Water and Surface Water: A Single Resource. Denver, CO: US Geological Survey Circular 1139

Wright, William R., and Edward Sautter. 1988. Soils of Rhode Island Landscapes. Kingston, RI University of Rhode Island Agricultural Experiment Station Bulletin 429 